Aus der Abteilung Neuropathologie

(Prof. Dr. med. W. Brück)

im Zentrum Pathologie und Rechtsmedizin

der Medizinischen Fakultät der Universität Göttingen

\title{
Einfluss systemischer Infektionen auf den Krankheitsverlauf der Alzheimer-Erkrankung im Maus-Modell
}

\author{
INAUGURAL - DISSERTATION \\ zur Erlangung des Doktorgrades \\ der Medizinischen Fakultät \\ der Georg-August-Universität zu Göttingen
}

vorgelegt von

Lena Rollwagen

aus Lauterbach

Göttingen 2010 
Dekan: Prof. Dr. med. C. Frömmel

I. Berichterstatter: Prof. Dr. med. R. Nau

II. Berichterstatter/in:

III. Berichterstatter/in:

Tag der mündlichen Prüfung: 


\section{INHALTSVERZEICHNIS}

\section{Einleitung ............................................................................ 1}

\subsection{Die AlZHeIMER-Demenz 1}

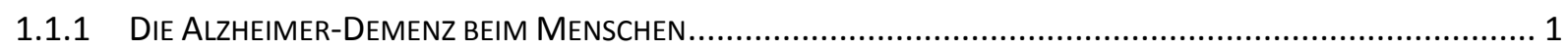

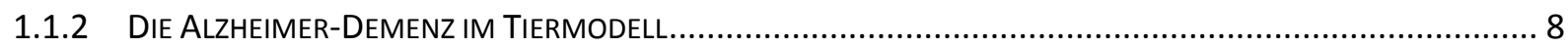

1.1.3 ENTZÜNDLICHE VERÄNDERUNGEN BeI DER ALZHEIMER-DEMENZ ..................................................... 9

1.2 SYSTEMISCHE BAKTERIELLE INFEKTIONEN UND IHR EINFLUSS AUF DAS ZENTRALE NERVENSYSTEM 10

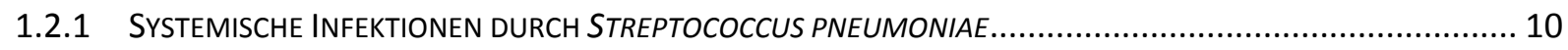

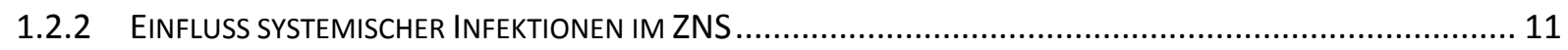

\begin{tabular}{ll}
1.3 & BAKTERIELLE INFEKTIONEN UND NEURODEGENERATIVE ERKRANKUNGEN \\
\hline
\end{tabular}

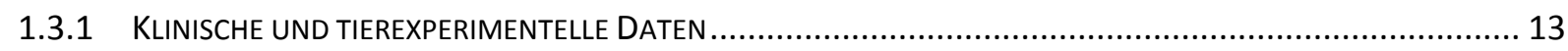

1.3.2 Aktivierung von Mikroglia bel der Alzheimer-Demenz und bel systemischen bakteriellen

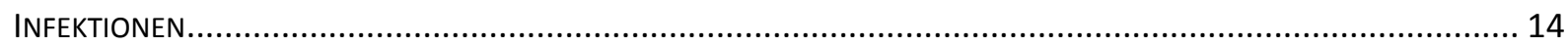

\begin{tabular}{lr}
1.4 & ZIEL DER ARBEIT \\
\hline
\end{tabular}

2 Material und Methoden ............................................................18

2.1 MATERIALIEN $\quad 18$

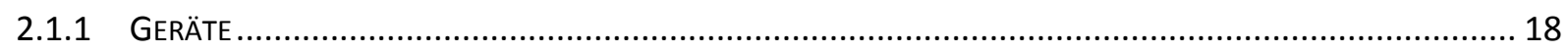

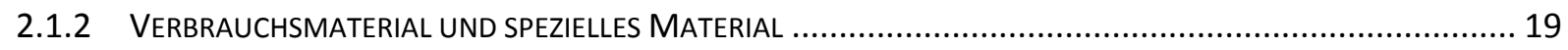

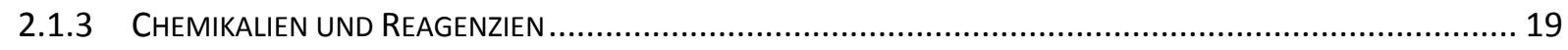

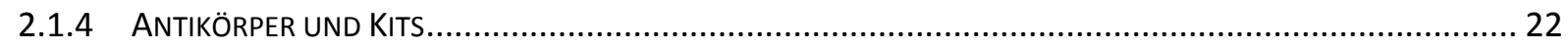

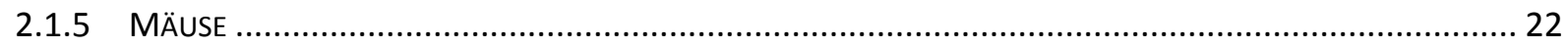

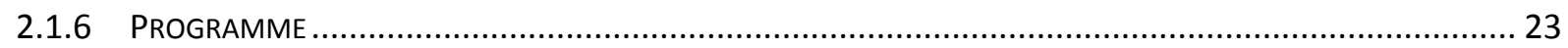

\begin{tabular}{ll}
2.2 & TIERVERSUCHE \\
\hline
\end{tabular}

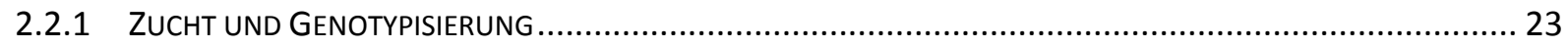

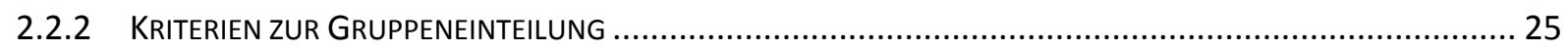

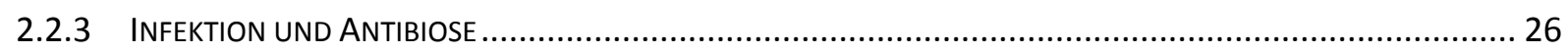

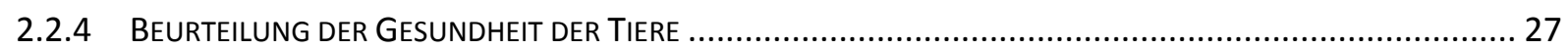

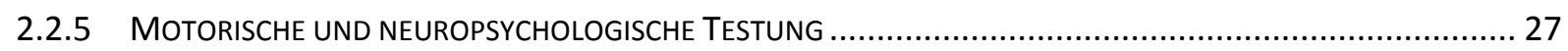

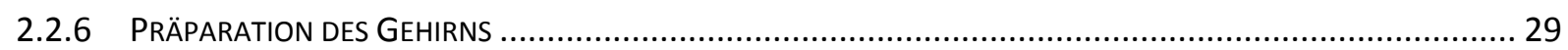

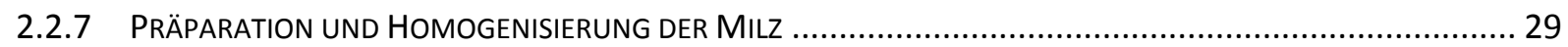

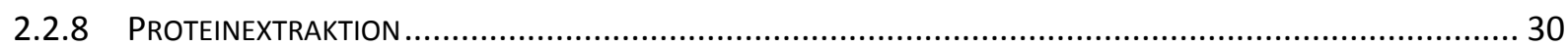




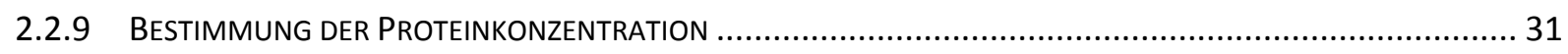

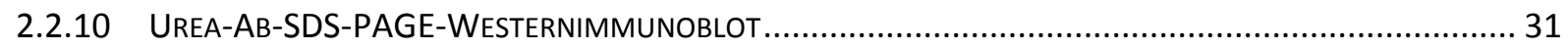

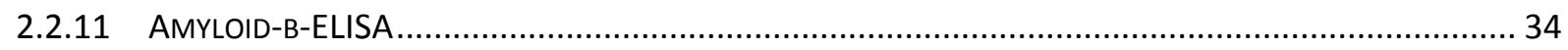

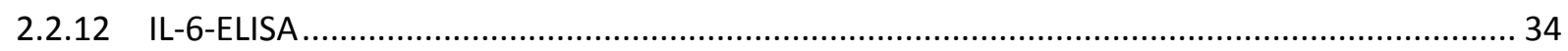

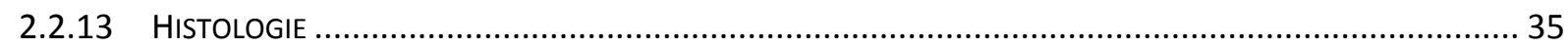

$\underline{2.3}$ ZelLKULtURen $\quad 36$

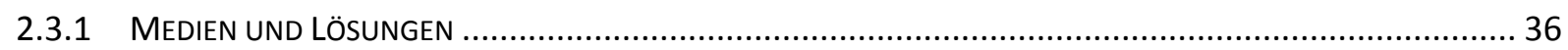

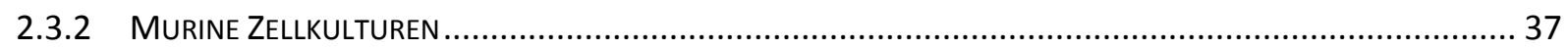

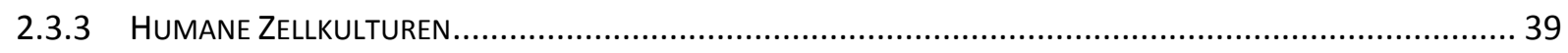

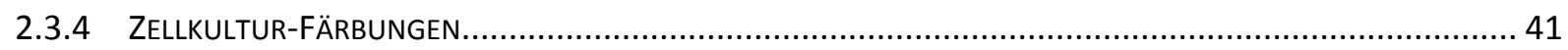

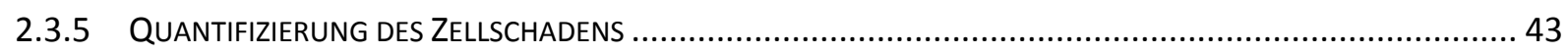

\begin{tabular}{llr}
2.4 & STATISTIK & 45 \\
\hline
\end{tabular}

3 Ergebnisse ............................................................................ 46

3.1 AUSWIRKUNG DER SYSTEMISCHEN INFEKTION DURCH STREPTOCOCCUS PNEUMONIAE IM ZNS BEI C57/B6-

\begin{tabular}{ll} 
MÄUSEN & 46 \\
\hline
\end{tabular}

3.2 ZUCHT UND GENOTYPISIERUNG VON TG2576-MÄUSEN $\quad 48$

3.3 AUSWIRKUNG WIEDERHOLTER SYSTEMISCHER INFEKTIONEN MIT STREPTOCOCCUS PNEUMONIAE AUF DEN \begin{tabular}{lr} 
KRANKHEITSVERLAUF BEI TG2576-MÄUSEN & 48 \\
\hline
\end{tabular}

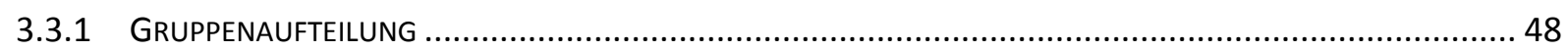

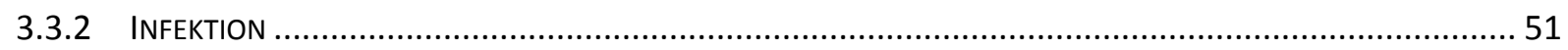

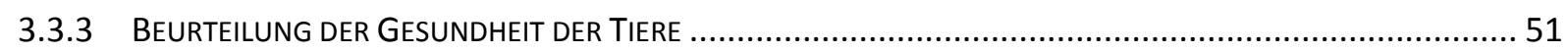

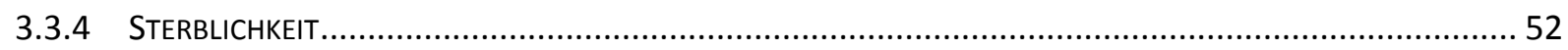

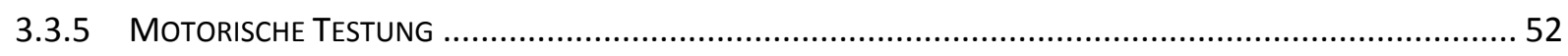

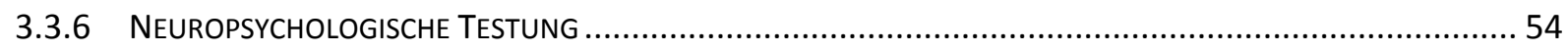

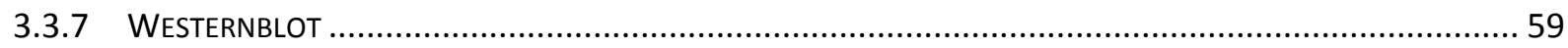

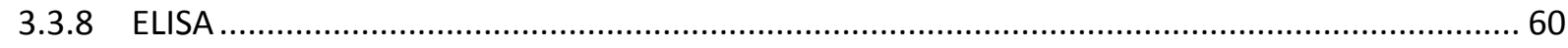

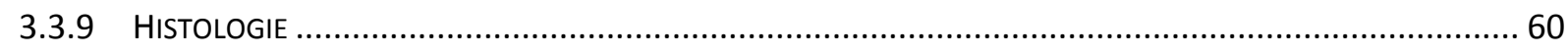

\begin{tabular}{ll}
3.4 & ZELLKULTUREN \\
\hline
\end{tabular}

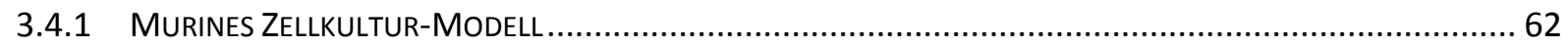

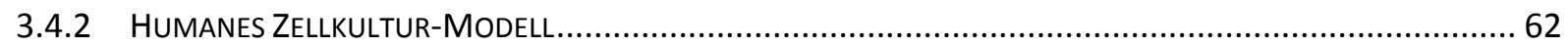

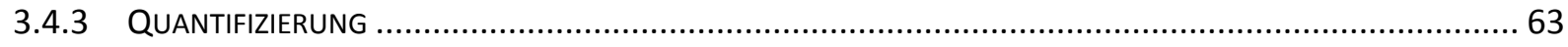

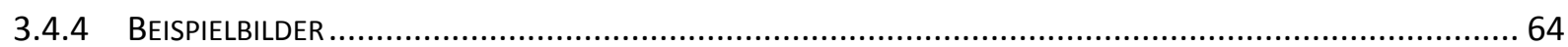

4 Diskussion ..................................................................................66 
4.1 SYSTEMISCHE INFEKTIONEN MIT STREPTOCOCCUS PNEUMONIAE FÜHREN ZU ERHÖHTEN INFLAMMATORISCHEN ZYTOKINEN IM ZNS 66

4.2 REZIDIVIERENDE INFEKTIONEN MIT STREPTOCOCCUS PNEUMONIAE BEWIRKEN KEINE VERSCHLECHTERUNG DES MORBUS ALZHEIMER IM MAUS-MODELL 67

4.3 DIE STIMULATION NEURONAL-MONOZYTÄRER KOKULTUREN DURCH AB 1-40 UND BAKTERIELLE ZERFALLSBESTANDTEILE FÜHRT ZUR SCHÄDIGUNG DER NEURONEN

5 Zusammenfassung .76

6 Literaturverzeichnis 77 


\section{Einleitung}

\subsection{Die Alzheimer-Demenz}

\subsubsection{Die Alzheimer-Demenz beim Menschen}

Die Alzheimer-Demenz ist mit einem Anteil von $60 \%$ die am häufigsten vertretene dementielle Erkrankung. Dementielle Erkrankungen sind die häufigsten Gehirnerkrankungen des fortgeschrittenen Lebensalters und zeigen eine altersabhängige Zunahme der Inzidenz und Prävalenz. Zirka sechs Prozent der über 65-Jährigen in Deutschland leiden an einer Demenz, Inzidenz und Prävalenz steigen mit zunehmendem Alter deutlich an. Frauen sind aufgrund ihrer höheren Lebenserwartung häufiger betroffen (Bickel 2000; Ferri et al. 2005; Masuhr und Neumann 2007). Entsprechend der Deutschen Gesellschaft für Neurologie wird sich die Prävalenz der Erkrankung in Hinblick auf die demographische Entwicklung bis 2050 voraussichtlich verdoppeln (Schmidtke und Riepe 2005).

Dabei versteht man unter einer Demenz nach dem „Diagnostischen und Statistischen Handbuch Psychischer Störungen“ (DSM-IV) (APA 2000) eine signifikante Beeinträchtigung der sozialen und beruflichen Funktionen durch kognitive Defizite, welche eine deutliche Verschlechterung gegenüber einem früheren Leistungsniveau darstellen und nicht im Rahmen einer rasch einsetzenden Bewusstseinstrübung oder eines Delirs auftreten. Zur Beeinträchtigung des Gedächtnisses muss noch mindestens eine der folgenden Störungen hinzu kommen: Aphasie, Apraxie, Agnosie und/oder Störung der Exekutivfunktionen. Damit sind Handlungen wie Planen, Organisieren, Einhalten einer Reihenfolge und Abstrahieren gemeint. Die 10. Revision der Internationalen Klassifikation der Krankheiten (ICD-10) (WHO 2006) nennt noch einen zeitlichen Faktor: Die Symptomatik muss über mindestens sechs Monate anhalten oder angehalten haben.

Demenzen lassen sich in primäre und sekundäre Demenzen untergliedern. Sekundäre Demenzen entstehen im Zusammenhang mit anderen Leiden wie kardiovaskulären Erkrankungen oder Alkoholabhängigkeit, können aber auch durch Medikamente hervorgerufen werden. Sekundär entstandene Demenzen sind teilweise reversibel (Beyreuther et al. 2002). Primäre Demenzen untergliedern sich in vaskuläre, idiopathische und gemischte Formen. Zu den primären Demenzen vom vaskulären Typ zählen durch Mikroangiopathien, Vaskulitiden und Einzelinfarkte entstandene Störungen. Zu den idiopathischen Demenzen im engeren Sinne zählen die Lewy-Körperchen Demenz, fokale kortikale Atrophien und der Morbus Alzheimer, welcher in dieser Gruppe zahlenmäßig dominiert. Eine klinische Unterscheidung der Demenztypen fällt oft schwer, da Mischformen häufig sind (Beyreuther et al. 2002). 
Die Alzheimer-Demenz ist nach DSM-IV (APA 2000) beschrieben als eine Demenz mit allmählichem Beginn und kontinuierlicher Verschlechterung. Dabei müssen andere zerebrale, systemische oder funktionelle Krankheiten, die eine Demenz verursachen können, ausgeschlossen werden. Es handelt sich bei der klinischen Diagnose stets um eine wahrscheinliche Diagnose, sicher kann sie nur durch einen pathologischen Befund werden.

Erstbeschrieben wurde diese Form der Demenz 1907 von Alois Alzheimer, der in der „Städtischen Anstalt für Irre und Epileptische“ in Frankfurt am Main der Patientin Auguste Deter und ihrer Erkrankung viel Aufmerksamkeit widmete. Nach dem Versterben der Patientin beschrieb er die pathologischen Korrelate im Gehirn und publizierte den Fall. Diese makroskopischen und mikroskopischen beobachteten Veränderungen sind inzwischen gut untersucht. Makroskopisch findet sich eine ausgeprägte diffuse Hirnatrophie. Die Atrophie wirkt sich jedoch nicht nur auf die Neuronenmasse, sondern auch auf deren Funktion aus, weshalb die Alzheimer'sche Erkrankung im Allgemeinen als „neurodegenerativ“ beschrieben wird. Der Untergang der Nervenzellen beginnt meist im medialen Temporallappen und dehnt sich später diffus auf alle Hirnareale aus. Am ausgeprägtesten ist der Neuronenuntergang in Hippokampus, Locus coeroleus und im Neokortex (Deckert et al. 2004; Masuhr und Neumann 2007).

Die mikroskopischen Korrelate lassen sich untergliedern in (1) senile Plaques, (2) AlzheimerFibrillen und (3) die zerebrale Amyloidangiopathie und sollen im Folgenden genauer beschrieben werden. Dabei sind die zwei erstgenannten Veränderungen schon 10-30 Jahre vor Manifestation klinischer Symptome zu finden. Sie sind vergesellschaftet mit einer Degeneration von Neuronen und Synapsen sowie mit entzündlichen Veränderungen, wobei letztere im Kapitel 1.1.3. auf Seite 9 detailliert geschildert werden sollen (Deckert et al. 2004). 


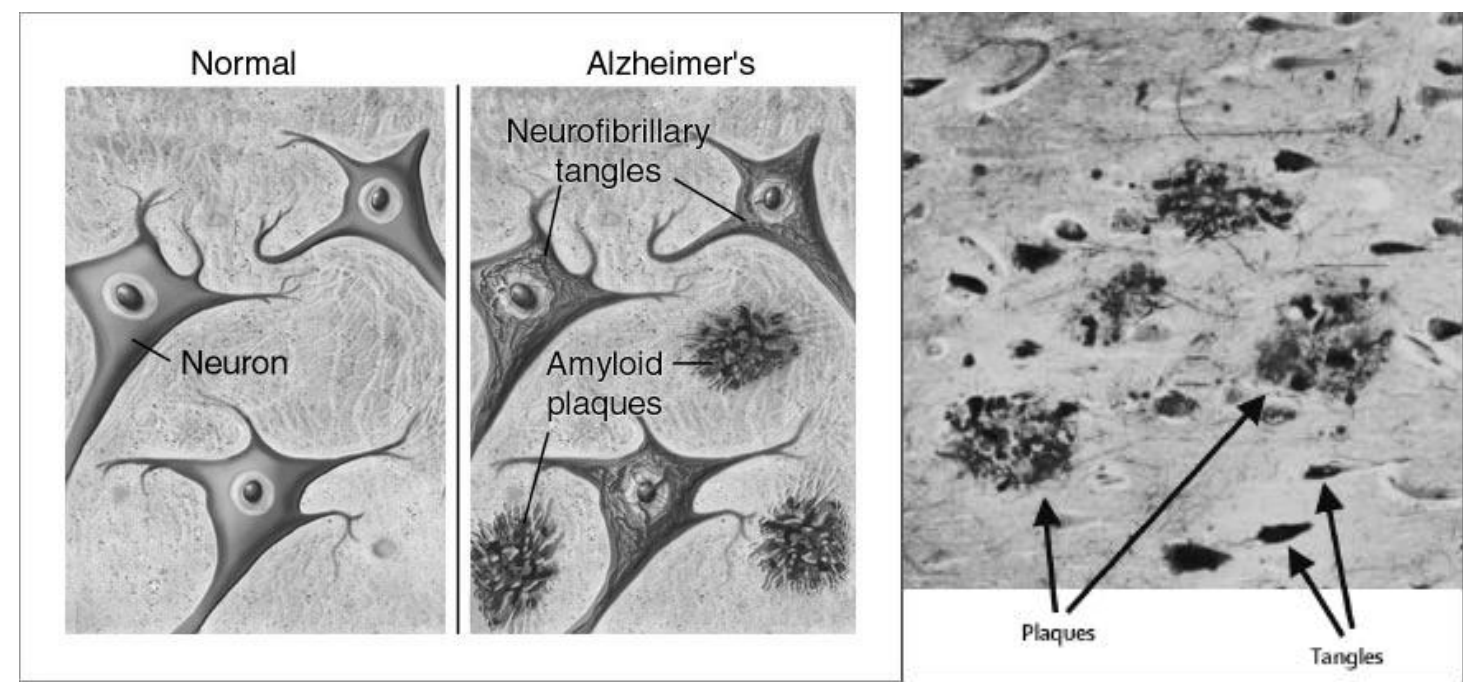

Abbildung 1-1. Schematische Darstellung der Veränderungen im Gehirn bei der AlzheimerDemenz [links, www.pakmed.net/academic/age/alz/alz030.htm] und im histopathologischen Bild [rechts, (Blennow et al. 2006, Seite 388)]

Die senilen Plaques (1) sind bis zu $100 \mu \mathrm{m}$ große Herde, welche sich in Neokortex, Hippokampus, Striatum, Dienzephalon, Hirnstamm und Kleinhirn finden. Dabei sind Plaques in Hirnstamm und Kleinhirn typisch für Alzheimer-Patienten, während sie an den anderen Orten in geringeren Mengen auch bei nicht-dementen alten Menschen vorkommen (Deckert et al. 2004). Die Plaques sind eine extrazelluläre Ablagerung aus fibrillen-bildendem Amyloid- $\beta$-Protein. Das Amyloid- $\beta$-Protein entsteht aus der Spaltung des Amyloid-PrecursorProteins (APP). APP ist ein integrales Membranprotein, welches vermutlich unterschiedliche Aufgaben im Nervensystem wahrnimmt. Die genaue Funktion ist jedoch unbekannt (Jacobsen und Iverfeldt 2009). APP kann einerseits durch eine $\alpha$ - und $y$-Sekretase zu einer löslichen Form gespalten werden, andererseits durch eine $\beta$ - und $\gamma$-Sekretase zu den 40 oder 42 Aminosäure großen $A \beta$-Proteinen prozessiert werden. Unter normalen Umständen wird das $A \beta$ ausreichend abgebaut und aus dem Gehirn abtransportiert - diese Mechanismen greifen auch bei der Alzheimer-Demenz, nur dass hier ein Ungleichgewicht zwischen Produktion und Abbau vorliegen muss. Bei dieser sogenannten Hypothese der $\beta$ Amyloid-Kaskade kommt es dazu, dass das überschüssige Protein polymerisiert und sich in fibrillärer $\beta$-Faltblattstruktur in Plaques zwischen den Nervenzellkörpern ablagert. Dabei scheint vor allem das $A \beta$ 1-42 die falsche Konformation der A (Blennow et al. 2006).

Alzheimer-Fibrillen (2), im englischsprachigen Raum auch „tangles“ genannt, sind fibrilläre Auftreibungen des neuronalen Zytoskeletts. Sie entstehen durch intrazelluläre Aggregation eines abnorm phosphorylierten Tau-Proteins, welches am axonalen Transport durch die Mikrotubuli beteiligt ist. Der gestörte axonale Transport führt zur neuronalen Dysfunktion. Die Alzheimer-Fibrillen findet man vor allem im Hippokampus und im medialen Temporallappen (Blennow et al. 2006) 
Das dritte mikroskopische Korrelat der Alzheimer-Demenz ist die zerebrale amyloide Angiopathie (3), welche auf die Ablagerung von A $\beta$-Peptiden an den Gefäßwänden zurückzuführen ist (Deckert et al. 2004).

Bis heute konnte die Ätiopathogenese der vor 100 Jahren beschriebenen Erkrankung nicht zufriedenstellend geklärt werden. Es gibt jedoch zahlreiche Risikofaktoren für die AlzheimerDemenz, deren Beitrag zur Genese vielfach noch wissenschaftlich diskutiert wird.

Der wichtigste, nicht zur Diskussion stehende Risikofaktor ist das Alter. Alle weiteren Risikofaktoren kann man grob in genetische und nicht genetische Risikofaktoren unterteilen. Als gesicherte Ursache kommen genetische Veränderungen in Frage. Diese familiäre Form der Erkrankung ist aber selten und tritt mit einer Prävalenz von unter 0,1\% auf (Harvey et al. 2003). Es handelt sich hierbei um autosomal-dominante Vererbung von Mutationen auf den Chromosomen 1, 14 und 21. Die betreffenden Gene codieren für Presenilin-1, Presenilin-2 und das Amyloid-Precursor-Protein. Presenilin ist eine Komponente der $\mathrm{Y}$-Secretase, welche für den Abbau des Amyloid-Precursor-Proteins notwendig ist. Bei vermindertem Abbau akkumuliert das A $\beta$-Protein. Bei der Mutation des APP-Gens wird das APP selbst überexprimiert. So fällt vermehrt $A \beta$ an (Blennow et al. 2006).

Ein wichtiger genetischer Risikofaktor für das Auftreten einer sporadischen AlzheimerDemenz ist das Apolipoprotein $\varepsilon 4-A l l e l$. Das physiologisch vorkommende Gen codiert für ein Protein, welches am Fettstoffwechsel beteiligt ist und möglicherweise als pathologisch wirkendes Chaperon die Fibrillen- und Plaquebildung von $A \beta$ fördert (Blennow et al. 2006). Da das Apolipoprotein $\varepsilon 4-A l l e l$ weder eine notwendige noch eine hinreichende Bedingung für die Krankheitsentstehung darstellt, wird es als Suszeptibilitätsgen bezeichnet. Heterozygote Träger dieses Allels haben ein dreifach erhöhtes, homozygote Träger hingegen ein 15-fach erhöhtes Erkrankungsrisiko (Farrer et al. 1997). Das Apolipoprotein $\varepsilon 4$-Allel ist mitverantwortlich für die meisten sporadisch auftretenden Fälle der Alzheimer-Demenz (Raber et al. 2004).

Dass das Vorkommen eines Alzheimer-Falles in der Familie das Risiko für die Erkrankung anderer Familienmitglieder wesentlich erhöht, konnte in einer europäischen Studie nicht nachgewiesen werden (Launer et al. 1999). In einer schwedischen Zwillingsstudie hatte der genetische Hintergrund jedoch einen deutlichen Einfluss auf das Erkrankungsrisiko (Gatz et al. 2006).

Weitere diskutierte nicht-genetische Risikofaktoren sind zum Beispiel eine geringere Größe des Gehirns, reduzierte mentale und körperliche Aktivität im Alter und ein niedriger Bildungsstand (Mayeux 2003; Mortimer et al. 2003). Durch prominente Patienten kamen Schädel-Hirn-Traumen als Risikofaktor für eine Alzheimer-Erkrankung ins Gespräch - ob diese tatsächlich Auslöser sein können oder lediglich die Reservekapazität des Gehirns 
verringern, bleibt unklar (Jellinger 2004; Van Den Heuvel et al. 2007). Auch die Schilddrüsendysfunktion wird als Risikofaktor für die Alzheimer-Demenz diskutiert (Tan und Vasan 2009). Schwierig ist es, den Einfluss von Nikotinkonsum, Hypercholesterinämie, Hypertonie, Diabetes und Übergewicht auf das Erkrankungsrisiko einzuschätzen, da diese Faktoren in Zusammenhang mit der schwer abgrenzbaren vaskulären Demenz stehen (Blennow et al. 2006). Durch das Zusammentreffen vaskulärer und degenerativer Effekte steigt die Wahrscheinlichkeit der Demenzmanifestation, so dass die umfassende internistische Behandlung an Bedeutung gewinnt.

Der Einfluss entzündlicher Prozesse auf die Entwicklung und den Verlauf der Alzheimer'schen Erkrankung wird aufgrund der hohen Relevanz für die Fragestellung dieser Arbeit in einem eigenen Kapitel (Kapitel 1.3.1 auf Seite 13) erörtert.

Wie oben beschrieben ist das Hauptsymptom der Alzheimer'schen Erkrankung der Verlust der Gedächtnisleistung. Dazu zählen neben der Merk- und Konzentrationsfähigkeit auch die Fähigkeit zur Orientierung und Ausübung von Alltagstätigkeiten. Charakteristisch ist, dass die Patienten diese Veränderungen lange kaschieren können. Man kann die Entwicklung der Erkrankung in drei Stadien einteilen, wobei diese zeitlich gesehen unterschiedlich schnell eintreten können (Beyreuther et al. 2002):

Im frühen Stadium bemerken Patienten eine Vergesslichkeit, bei der vor allem das Speichern neuer Information schwierig wird. Es kommt zu Stimmungsschwankungen, wobei die Persönlichkeit lange unversehrt bleibt und die Patienten an konventionellen Umgangsformen festhalten. Wortfindungsstörungen treten auf, die örtliche und zeitliche Orientierung wird eingeschränkt. Als Folge dieser Symptome fallen die Patienten in eine geistige Passivität, während sie physisch unruhig werden. Aufgrund des Krankheitsbewusstseins kann es zur Depression kommen.

Im mittleren Stadium wird das selbständige Erledigen von alltäglichen Tätigkeiten wie Waschen oder Ankleiden für die Patienten unmöglich. Die Desorientierung der zeitlichen und örtlichen Dimension verschlimmert sich und beginnt auch in der situativen und persönlichen Dimension. $\mathrm{Zu}$ den Wortfindungsstörungen gesellen sich Schwierigkeiten beim Sprachverständnis. Die emotionale Instabilität und Unruhe bleibt, zusätzlich kann es zu zwanghaftem Verhalten, Wahnvorstellungen und Halluzinationen kommen.

Im späten Stadium erkennen die Patienten vertraute Personen und ihre Angehörigen nicht mehr. Ihre Abhängigkeit dehnt sich auf die Nahrungsaufnahme und Fortbewegung aus. Die Vergesslichkeit betrifft nun auch das Langzeitgedächtnis. Die Sprache der Patienten beschränkt sich auf wenige Worte oder Silben, sie können auch ganz verstummen. Durch die Beeinträchtigung der Bewegung und eventuell entstehenden Kontrollverlust über Darm und Blase steigt die Wahrscheinlichkeit für Zusatzerkrankungen. 
Als Ursache für den Tod der Patienten findet man meist „banale“ Infektionen wie grippale Infekte, Pneumonien, Zystitiden, Nephritiden oder ähnliches. Alzheimer-Patienten sterben durchschnittlich sieben Jahre nach Diagnosestellung.

Die Diagnosestellung kann nach einer umfassenden neuropsychologischen Untersuchung und dem Ausschluss behandelbarer intrakranieller oder internistischer Ursachen erfolgen. Dabei kommt den apparativen Untersuchungen weniger Bedeutung zu, vielmehr machen eine genaue Anamnese sowie Fremdanamnese, der neurologische und psychiatrische Befund sowie kognitive Leistungstestung (z.B. Mini-Mental-Status-Test) die Basis der Diagnostik aus. Eine Verlaufsuntersuchung nach 6-12 Monaten gibt Auskunft über die Chronizität und Progression der Erkrankung und einen etwaigen Therapieerfolg (Schmidtke und Riepe 2005). Dabei muss man sich bewusst sein, dass die Diagnose der AlzheimerDemenz ohne histologischen Befund oder Mutationsnachweis in den oben beschriebenen Genen immer nur eine wahrscheinliche Diagnose ist.

Die Genauigkeit einer fundierten klinischen Diagnostik ist höher als die einzelner apparativer Verfahren (Villareal und Morris 1999). Trotzdem gehören apparative Untersuchungen wie die zerebrale Bildgebung, EEG, Labor- und Liquordiagnostik zum diagnostischen Weg hinzu. Sie ermöglichen den Ausschluss zahlreicher Ursachen sekundärer Demenzen wie zum Beispiel: Hypo-/Hyperthyreose, funikuläre Myelose, zerebrale Raumforderungen, Normaldruckhydrozephalus, progressive Paralyse oder Morbus Wilson. Zum Teil gewinnen diese Methoden durch Weiterentwicklung an Sensitivität und Spezifität, so dass sie auch zur Diagnoseerhärtung beitragen können. Dies gilt insbesondere für die Magnet-ResonanzTomographie, die Positronen-Emissions-Tomographie und die Bestimmung von Biomarkern im Liquor.

Die bildgebende Diagnostik zeigt - im MRT deutlicher als im CCT - im Frühstadium eine Atrophie im Hippokampus und im entorhinalen Kortex. Im Verlauf findet sich eine progrediente globale Atrophie. Eine Hippokampus-Volumetrie im MRT kann die AlzheimerDemenz von mental gesunden alten Menschen mit einer Genauigkeit von 80-90 \% unterscheiden. Eine Abgrenzung von anderen Demenzformen bleibt allerdings schwierig (Blennow et al. 2006).

Eine bessere Differenzierung zwischen den Demenzformen ist mit der PositronenEmissions-Tomographie möglich. Diese zeigt einen Hypometabolismus im temporalen, parietalen und posterioren cingulären Kortex. Vielversprechend sind hier die Weiterentwicklungen in Hinblick auf eine direkte Darstellung der A $\beta$-Plaques (Nordberg 2008).

Die Liquordiagnostik hat in den letzten Jahren durch Bildung von Indizes an Bedeutung gewonnen. Gemessen wird eine vermutlich durch die neuronale Degeneration bedingte, 
erhöhte Konzentration des phosphorylierten und gesamten Tau-Proteins und eine Erniedrigung des Quotienten von $A \beta$ 1-42 zu $A \beta$ 1-40. Dabei ist die reduzierte Konzentration von $A \beta-42$ am ehesten bedingt durch die vermehrte Ablagerung dieses Proteins. Eine kombinierte Bestimmung dieser Biomarker kann eine beginnende Alzheimer-Demenz mit einer Spezifität und Sensitivität von ca. 80 \% erfassen (Shoji et al. 1998; Mattsson et al. 2009).

Wichtig ist diese Möglichkeit der frühzeitigen Erkennung einer sich entwickelnden AlzheimerDemenz deshalb, weil bei Manifestation der Klinik schon eine starke Degeneration im Gehirn stattgefunden hat. Akutell wird intensiv an Strategien geforscht, welche diese Degeneration verhindern können. Sollte es in Zukunft therapeutische Möglichkeiten zur Verhinderung der Krankheitsentstehung geben, so könnten diese dank einer frühzeitigen Diagnose auch rechtzeitig eingesetzt werden.

Bislang hat die Diagnosestellung des Morbus Alzheimer geringe therapeutische Konsequenzen, da eine suffiziente, den Progress der Erkrankung stoppende oder stark verlangsamende Therapiemöglichkeit für diese Demenz nicht existiert. Die Entwicklung einer ursächlichen Therapie der Alzheimer-Demenz wird erst mit einem besseren Verständnis des zugrundeliegenden Pathomechanismus erreichbar sein. Die existierenden therapeutischen Möglichkeiten kann man grob in eine symptomatische, eine antidementive und eine supportive Therapie einteilen.

Als evidenzbasierte antidementive Therapie sind bisher Acetylcholinesterase-Hemmstoffe und/oder Memantin empfohlen. Acetylcholinesterase-Hemmstoffe werden bei leichter bis mittelschwerer Alzheimer-Demenz eingesetzt und verhindern den Abbau des Neurotransmitters Acetylcholin, was zu einer Konzentrationserhöhung desselben im synaptischen Spalt führt (Doody et al. 2001; Lanctot et al. 2003). Memantin ist insbesondere bei einer mittelschweren bis schweren Alzheimer-Erkrankung geeignet. Dabei ist Memantin ein nichtkompetitiver NMDA-Rezeptorantagonist und moduliert somit potentiell schädliche Wirkungen des Neurotransmitters Glutamat (Winblad und Poritis 1999; Reisberg et al. 2003). Weitere, noch in klinischer Forschung stehende Therapien umfassen eine Immunotherapie im Sinne einer „Impfung“ gegen $A \beta$, antientzündliche Medikamente und Substanzen, welche an unterschiedlichen Punkten der $\beta$-Amyloid-Kaskade oder der Alzheimer-Fibrillen-Bildung eingreifen (Neugroschl und Sano 2009).

Zur Supportivtherapie gehört eine Behandlung von Begleiterkrankungen wie der Depression und das konsequente Meiden und/oder Therapieren kardio- beziehungsweise zerebrovaskulärer Risikofaktoren. $\mathrm{Ob}$ eine frühe medikamentöse Intervention bei systemischen Infektionen den Krankheitsverlauf positiv beeinflussen kann, gilt es noch zu erforschen (Holmes et al. 2009). Neben diesen medikamentösen Möglichkeiten haben 
geistige und körperliche Aktivität einen prophylaktischen Effekt. Durch Gedächtnistraining und Merkhilfen kann man versuchen, die kognitive Fähigkeit möglichst lange zu erhalten und ein eigenständiges Leben zu gewähren (Schmidtke und Riepe 2005).

\subsubsection{Die Alzheimer-Demenz im Tiermodell}

Mit dem Ziel, die Pathogenese der Alzheimer-Erkrankung besser zu verstehen und gezielte Therapien entwerfen zu können, wurden Maus-Modelle entwickelt, die die typischen Merkmale der Alzheimer-Erkrankung möglichst genau widerspiegeln sollen. In vielen Fällen wurde dabei auf Mutationen der Gene für APP und Presenilin zurückgegriffen.

Ein weit verbreitetes tierexperimentelles Modell der Alzheimer-Demenz sind transgene Mäuse, die das humane Amyloid-Precursor-Protein überexprimieren (Hsiao et al. 1996). Zur Entwicklung dieser transgenen Mäuse wurde ein Gen, welches bei einer schwedischen Familie mit früh beginnender Alzheimer-Erkrankung gefunden wurde, über ein HamsterPrion-Protein als Vector in C57B6/SJL-Mäuse eingebracht. Auf dem Gen für das humane APP 695 liegt eine Doppelmutation mit Lys ${ }^{670} \rightarrow$ Asn und Met $^{671} \rightarrow$ Leu vor, die Tiere heißen Tg(HuAPP695.K670-M671L)2576 oder kurz Tg2576. Da dieses Modell in dieser Arbeit zum Einsatz kam, sollen im folgenden Abschnitt kurz die Eigenschaften dieser Tiere aufgezeigt werden.

Diese transgenen Mäuse entwickeln ab dem Alter von sechs Monaten $\beta$-AmyloidAblagerungen im frontalen, entorhinalen und temporalen Kortex sowie im Hippokampus, Subikulum, Präsubikulum und Zerebellum. Dabei finden sich sowohl klassische senile Plaques als auch diffuse Ablagerungen. In der Umgebung der Plaques zeigen sich dystrophe Neuriten und hyperphosphoryliertes Tau-Protein. Wie beim Menschen treten auch entzündliche Veränderungen auf (siehe Kapitel 1.1.3. auf Seite 9). Des Weiteren kann eine amyloide Angiopathie nachgewiesen werden (Irizarry et al. 1997; Klunk et al. 1997; Terai et al. 2001; Tomidokoro et al. 2001).

$\mathrm{Ab}$ einem Alter von ca. 9 Monaten treten bei den Tg2576-Mäusen Störungen des Erinnerungsvermögens und des räumlichen Lernens auf. Diese dementielle Entwicklung zeigt eine Korrelation mit der Zunahme der intrazerebralen $\beta$-Amyloid-Konzentration. Wesentliche sensomotorische Störungen werden nicht beobachtet (Hsiao et al. 1996; Janus und Westaway 2001).

Unterschiede zur sporadischen menschlichen Alzheimer-Demenz sind beispielsweise das Überwiegen bei der Ablagerung von $A \beta$ 1-40 bei den Tg2576-Mäusen im Gegensatz zu $A \beta$ 1-42 beim Menschen. Auch unterliegt das $A \beta$ bei den transgenen Mäusen weniger Modifikationen. Außerdem lässt sich in der Region CA1 des für die Gedächtnisbildung essentiellen Hippokampus kein Neuronenverlust wie beim Menschen nachweisen (Irizarry et al. 1997; Kawarabayashi et al. 2001). Sowohl diese Unterschiede, als auch die Tatsache, 
dass der physiologische Alterungsprozess in Maus und Mensch Abweichungen zeigt (z.B. zeigt sich bei der alten Maus kaum Plaquebildung), sollten zu Vorsicht bei der Übertragung von Ergebnissen aus Maus-Modellen auf den Menschen anhalten (Janus und Westaway 2001; Blennow et al. 2006).

\subsubsection{Entzündliche Veränderungen bei der Alzheimer-Demenz}

Neben den drei oben geschilderten pathoanatomischen Veränderungen im Gehirn des Alzheimer-Patienten - den amyloiden Plaques, den Alzheimer-Fibrillen und der amyloiden Angiopathie - finden sich als weiteres histologisches Merkmal vermehrt Mikroglia. Mikroglia gehören neben den Astrozyten und Oligodentrozyten zu den Gliazellen des Gehirns. Sie stellen die residenten Makrophagen des ZNS dar und bilden somit eine Schnittstelle zwischen Immunsystem und Hirnparenchym. Mittels der Positronen-Emissions-Tomographie hat man bei Patienten mit milder bis moderater Alzheimer-Demenz eine erhöhte Mikrogliadichte im entorhinalen, temporoparietalen und cingulären Kortex nachweisen können (Cagnin et al. 2001; Versijpt et al. 2003). Dabei gruppieren sich die Mikroglia um die amyloiden Plaques herum und zeigen eine erhöhte Expression von Oberflächenmolekülen (z.B. MHC-Proteine) wie bei aktivierten Immunzellen (McGeer et al. 1988; Bamberger und Landreth 2001). Ultrastrukturelle Untersuchungen konnten die Anheftung von Komplementfaktoren und Lyse der Neuriten als Zeichen für die entzündliche Toxizität im Alzheimer-Demenz-Gehirn bestätigen (Webster et al. 1997; Akiyama et al. 2000).

Auch im Tg2576-Maus-Modell der Alzheimer-Demenz lassen sich diese Mikrogliaansammlungen nachweisen (Irizarry et al. 1997; Frautschy et al. 1998) Es kann eine veränderte Expression von inflammatorisch relevanten Genen nachgewiesen werden, die allerdings von denen im Menschen abweichen (Wyss-Coray 2006).

Diese Mikrogliazellen oder auch die lokalen Astrozyten, Endothelzellen und Neurone schütten signifikant erhöhte Konzentrationen inflammatorischer Marker, wie z.B. Komplementfaktoren, IL-1, IL-6, TNF- $\alpha$ und chemotaktische Zytokine aus (Akiyama et al. 2000; Münch et al. 2003). Bei Patienten, bei denen sich in der Autopsie A $\beta$-Plaques und Alzheimer-Fibrillen zeigen, die jedoch keine Demenz in der Vorgeschichte aufweisen, findet man gegenüber typischen nicht-dementen Patienten erhöhte Entzündungsparameter, gegenüber Patienten mit Alzheimer-Demenz jedoch deutlich niedrigere Entzündungsparameter (Lue et al. 1996). In verschiedenen Studien konnte ein Zusammenhang der Alzheimer-Demenz mit gewissen Polymorphismen von Zytokinen oder anderen immunologisch relevanten Molekülen aufgezeigt werden. Auch das Suszeptibilitätsgen Apo \&4 scheint die Reaktion des Immunsystems zu beeinflussen (WyssCoray 2006). Gene, welche in entzündliche Prozesse involviert sind, werden auch beim alten Menschen vermehrt exprimiert, dieser Zustand ist aber beim Alzheimer-Demenz-Patienten 
intensiviert (Blalock et al. 2005). Patienten, welche eine Demenz entwickeln, zeigten fünf Jahre vor Manifestation der Erkrankung höhere Konzentrationen entzündungsassoziierter Plasmaproteine wie IL-6 im Vergleich zu den im weiteren Verlauf nicht-dementen Kontrollpersonen (Engelhart et al. 2004).

Das Vorhandensein dieser entzündlichen Veränderungen bei der Alzheimer-Demenz hat neben der Hypothese der Amyloid-Kaskade zu der Annahme geführt, dass inflammatorische Mechanismen für die Krankheitsentstehung relevant sein könnten. Dafür spricht neben den oben genannten Veränderungen unter anderem, dass bei Menschen mit Arthritis die Alzheimer-Demenz seltener auftritt. Möglicherweise ist hieran ein positiver Effekt der dort häufig eingesetzten anti-entzündlichen Nicht-steroidalen-Antiphlogistika (NSAR) beteiligt (Wyss-Coray 2006). Auch konnte durch passive oder aktive Immunisierung im Tiermodell die zerebrale $A \beta-K o n z e n t r a t i o n ~ g e s e n k t$ und die Erinnerungsfähigkeit verbessert werden (Wisniewski und Konietzko 2008).

Unklar bleibt, ob die Entzündung bei der Alzheimer-Demenz eine mögliche Ursache, eine beschleunigende Kraft, eine heilende Reaktion oder aber auch ein Nebenprodukt der Erkrankung ist. Möglicherweise könnte auch eine Dysfunktion des Immunsystems vorliegen (Wyss-Coray 2006).

\subsection{Systemische bakterielle Infektionen und ihr Einfluss auf das zentrale Nervensystem}

\subsubsection{Systemische Infektionen durch Streptococcus pneumoniae}

Systemische Infektionen entstehen, wenn Bakterien von ihrem primären lokalen Infektionsherd wie z.B. der Lunge in die Blutbahn gelangen, dort persistieren und sich vermehren. Dabei nennt man den Übertritt von Bakterien in die Blutbahn Bakteriämie, während die Persistenz der Bakterien in der Blutbahn mit einer gesamtkörperlichen Allgemeinreaktion als systemische Infektion bezeichnet wird (Hildebrandt 1997). Zu dieser kommt es, wenn bei einer schweren Bakteriämie das Immunsystem aufgrund der präsenten Bakterienantigene aktiviert wird und dadurch immunkompetente Zellen wie Makrophagen und Leukozyten zahlreiche Mediatoren in die Blutbahn ausschütten (Nau und Eiffert 2002). Diese Mediatoren, wie auch die Zerfallsbestandteile der Bakterien selbst, führen zu Reaktionen an Organen unabhängig vom primär infizierten Organ. Klinisch kommt es zu einer Allgemeinreaktion des Körpers mit Schwäche und Fieber (Rivest et al. 2000). Bei fehlender Therapie kann eine systemische Infektion in eine Sepsis, einen septischen Schock oder ein Multiorganversagen übergehen und zum Tod des Patienten führen.

Ein häufiger Erreger systemischer Infektionen ist das Gram-positive Bakterium 
Streptococcus pneumoniae. Es ruft typischerweise endogene Infektionen des respiratorischen Traktes wie Pneumonien hervor, welche neben urogenitalen Infektionen die häufigsten Ausgangsorte systemischer Infektionen beim Erwachsenen sind (Kayser et al. 2001). Eine systemische Infektion durch S. pneumoniae kann im Maus-Modell z.B. durch eine intraperitoneale Injektion des Keims erreicht werden.

Die Therapie von Infektionen mit S. pneumoniae kann mit Penicillinen, Makrolid-Antibiotika oder Cephalosporinen erfolgen. Da gegenüber Penicillinen und Makroliden jedoch Resistenzen bestehen können und der Keim zu Beginn der Infektion selten bekannt ist, erfolgt die Therapie in der Klinik häufig mit Ceftriaxon, welches als Cephalosporin der dritten Generation ein sehr breites Wirkspektrum aufweist. Cephalosporine stören die Zellwandsynthese und wirken so bakterizid auf proliferierende Keime (Karow und Lang-Roth 2005). Dabei werden im Gegensatz zum Einsatz nicht-bakteriolytischer Antibiotika hohe Konzentrationen proinflammatorischer Bakterienbestandteile frei (Nau und Eiffert 2002).

Zerfallsbestandteile von Bakterien entstehen bei einer systemischen Infektion spontan, insbesondere jedoch bei Gabe bakteriolytischer Antibiotika. Beispiele hierfür sind Lipopolysaccharide, Teichonsäure, Lipoteichonsäure, Peptidoglycane, Lipopeptide oder bakterielle DNA. Diese Stoffe sind in der Lage, das Immunsystem des Wirtes zu aktivieren, wodurch es zu einer Aktivierung von Makrophagen und Leukozyten, der Ausschüttung von Zytokinen und der vermehrten Expression von Adhäsionsmolekülen in Endothelzellen kommt. Eine massive Ausschüttung dieser bakteriellen Produkte kann zu der so genannten Jarisch-Herxheimer-Reaktion führen, welche mit Fieber, Myalgien, Kopfschmerzen, Tachykardie und Hypotension einhergeht (Nau und Eiffert 2002). Die alleinige Gabe von LPS oder Lipoteichonsäuren kann im Tierversuch zu einer Reaktion wie bei der Sepsis führen (De Kimpe et al. 1995; Rittirsch et al. 2007). Zusammengefasst kann man sagen, dass Bakterien bei ihrem Zerfall eine proinflammatorische und toxische Wirkung entfalten können.

S. pneumoniae als Gram-positives Bakterium enthält Peptidoglycane, Teichonsäuren, Lipoteichonsäuren und natürlich bakterielle DNA, wobei darin die unmethylierten CytosinPhosphatidyl-Guanosin-haltigen Dinukleotide (CpG) die Reaktion des befallenen Vertebraten auslösen. Eine Besonderheit des $S$. pneumoniae ist die Produktion des Proteins Pneumolysin. Pneumolysin kann die klassische Komplement-Kaskade aktivieren, es kann zur Ausschüttung von IL-1 $\beta$ und TNF- $\alpha$ aus Monozyten führen und die Aktivität von Phagozyten und Lymphozyten hemmen (Hahn et al. 2009).

\subsubsection{Einfluss systemischer Infektionen im ZNS}

Damit während einer systemischen Infektion die Homöostase des Körpers durch Fieber, neuroendokrine Reaktionen und andere autonome Funktionen aufrecht erhalten werden kann, ist es nötig, dass zwischen der Peripherie und dem ZNS Kommunikation stattfindet 
(Rivest et al. 2000). Um das Gehirn weitestgehend vor dem Übergreifen schädlicher Organismen und toxischer Substanzen aus der systemischen Zirkulation zu schützen, ist der Austausch zwischen Blut und Gehirn durch die Blut-Hirn-Schranke erschwert. Nichtsdestotrotz kommen Signale über eine periphere Infektion auf unterschiedlichen Wegen im ZNS an (Sharshar et al. 2005). Zum Beispiel sind die zirkum-ventrikulären Organe nicht durch die Blut-Hirn-Schranke geschützt und haben eine Vermittlerfunktion zwischen Blut und Gehirn in Bezug auf mikrobielle Produkte. Proinflammatorische Zytokine können in den Regionen ohne Blut-Hirn-Schranke passiv ins ZNS diffundieren, in Regionen mit Blut-HirnSchranke gibt es dafür energieabhängige, aktive Transporter (Dilger und Johnson 2008; Semmler et al. 2008). Auch bakterielle Zerfallsbestandteile wie LPS können eine direkte Reaktion im ZNS hervorrufen, indem sie z.B. Endothelzellen des Gehirns zur Ausschüttung der Zytokine IL-1 $\beta$, TNF- $\alpha$ und IL- 6 bringen und damit die Mikroglia aktivieren (Fabry et al. 1993; Breder et al. 1994; Reyes et al. 1999; Rivest et al. 2000; Rivest 2003). Außerdem kann der Nervus vagus, vermutlich über Zytokinrezeptoren, die Information über eine periphere Entzündung vermitteln (Maier et al. 1998). Des Weiteren können Endothelzellen durch zirkulierende bakterielle Produkte oder Zytokine aktiviert werden und schütten daraufhin Entzündungsmediatoren ins ZNS aus (Sharshar et al. 2005). Da die Endothelzellen über diese Mechanismen selbst Schaden nehmen können, kann ein septisches Geschehen zu einer erhöhten Permeabilität der Blut-Hirn-Schranke führen (Tsao et al. 2001). All diese Mechanismen sorgen für einen Transport von Informationen und sind nicht primär schädlich für das Hirngewebe. Sie bedingen jedoch Zeichen einer entzündlichen Reaktion im ZNS selbst und können bei einem entstehenden Ungleichgewicht zu Schaden führen. Diese entzündliche Reaktion des ZNS zeigt sich sowohl im Anstieg von Zytokinen, in der Erhöhung der Transkriptionsraten verschiedener Rezeptoren und Enzyme, in der Aktivierung und Anlockung von Mikroglia, in der Änderung der zerebralen Durchblutung als auch im Untergang von Neuronen (Kloss et al. 2001; Sharshar et al. 2005; Semmler et al. 2008).

Die Maximalform dieser Dysfunktion des Gehirns, welche bei einer systemischen Entzündung ohne direkte Infektion des ZNS entsteht, wird auch septische Enzephalopathie genannt. Sie zeigt sich klinisch durch verlangsamtes Denken, geminderte Konzentrationsfähigkeit, Desorientierung, Delirium oder Koma und ist teilweise irreversibel (Semmler et al. 2008). Diese klinischen Merkmale sind zum Teil auch bei neurodegenerativen Erkrankungen $\mathrm{zu}$ finden. Interessanterweise konnte man in Hirnregionen, die für Lernen, Erinnerung und Koordination zuständig sind, Zytokinrezeptoren nachweisen und somit einen möglichweise direkten Wirkweg der inflammatorischen Zytokine auf die Kognition aufzeigen (Dilger und Johnson 2008).

Obwohl Mechanismen der septischen Enzephalopathie beim Menschen nicht vollständig geklärt sind, konnte bei Patienten, welche aufgrund einer Sepsis starben, neben 
makroskopischen Gewebeschäden wie ischämischen Läsionen und Hämorrhagien, auch eine lokale Expression von proinflammatorischen Zytokinen bestätigt werden (Sharshar et al. 2004). In einer Fall-Kontroll-Studie konnte gezeigt werden, dass der Anteil von aktivierten Mikrogliazellen in der grauen Substanz bei Patienten, welche an einem septischen Geschehen verstarben, deutlich höher war als bei den Kontrollpatienten mit nichtentzündlicher Todesursache (Lemstra et al. 2007). Patienten, welche unter einer vorbestehenden ZNS-Erkrankung leiden, haben ein höheres Risiko für die Entwicklung einer septischen Enzephalopathie (Semmler et al. 2008).

\subsection{Bakterielle Infektionen und neurodegenerative Erkrankungen}

\subsubsection{Klinische und tierexperimentelle Daten}

In den letzen Jahren wird eine entzündliche Komponente bei der Pathogenese neurodegenerativer Erkrankungen, insbesondere der des Morbus Alzheimer verstärkt diskutiert. Diese Vermutungen gründen unter anderem auf klinisch auffälligen Zusammenhängen zwischen akuten Infektionen und einer schubförmigen irreversiblen Verschlechterung der Erkrankungen (Holmes et al. 2009). Dies stellt ein klinisch bedeutendes Problem dar, weil Infektionen bei dementen Patienten vor allem im fortgeschrittenen Stadium häufig sind. Ein Delir bei älteren Menschen, welches eine häufige Folge von Infektionen, jedoch auch ein frühes Zeichen einer Alzheimer-Demenz sein kann (Lerner et al. 1997), führt in der akuten Phase und darüber hinaus zu einer neuropsychologischen Verschlechterung und einer erhöhten Mortalität (Elie et al. 1998; Fick et al. 2002). Dies weist darauf hin, dass eine Erkrankung, die ein Delir verursacht, langfristigen Einfluss auf die mnestischen Funktionen haben kann (Murray et al. 1993). Eine Studie an ein- und zweieiigen Zwillingen, bei denen ein Zwilling eine schwere Infektion durchgemacht hatte und einen Morbus Alzheimer entwickelte, ergab eine fehlende oder verzögerte Demenzentwicklung bei dem Zwilling, der keine schwere Infektion durchgemacht hatte. Darüber hinaus hatte der Zwilling, der von einer schweren Infektion verschont blieb, eine höhere Lebenserwartung (Nee und Lippa 1999). In einer Fall-Kontrollstudie konnte ein positiver Zusammenhang zwischen stattgehabten Infektionen und einer Demenzdiagnose beim alten Menschen dargestellt werden (Dunn et al. 2005). Die kognitive Funktion von Alzheimer-Demenz-Patienten verschlechtert sich häufig während begleitender Infektionen und bleibt auch in den zwei Folgemonaten beeinträchtigt (Holmes et al. 2003). Diese von Holmes et al. durchgeführte Studie zu den Zusammenhängen von systemischen Infektionen und der Progression der Alzheimer-Demenz wurde in Form einer prospektiven Kohortenstudie an 300 Patienten weiterführend betrachtet. Darin konnte gezeigt werden, 
dass sich die Demenz auch im Verlauf von sechs Monaten nach akuter Infektion oder bei begleitender chronischer Entzündung verschlechterte. Dabei war die akute systemische Infektion, welche sich bei rund der Hälfte der Patienten zeigte, mit einem Anstieg der Serumkonzentrationen des proinflammatorischen TNF- $\alpha$ verknüpft. Je höher die Ausgangskonzentration des TNF- $\alpha$ war, desto drastischer verschlechterte sich die dementielle Symptomatik (Holmes et al. 2009).

Auch tierexperimentell gibt es Studien über das Zusammenwirken eines peripheren bakteriellen Geschehens und der inflammatorischen Veränderung bei neurodegenerativen Erkrankungen. Die systemische Gabe des Endotoxin LPS bei Mäusen mit einer noch nicht klinisch manifesten Prionenerkrankung führte zu einer stärkeren IL-1 $\beta$-Synthese im Gehirn und einem rascheren Verlust der motorischen Fähigkeiten als bei Kontroll-Mäusen, die nicht mit LPS behandelt wurden (Combrinck et al. 2002). Des Weiteren konnte im Maus-Modell der Amyotrophen Lateralsklerose eine deutliche klinische Verschlechterung durch eine chronische systemische LPS-Gabe gezeigt werden (Nguyen et al. 2004). Zusammengefasst konnte in vivo eine periphere Applikation eines bakteriellen Bestandteils, möglicherweise über eine weitere Aktivierung bereits aktivierter Mikroglia, zum Fortschreiten eines neurodegenerativen Prozesses führen (Combrinck et al. 2002; Perry et al. 2003; Nguyen et al. 2004; Cunningham et al. 2005; Morgan et al. 2005).

\subsubsection{Aktivierung von Mikroglia bei der Alzheimer-Demenz und bei systemischen bakteriellen Infektionen}

Mikroglia entstammen der Makrophagen-Monozyten-Linie und sind Teil des Immunsystems des Gehirns. In akuten pathologischen Situationen treten unterschiedlich stark aktivierte Mikroglia innerhalb von Stunden in den Läsionen auf, zusätzlich werden vermehrt Monozyten aus der Blutbahn rekrutiert (Perry et al. 2007). Ihre Aufgabe besteht im Schutz des ZNSGewebes vor eindringenden Mikroorganismen und in der Beseitigung von untergegangenem neuronalem Gewebe (Kreutzberg 1996). Diese Aufgaben erfüllen sie mittels Antigenpräsentation, Phagozytose, Induktion von Entzündung, Zytotoxizität und Gewebereparation durch Ausschütten von Wachstumsfaktoren (Kreutzberg 1996; Aloisi 2001). Dabei zeigt sich neben der dazu notwendigen veränderten Genexpression auch eine morphologische Wandlung der Zellen.

Klassischerweise ist für die Aktivierung von Makrophagen sowohl ein vorbereitender Stimulus als auch ein auslösender Stimulus nötig. Durch den vorbereitenden Stimulus werden in den Makrophagen bestimmte Oberflächenantigene wie MHC, CD-68 oder Toll-like Rezeptoren (TLR) vermehrt exprimiert und befähigen die Zellen zu einer schnelleren, stärkeren Reaktion mit längerer Dauer (Dilger und Johnson 2008). 


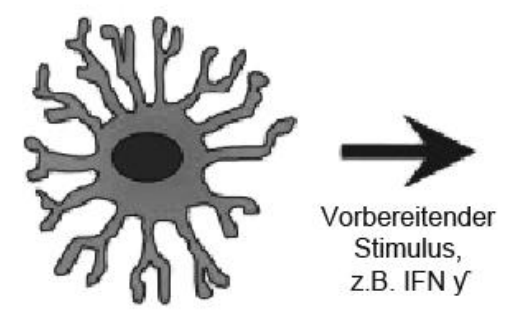

Ruhende Mikrogliazelle

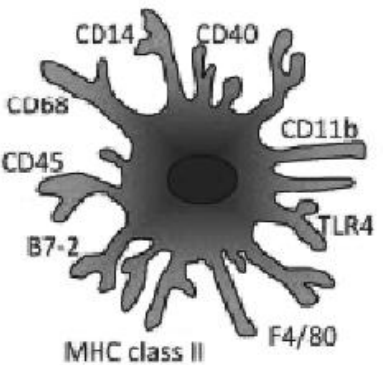

Vorbereitete Mikrogliazelle
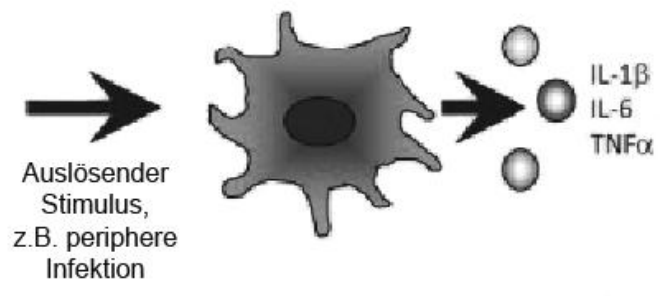

Infektion

Abbildung 1-2. Darstellung der unterschiedlichen Aktivierungszustände der Mikroglia. Modifiziert nach Dilger und Johnson (2008, Seite 936)

Mögliche Stimuli für die Mikroglia bei der Alzheimer-Demenz sind das $A \beta$, die AlzheimerFibrillen oder die absterbenden Neuronen (Akiyama et al. 2000). Mikroglia bei Menschen mit neurodegenerativen Erkrankungen gleichen phänotypisch den vorbereiteten Mikroglia und exprimieren dauerhaft kleine Mengen proinflammatorischer Zytokine. Schon der physiologische Alterungsprozess scheint ein vermehrtes Auftreten dieser vorbereiteten Mikroglia mit sich zu bringen, außerdem wird eine Reduktion der antiinflammatorischen Zytokine beim alten Menschen vermutet (Dilger und Johnson 2008). Ob eine weitere Aktivierung der Mikroglia letztendlich einen protektiven Wert für das ZNS hat oder ob sie sich negativ im Sinne einer vermehrten Akkumulation von $A \beta$ und dem Absterben von Neuronen auswirken könnte, wird kontrovers diskutiert und ist von großem Interesse, falls sich die Hypothese der $\beta$-Amyloid-Kaskade als richtig erweisen sollte. Dass die Mikroglia trotz ihrer Fähigkeit, $A \beta$ in seinen verschiedenen Konformationen $z u$ internalisieren und $z u$ degradieren, dies bei der Alzheimer-Demenz anscheinend nicht in ausreichendem Maße tun, könnte damit zusammenhängen, dass der chronisch einwirkende Reiz nicht zu dem dazu nötigen stimulierten Zustand der Zellen führt (Perry et al. 2007).

Die im Kapitel 1.2.2 auf Seite 12 beschriebene septische Enzephalopathie beruht unter anderem auf der Aktivierung von Mikroglia durch bakterielle Zerfallsbestandteile. LPS beispielsweise führt zu einer starken Aktivierung des angeborenen und erworbenen Immunsystems und resultiert in einer deutlichen Aktivierung der Mikroglia (Wyss-Coray 2006). Für die Fähigkeit der Mikroglia, auf die Gefahr aus dem Umfeld reagieren zu können, sind verschiedene „pattern-recognition receptors“ zuständig. Dazu zählen auch die TLR. Sie sind eine Gruppe von Transmembranproteinen, die als Teil des angeborenen Immunsystem verschiedene funktionale Bestandteile von Viren, Bakterien und Pilzen erkennen und der Abwehr dieser Erreger dienen (Kaisho und Akira 2006). Bindet ein Substrat über TLR an Mikroglia, so wird je nach Substrat und TLR-Subtyp eine bestimmte Reaktion mit Produktion von Zytokinen, Enzymen oder anderen inflammatorischen Agenzien ausgelöst (Konat et al. 2006). Interessanterweise werden die TLR nicht nur durch Bestandteile von 
Krankheitserregern aktiviert, sondern auch durch endogene Moleküle aus geschädigtem Gewebe. Auch das bei der Alzheimer-Demenz in pathologischem Maße vorhandene A $\beta$ kann mit Mikroglia über TLR interagieren und so zu einer proinflammatorischen Reaktion führen (Lotz et al. 2005; Tahara et al. 2006).

Die Aktivierung von Mikroglia durch $A \beta$ oder bakterielle Zerfallsbestandteile führt zur Ausschüttung zahlreicher pro- und antiinflammatorischen Substanzen wie Stickoxid, TNF- $\alpha$, IL-6 oder IL-1 $\beta$ (Akiyama et al. 2000) und dient primär dem Schutz des Organismus. Substanzen wie TNF- $\alpha$ werden neuroprotektive und neurotrophe Effekte zugeschrieben, dennoch scheint TNF- $\alpha$ den Zelltod von Neuronen hervorrufen zu können, wenn es den Neuronen als Teil eines entzündlichen Milieus mit Gliazellen präsentiert wird (MunozFernandez und Fresno 1998; Combs et al. 2001; Rosenberg 2005; Pickering und O'Connor 2007). Eine tiefergehende Betrachtung bereits vorliegender Daten zur Aktivierung der Mikroglia durch $A \beta$ und bakterielle Zerfallsbestandteile findet sich im Kapitel 4.3 auf Seite 74 . Insgesamt deuten die oben genannten Angaben auf sehr komplexe Aktivierungsvorgänge der Mikroglia hin - diese scheinen von der Umgebung, den aktivierenden Liganden und der genetischen Grundlage abhängig zu sein (Miller 2005; Morgan et al. 2005; Perry et al. 2007). Zusammenfassend lässt sich sagen, dass

1) eine systemische Infektion zu einer entzündlichen zerebralen Reaktion mit Mikrogliaaktivierung und konsekutiver Nervenschädigung führen kann und dass

2) die Pathologie beim Morbus Alzheimer in Zusammenhang mit einer entzündlichen Komponente mit Mikrogliaaktivierung auftritt.

Naheliegend wäre daher, dass das in der Klinik beobachtete Phänomen der Progression der Alzheimer-Demenz unter einer systemischen Infektion auf dem Zusammenspiel dieser Mechanismen beruht. 


\subsection{Ziel der Arbeit}

Die neurologischen Symptome von Patienten mit neurodegenerativen Erkrankungen wie der Alzheimer-Demenz verschlechtern sich häufig unter systemischen Infektionen. Es liegt die Vermutung nahe, dass Neurone von Alzheimer-Patienten besonders vulnerabel auf die durch bakterielle Allgemeininfektionen in Gang gesetzten Vorgänge reagieren. Verantwortlich dafür könnte sein, dass es aufgrund der endogenen Stimulation der Mikroglia durch $A \beta$ und die hinzukommende bakterielle Stimulation des innaten Immunsystems zu einer additiven Mikrogliastimulation mit additivem Mikroglia-vermitteltem-Neuronenschaden kommt. Die genauen Mechanismen dieses Phänomens gilt es zu erforschen, wobei in dieser Arbeit Verhältnisse in vivo und in vitro betrachtet werden sollen.

Das Hauptziel dieser Arbeit ist es, zu untersuchen, ob rezidivierende systemische Infektionen mit $S$. pneumoniae den Beginn und Verlauf der Alzheimer-Demenz im MausModell beeinflussen. Dazu sollen transgene Mäuse, welche humanes mutantes $A \beta$ überexprimieren (Tg2576), rezidivierend intraperitoneal mit S. pneumoniae Typ 3, dem bedeutendsten respiratorischen bakteriellen Pathogen, infiziert und anschließend mit dem 3.Generation-Cephalosporin Ceftriaxon therapiert werden. Während der Versuchszeit sollen regelmäßige motorische und neuropsychologische Tests erfolgen, um eine mögliche Aggravation der Erkrankung bei den infizierten Tieren im Gegensatz zu den nicht-infizierten transgenen Tieren feststellen zu können. Am Versuchsende soll ein Vergleich der A $\beta$ Konzentrationen im Gehirn zwischen infizierten Mäusen und nicht-infizierten Kontrollen stattfinden.

Des Weiteren soll der Einfluss einer Kostimulation mit $A \beta$ 1-40 und bakteriellen Zerfallsbestandteilen auf die Toxizität von monozytären Zellen gegenüber Neuronen charakterisiert werden. Dazu soll in Kokulturen von Mikrogliazellen und Neuronen (Maus) sowie Makrophagen und SH-SY5Y-Neuroblastomzellen (Mensch) untersucht werden, ob die synergistische Aktivierung durch $A \beta$ 1-40 und einen bakteriellen Zerfallsbestandteil, wie z.B. das synthetische Lipopeptid ( $\left.\mathrm{Pam}_{3} \mathrm{CysSK}_{4}\right)$, nicht nur zur Aktivierung der Immunzellen, sondern auch zu einem verstärkten Neuronenuntergang führt. 


\section{Material und Methoden}

\subsection{Materialien}

\subsubsection{Geräte}

Bio-Rad-Mini-Protean-II-Elektrophorese-System

Branson Sonifier

Eismaschine

Elektrophoresekammern

Fluor-S Multi Imager

Heizblock

Inkubator

Kaltlichtlampe

LIAISON®-Analyzer

Magnetrührer

Membran-Vakuumpumpe

Microplate-Reader

Mikroskop (biokkulares)

Mikroskop (inverses)

Mikroskop BX 51 System-Mikroskop

Mikrowelle

Neubauer-Zählkammer

Ofen

PCR-Thermocycler

Pipettierhilfe

Polaroid-Kamera

Rotarod

Schlittenmikrotom

Schüttelplatte „rotomix“

Semi-Dry-Elektroblotter Model TE77

Spannungsgeber

Speed Vac

Sterilbank-Laminair ${ }^{\circledR}$

Stoppuhr

Ultraviolett-Kontaktlampe

Waage
Bio-Rad (München, D)

Branson (Danbury, USA)

Ziegra (Isernhagen, D)

Pharmacia Biotech (Freiburg, D)

Bio-Rad (München, D)

HLC Bio Tech (Bovenden, D)

Heraeus (Hannover, D)

Schütt (Göttingen, D)

DiaSorin (Saluggia, I)

Bioblock Scientific (Wohlen, $\mathrm{CH}$ )

Vacuubrand (Wertheim, D)

Tecan (Crailsheim, D)

Zeiss (Göttingen, D)

Olympus (Hamburg, D)

Oympus (Hamburg, D)

Schütt (Göttingen, D)

Schütt (Göttingen, D)

Memmert (Schwabach, D)

Biometra (Göttingen, D)

Eppendorf (Hamburg, D)

Polaroid (Enschede, NL)

TSE-Systems (Bad Homburg, D)

Leica (Nussloch, D)

Zeipel (Bovenden, D)

Hoefer Pharmacia (San Francisco, USA):

Pharmacia Biotech (Freiburg, D)

Heto-Holten (Wettenberg, D)

Heraeus (Hannover, D)

Casio (London, England, UK)

Vetter (Wiesloch, D)

Omnilab (Göttingen, D) 
Wasserbad

Zentrifuge

Zentrifuge
GFL (Burgwedel, D)

Eppendorf (Hamburg, D)

Jouan (St-Herblain, Frankreich)

\subsubsection{Verbrauchsmaterial und spezielles Material}

13-ml-Pipette

24- und 96-Loch-Gewebekulturplatten

Blutagar-Platten

Einbettkassetten

Eppendorfcups

Filterpapier (extra dick)

Gewebekulturflaschen

Gießschälchen

Glaspipetten

Glasplättchen/Coverslip

Kanülen

Kryoröhrchen/Kryoboxen

Objektträger

Petrischalen

Pinsel

Pinzetten

Polaroid-Filme 667

PVDF-Membran (Immobilon-P 0,45 $\mu \mathrm{m}$ )

Röhrchen

Skalpell

Spritzen

Zellschaber

\subsubsection{Chemikalien und Reagenzien}

100bp-DNA-Leiter

Agarose

Albumin

Ameisensäure

Amyloid-Beta-Protein 1-40

APAAP

APS

Aqua (destilliert)
Greiner (Frickenhausen, D)

Sarstedt (Newton, USA)

Institut für Mikrobiologie (Göttingen, D)

Roth (Karlsruhe, D)

Eppendorf (Hamburg, D)

Bio-Rad (München, D)

Corning Costar (Wiesbaden, D)

Leica (Nussloch, D)

Brandt (Wertheim, D)

Menzel (Braunschweig, D)

Braun (Melsungen, D)

Greiner (Frickenhausen, D)

Menzel (Braunschweig, D)

Falcon (Heidelberg, D)

Wiederholdt (Göttingen, D)

Rettberg (Göttingen, D)

Polaroid (Enschede, NL)

Millipore Corporation (Bredford, UK)

Falcon (Heidelberg, D)

Rettberg (Göttingen, D)

Braun (Melsungen, D)

Sarstedt (Newton, USA)
Fermentas (St. Leon-Rot, D)

Gibco Invitrogen (Karlsruhe, D)

Perbio (Bonn, D)

Merck (Darmstadt, D)

Bachem (Weil am Rhein, D)

DAKO (Glostrup, Dänemark)

Biomol (Hamburg, D)

Merck (Darmstadt, D) 
Avidin

A $\beta$-Peptid Standards

B-27 Supplement mit Antioxidanzien

Bicinchoninsäure

Bicine

Biotin

Bis-Tris

Borsäure

Bromochloroindolyl-Phosphat

Bromphenolblau-Stocklösung

Ceftriaxon (Rocephin)

Citronensäure-Monohydrat

Compete Mini Protease Inhibitor

DePeX

Diaminobenzidin

Diethyldithiocarbamat

Dimethylformamid

Dimethylsulfoxid

D-MEM

dNTP Set

D-PBS

ECL Plus

EDTA

Essigsäure

Ethanol

Ethidiumbromid

FCS

Ficoll Paque PLUS

Fluorescent Mounting Medium

Formaldehyd

Hämalaun

Harnstoff

HEPES

Interferon- $\mathrm{Y}$ (Maus)

Isolectin-B4 (Nr. L2140)

Kaliumdisulfid

Kaliumpermanganat
Vektor (Burlingame, Kanada)

Bachem (Bubendorf, $\mathrm{CH}$ )

Gibco Invitrogen (Karlsruhe, D)

Sigma (Deisenhofen, D)

Biomol (Hamburg, D)

Vektor (Burlingame, Kanada)

Biomol (Hamburg, D)

Sigma (Deisenhofen, D)

Roche (Mannheim, D)

Merck (Darmstadt, D)

Roche (Mannheim, D)

Merck (Darmstadt, D)

Roche (Mannheim, D)

Serva (Heidelberg, D)

Roche (Mannheim, D)

Sigma (Deisenhofen, D)

Sigma (Deisenhofen, D)

Sigma (Deisenhofen, D)

Gibco Invitrogen (Karlsruhe, D)

Fermentas (St. Leon-Rot, D)

Gibco Invitrogen (Karlsruhe, D)

Amersham Biosciences (Freiburg, D)

Fluka (Seelze, D)

Merck (Darmstadt, D)

Merck (Darmstadt, D)

AppliChem (Darmstadt, D)

Gibco Invitrogen (Karlsruhe, D)

GE Healthcare (München, D)

DAKO (Glostrup, Dänemark)

Merck (Darmstadt, D)

Merck (Darmstadt, D)

Applichem (Darmstadt, D)

Sigma (Deisenhofen, D)

Sigma (Deisenhofen, D)

Sigma (Deisenhofen, D)

Merck (Darmstadt, D)

Merck (Darmstadt, D) 
Kernechtrot

Kupfer(II)sulfat $=\mathrm{CuSO}_{4} 5 \mathrm{H}_{2} \mathrm{O}$

Levamisole

L-Glutamin

Lichtgrün (SF gelblich)

Magnesiumchlorid

Methanol

$\mathrm{N}$-Acetylcystein

$\mathrm{Na}-\mathrm{DOC}$

Naphthol

Natriumchlorid

Natriumnitrit

Neufuchsin

Neurobasal Medium ohne L-Glutamin

Nitroblau-Tetrazolium

$\mathrm{N}$-Naphthyl-Ethylendiamin

Nonidet P 40

Nontronit

Oxalsäure

$\mathrm{Pam}_{3} \mathrm{CysSK}_{4}$

Paraffin (Paraplast)

PBS/TBS

PCR-Primer

PCR-Puffer

Penicillin/Streptomycin

Polyacrylamid (60 \% T5 \%C)

Poly-L-Lysin-Hydrobromid

Proteinase K Complete ${ }^{\mathrm{TM}}$ Mini

Rotiblock 10x Konzentrat

RPMI 1640 (mit Glutamin)

SDS

Streptavidin-Peroxidase-Komplex

Sucrose

Sulfonamid

Taq-Polymerase

TEMED

Thioflavin S
Merck (Darmstadt, D)

Sigma (Deisenhofen, D)

ICN Biomedicals (Eschwege, D)

Biochrom (Berlin, D)

Chroma (Stuttgart, D)

Merck (Darmstadt, D)

Applichem (Darmstadt, D)

Sigma (Deisenhofen, D)

Fluka Chemie (Buchs, $\mathrm{CH}$ )

Sigma (Deisenhofen, D)

Roche (Mannheim, D)

Merck (Darmstadt, D)

Merck (Darmstadt, D)

Gibco Invitrogen (Karlsruhe, D)

Roche (Mannheim, D)

Sigma (Deisenhofen, D)

AppliChem (Darmstadt, D)

Hoher Hagen (Dransfeld, D)

Merck (Darmstadt, D)

EMC Microcollections (Tübingen, D)

Kendall (Mansfield, USA)

Biochrom (Berlin, D

MWG Biotech (Ebersberg, D)

Promega (Madison, USA)

Sigma (Deisenhofen, D)

Bio-Rad (München, D)

Sigma (Deisenhofen, D)

Roche (Mannheim, D)

Roth (Karlsruhe, D)

Gibco Invitrogen (Karlsruhe, D)

Biomol (Hamburg, D)

Amersham Biosciences (Freiburg, D)

Merck (Darmstadt, D)

Sigma (Deisenhofen, D)

Promega (Madison, USA)

Serva Elektrophoresis (Heidelberg, D)

Sigma (Deisenhofen, D) 
Tris

Triton X-100

Trypanblau-Lösung

Trypsin/EDTA Lösung

Tween-20

Wasserstoffperoxid

Xylol

$\beta$-Mercaptoethanol
AppliChem (Darmstadt, D)

Sigma (Deisenhofen, D)

Sigma (Deisenhofen, D)

Sigma (Deisenhofen, D)

Serva Elektrophoresis (Heidelberg, D)

Merck (Darmstadt, D)

Merck (Darmstadt, D)

Sigma (Deisenhofen, D)

\subsubsection{Antikörper und Kits}

Anti-Maus-Ig-Antikörper (vom Schaf)

Anti-Maus-lgG (sekundär, biotinyliert)

Biotinylierter anti-Kaninchen-Antikörper

Digoxin DNA Labeling Mix Kit

hAmyloid $\beta 40$ Brain ELISA

hAmyloid $\beta 42$ Brain ELISA

IL-6 ELISA (Cat \# M6000B)

Kaninchen-anti-Maus-Ig

Monoklonaler Antikörper 1E8 (anti-Maus-IgG1)
Amersham Biosciences (Freiburg, D)

Vector Laboratories (Lörrach, D)

GE Healthcare (Freiburg, D)

Roche (Mannheim, D)

The Genetics Company (Schlieren, $\mathrm{CH}$ )

The Genetics Company (Schlieren, $\mathrm{CH}$ )

R\&D Systems (Wiesbaden, D)

DAKO (Glostrup, Dänemark)

Bayer Schering (Berlin, D)

Monoklonaler Maus-anti-Mensch-CD-68-Antikörper

(Makrophagen Klon KP1)

DAKO (Glostrup, Dänemark)

NSE LIAISON® KIT

DIASORIN (Saluggia, I)

Polyklonaler Kaninchen-anti-lba1- Antikörper

Wako Chemicals (Neuss, D)

Vectastatin ABC (Avidin/Biotin-Komplex)

Vector (Burlingame, Kanada)

$\beta$-Tubulin (Neuronal Class III, Maus, monoklonal) Covance (Princeton, USA)

\subsubsection{Mäuse}

Die Zucht sowie Unterbringung und Verpflegung der Tiere erfolgte in der Zentralen Tierexperimentellen Einheit der Medizinischen Fakultät der Universität Göttingen. Die Genehmigung für die Experimente wurde von der Tierschutzkommission der Medizinischen Fakultät der Universität Göttingen und der Bezirksregierung Braunschweig erteilt. Die Weibchen zur Zucht wurden bei Charles River WIGA (Deutschland) GmbH bestellt.

- Für die Zellkultur:

C57/B6-Mäuse unterschiedlichen Alters beziehungsweise schwangere Tiere

- Für die Tierversuche:

Tg(HuAPP695.K670N-M671)2576-Mäuse

C57/B6-J/SJL-Mäuseweibchen für die Zucht 
C57/B6-Mäuse als Kontrolltiere

\subsubsection{Programme}

Analysis 3.2

Graph Pad Prism 4.0

Magellan 3.11

Quantity one

Videomot 2

WCIF Image J
Olympus Soft Imaging Systems (Münster, D)

Graph Pad Software (La Jolla, USA)

Tecan (Crailsheim, D)

Bio Rad Laboratories (München, D)

TSE Systems (Bad Homburg, D)

Download von www.uhnres.utoronto.ca/facilities/wcif/

\section{$2.2 \quad$ Tierversuche}

\subsubsection{Zucht und Genotypisierung}

Zucht

Die APP-überexprimierenden Mäuse mit dem Stammnamen Tg2576 wurden zuerst von K. Hsiao (Hsiao et al. 1996) entwickelt und beschrieben. Wir bekamen freundlicherweise von Prof. Dr. R. Schliebs (Abteilung Neurochemie, Paul-Flechsig-Institut für Hirnforschung, Leipzig) eine Gruppe von Zuchttieren zur Verfügung gestellt. Zur Vermehrung der Tiere wurden transgene TG(HuAPP695.K670N-M671)2576-Männchen mit C57 B6-J/SJLWeibchen verpaart.

Um kontrollieren zu können, ob eine Maus nach der Infektion ohne Antibiotikagabe stirbt, wurden C57/B6-Mäuse vergleichbaren Alters als Kontrolltiere verwendet. Selbige Tiere wurden auch zum Nachweis des Anstiegs der Entzündungsparameter im ZNS bei einer intraperitonealen Infektion eingesetzt.

\section{Genotypisierung}

Zur Genotypisierung der Mäuse waren die DNA-Extraktion aus etwas Tiergewebe, die Vermehrung der Genabschnitte mittels einer PCR und die Gelelektrophorese zur Auftrennung der unterschiedlich langen Genfragmente notwendig.

\section{DNA-Extraktion}

Zur DNA-Extraktion wurden zu dem im 1,5 ml Eppendorfcup liegenden Gewebsstückchen (Ohr oder Schwanzstück) $350 \mu \mathrm{l}$ Tail-Lysis-Puffer sowie $20 \mu \mathrm{l}$ Proteinase K gegeben. Zur Herstellung des Tail-Lysis-Puffers wurden in doppelt destilliertem Wasser $100 \mathrm{mM}$ Tris gelöst und diese Lösung autoklaviert. Dazu wurden $5 \mathrm{mM}$ EDTA gegeben und der $\mathrm{pH}$ auf 8,5 eingestellt. Zuletzt erfolgte die Zugabe von $200 \mathrm{mM} \mathrm{NaCl}$ sowie 1\% SDS. 
Die Proben wurden über Nacht bei $56^{\circ} \mathrm{C}$ auf einer Schüttelplatte verdaut. Am Folgetag erfolgte die Zentrifugation über 5 Minuten bei 20800 x g, der Überstand wurde in ein neues Eppendorfcup pipettiert. Dazu wurden zur Ausfällung der DNA $350 \mu \mathrm{l}$ Isopropylalkohol beigemischt. Nach erneuter Zentrifugation für 5 Minuten bei 20800 x g wurde der Überstand verworfen und das Pellet (Achtung: Dieses ist oft für das Auge nicht sichtbar) in $350 \mu \mathrm{l}$ 70\%igem Alkohol gewaschen. Zum letzten Mal wurde wie oben angegeben zentrifugiert, der Überstand wurde verworfen und das Pellet getrocknet. Dann wurde die DNA in $100 \mu \mathrm{H}_{2} \mathrm{O}$ dd gelöst und die Probe bei $-20 \stackrel{\circ}{\circ}$ im Gefrierschrank gelagert.

\section{Polymerase-Kettenreaktion}

Für die Polymerase-Kettenreaktion erfolgte zuerst auf Eis die Zusammenstellung eines Mastermix für alle Proben. Pro Probe war nötig:

$6,21 \mu \mathrm{l} \quad$ doppelt destilliertes Wasser

$0,69 \mu \mathrm{l} \quad$ DMSO

$2,5 \mu \mathrm{l} \quad$ Puffer

$0,5 \mu \mathrm{l} \quad$ dNTP Mix 2,5 mM

Je $0,5 \mu \mathrm{l} \quad$ Primer

1: 5’ AAG CGG CCA AAG CCT GGA GGG TGG AAC A 3`

2: 5’ GTG GAT AAC CCC TCC CCC AGC CTA GAC CA 3`

3: 5' CTG ACC ACT CGA CCA GGT TCT GGG T 3'

\section{$0,1 \mu \mathrm{l} \quad$ Taq Polymerase}

Je 11,5 $\mu \mathrm{l}$ des Mastermix wurden auf die bereitgestellten $500 \mu$ l Eppendorf-Cups aufgeteilt. Dabei musste berücksichtigt werden, dass je ein Cup für die transgene und die nichttransgene Kontrolle notwendig war, außerdem ein Cup für das zum Herstellen des Master Mix verwendete doppelt destillierte Wasser (Negativ-Probe). Erst dann wurden je $2 \mu \mathrm{l}$ der zuvor trituierten DNA Lösung beziehungsweise des Wassers, mit dem auch der Mastermix hergestellt wurde, hinzugegeben. DNA und Mastermix wurden vorsichtig vermischt und in den PCR-Thermocycler gestellt. Dieser sollte wie folgt programmiert werden:

\begin{tabular}{|l|l|l|}
\hline Temperatur in ${ }^{\circ} \mathrm{C}$ & Zeit in Sekunden & \\
\hline 95 & 180 & \\
\hline 95 & 40 & $\begin{array}{l}\text { wiesen Zyklus 35 mal } \\
\text { wiederholen }\end{array}$ \\
\hline 54 & 30 & \\
\hline 72 & 60 & (zur Lagerung) \\
\hline 72 & 600 & \\
\hline 4 & z.B. 72 Stunden & \\
\hline
\end{tabular}

Tabelle 2-1. Programmierung des PCR-Thermocyclers 
Zur sich anschließenden Gelelektrophorese wurde eine 2 \%ige Gellösung aus Agarose und einer einfach konzentrierten Lösung aus Tris, Borsäure und EDTA (1 x TBE) hergestellt. Dieses 1 x TBE wurde aus Verdünnung mit $\mathrm{H}_{2} \mathrm{O}$ dd aus 10x TBE-Puffer produziert, für welchen 303,5 g Tris, 18,6 g EDTA und $130 \mathrm{~g}$ Borsäure in $5 \mathrm{I} \mathrm{H}_{2} \mathrm{O}$ dd aufgelöst wurden. Es erfolgte das kurze Aufkochen der Gellösung und, sobald die Flüssigkeit etwas abgekühlt war, die Addition von 2,5 $\mu$ l Ethidiumbromid/75 ml Lösung. Die Lösung wurde geschwenkt und in vorbereitete Gelträger gegossen. Vorhandene Luftblasen wurden entfernt oder an den Rand gedrängt und pro Gel ein Kamm eingesetzt. Nachdem das Gel ausgehärtet war, wurde es in die mit 1 x TBE gefüllte Elektrophoresekammer gesetzt. In die erste Aussparung wurden vorsichtig $12 \mu$ leiner 100bp-DNA-Leiter pipettiert, in die folgenden je $12 \mu \mathrm{l}$ der Proben. Bei einer Spannung von 120-130 Volt lief die Elektrophorese so lange, bis sich die einzelnen Banden ausreichend differenzieren und den Kontrollbanden zuordnen ließen. Das entsprach in etwa einem Zeitraum von einer $3 / 4$ Stunde.

Im Falle eines transgenen Tieres zeigte sich eine Bande bei 703 Basenpaaren und eine bei 430 Basenpaaren, während beim nicht-transgenen Tier nur eine 703 Basenpaar-Bande zu finden war. Die Gele wurden auf eine Ultraviolett-Kontaktlampe gelegt und mit einer Polaroid-Kamera zur Dokumentation fotografiert.

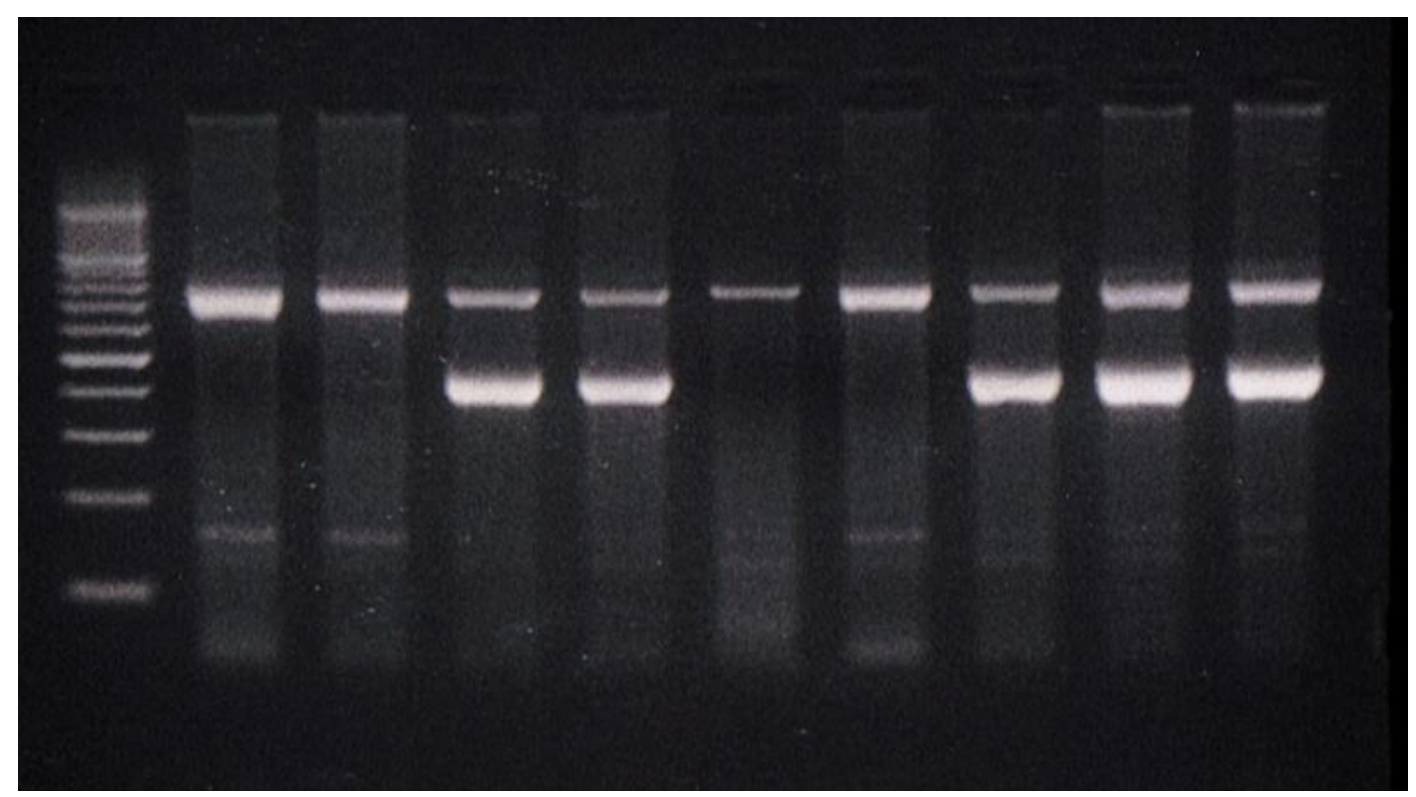

Abbildung 2-1. Beispiel eines Elektrophorese-Ergebnisses zur Genotypisierung: Doppelte Banden finden sich bei transgenen Tieren (hier insgesamt fünf), einfache Banden bei nichttransgenen Tieren (hier insgesamt vier). Ganz links die Bande des 100bp-DNA-Leiters.

\subsubsection{Kriterien zur Gruppeneinteilung}

Um möglichst einheitliche Gruppen zu gewinnen, wurden die folgenden Kriterien zur Einteilung berücksichtigt: Geschlecht, Alter und Zeit zum Auffinden der Plattform in den Trainingsversuchen 1-3 sowie im Wiederholungslauf 1. Die Berücksichtigung der Leistung im 
Morris-Water-Maze vor der Infektion war aufgrund der kleinen Gruppengrößen und der individuell unterschiedlichen Schwimmleistung unerlässlich.

\subsubsection{Infektion und Antibiose}

Herstellen des Inokulums

Der Keim S. pneumoniae Typ 3 wurde ursprünglich von einem Erwachsenen mit Meningitis isoliert und stand uns dank der freundlichen Gabe von Prof. Dr. med. M. G. Täuber (Institut für Infektionskrankheiten, Universität Bern, Schweiz) zur Verfügung. Die Bakterien wurden auf Blutagar-Platten gezüchtet, in isotone Kochsalzlösung aufgenommen und bei $-80 \stackrel{\circ}{\circ}$ konserviert. Erst direkt vor der Infektion wurde der Keim aufgetaut und in isotoner Kochsalzlösung auf die gewünschte Zielkonzentration verdünnt.

\section{Intraperitoneale Infektion}

Zur Infektion wurden die Tiere in der Hand fixiert. Mit einer 27-Gauge-Kanüle erfolgte der Einstich in den mittleren Unterbauch (Minimierung der Verletzungsgefahr von Organen), das Inokulum beziehungsweise die Kochsalzlösung wurde intraperitoneal appliziert.

\section{Bestimmung der Keimanzahl im Inokulum und im Organgewebe}

Zur Bestimmung der Keimanzahl im Inokulum oder im Organgewebe wurde eine 1:10Verdünnungsreihe in 0,9\%iger $\mathrm{NaCl}$-Lösung mit 8 Verdünnungsstufen angefertigt. Von jeder Verdünnung wurden $10 \mu \mathrm{l}$ auf eine Blutagar-Platte pipettiert und 24 Stunden bei $37^{\circ} \mathrm{C}$ inkubiert. Die Zahl der Kolonie-bildenden-Einheiten = KBE wurde gezählt und die Keimkonzentration pro Milliliter berechnet.

\section{Antibiose}

Zur Antibiose kam Ceftriaxon zum Einsatz. Ceftriaxon ist ein $\beta$-Laktam-Antibiotikum aus der Gruppe der Cephalosporine der 3.Generation. Die bakterizide Wirkung erfolgt durch Hemmung der bakteriellen Zellwandsynthese. Es wurden $100 \mathrm{mg} / \mathrm{kg}$ Körpergewicht subkutan injiziert. Die Erstantibiose fand bei den intraperitoneal infizierten Tieren 12 Stunden nach der Infektion statt. Alle weiteren Antibiotika-Gaben erfolgten im Abstand von 12 Stunden, die letzte nach 72 Stunden.

Zum Nachweis, dass eine intraperitoneale Infektion auch zerebrale Veränderungen verursacht, wurden C57/B6-Mäuse verwendet. Diese wurden 12, 24 oder 36 Stunden nach der Infektion getötet, so dass sie entsprechend keine beziehungsweise eine oder zwei antibiotische Behandlungen erhalten haben. 


\subsubsection{Beurteilung der Gesundheit der Tiere}

Der gesundheitliche Zustand der Tiere wurde nach einem klinisch-neurologischen Score beurteilt:

\begin{tabular}{|l|l|}
\hline 0 & gesund \\
\hline 1 & pathologischer Reflex der Hinterbeine bei Anheben am Schwanz \\
\hline 2 & leichte Lähmungserscheinungen der Extremitäten \\
\hline 3 & schwere Lähmungserscheinungen der Extremitäten \\
\hline 4 & $\begin{array}{l}\text { Tier kann sich nicht mehr innerhalb von } 30 \text { s aus der Seit - und Rückenlage alleine } \\
\text { aufrichten oder } \\
\text { Gewichtsverlust von mehr als 20\% }\end{array}$ \\
\hline
\end{tabular}

Tabelle 2-2. Klinisch-neurologischer Score zur Gesundheitsbeurteilung

Einem kranken Tier wurden Futter und Wasser auf den Käfigboden gestellt. Um einen Gewichtsverlust beurteilen zu können, wurden die Tiere $3 x$ /Woche gewogen. In der Infektionsphase und bei Krankheitszeichen wurden die Tiere täglich gewogen.

\subsubsection{Motorische und neuropsychologische Testung}

Seiltest

Ein Test zur Einschätzung der muskulären Koordination und Kraft einer Maus ist der Seiltest, welcher von Miquel und Blasco (Miquel und Blasco 1978) erstmals beschrieben wurde. Dieser Test wurde zweimal wöchentlich durchgeführt. Dazu wurde die Maus am Schwanz gefasst und mit den Vorderpfoten in die Mitte eines ca. $60 \mathrm{~cm}$ langen gestrafften Seiles gehängt. Es befand sich $60 \mathrm{~cm}$ über dem Boden, und an den Enden existierte jeweils eine Plattform, welche die Maus erreichen sollte. Zum Schutz vor Verletzungen durch Herunterfallen wurde eine Box mit weichem Boden untergestellt.

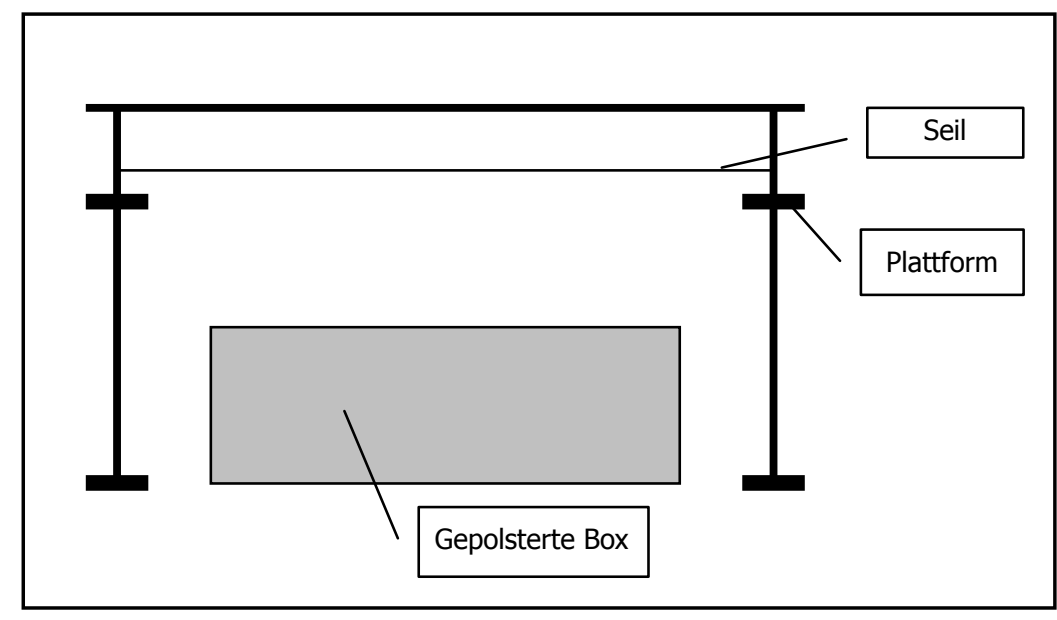

Abbildung 2-2. Schematische Darstellung des Versuchsaufbaus für den Seiltest. 
Gemessen wurde die Zeit bis zum Erreichen einer der beiden Plattformen. Der Test endete, wenn die Maus die Plattform erreicht hatte oder wenn 60 Sekunden vergangen waren.

Für die statistische Auswertung des Seiltests verwendeten wir den Wellmer-Score (Wellmer et al. 2004): Mäuse, die ein Seilende in weniger als 6 Sekunden erreichten, bekamen den Score 0. Für alle weiteren 6 Sekunden wurde ein zusätzlicher Punkt addiert. Tiere, die mehr als 60 Sekunden am Seil hingen ohne herunterzufallen, das Ziel jedoch nicht erreichten, bekamen den Score 11. Fiel die Maus vor Ablauf von 60 Sekunden vom Seil, wurde für alle 6 Sekunden (absteigend von 60 Sekunden) jeweils ein Punkt zum Score 11 addiert, so dass ein Maximalscore von 20 erreicht werden konnte.

\section{Rotarod-Test}

Zum Ausschluss motorischer Lähmungen und der Überprüfung von Koordination, Kraft und Ausdauer wurde der Rotarod-Test, ähnlich wie durch Dunham und Miya beschrieben (Dunham und Miya 1957), eingesetzt. Dabei begannen die Tiere auf einem Laufrad mit 4 Umdrehungen pro Minute zu laufen. Die Geschwindigkeit steigerte sich im Verlauf auf maximal 40 Umdrehungen pro Minute, nach 300 Sekunden wurde der Test beendet. Die Zeit bis zum Herunterfallen vom Laufrad wurde gemessen. Nach einem Training erfolgte dieselbe Testung einmal pro Woche.

\section{Morris-Water-Maze}

Zum Testen der Gedächtnisleistung bedienten wir uns des Morris-Water-Maze, welches zum ersten mal von R. Morris beschrieben wurde (Morris 1984). Dazu wurde ein Wasserbecken mit $50 \mathrm{~cm}$ Höhe und $104 \mathrm{~cm}$ Durchmesser mit handwarmem Wasser gefüllt, bis das Wasser die hineingestellte Plattform (umgedrehtes Becherglas mit $15 \mathrm{~cm}$ Durchmesser und 16,5 cm Höhe) zu circa $1 \mathrm{~cm}$ bedeckte. Die Plattform wurde auf eine vorbestimmte Stelle exakt platziert und war so für die schwimmende Maus nicht sichtbar. Durch eine Stellwand wurde der Untersucher vom Schwimmgelände abgeschirmt. Dieses war stets von den gleichen Gegenständen umgeben, an denen sich die Maus orientieren konnte. Während der immer zur gleichen Tageszeit stattfindenden Untersuchung musste Ruhe herrschen.

Gleichzeitig mit dem Einsetzen des Tieres ins Wasser an der dafür vorhergesehenen Stelle wurde die Computermessung mittels der Software Videomot 2 gestartet, die über eine Kamera Strecke und Dauer der Schwimmaktion aufzeichnen konnte. Die Messung wurde beendet, wenn die Maus die Plattform erreicht hatte und dort sitzen blieb oder diese nach 90 Sekunden immer noch nicht gefunden hatte.

Die Maus wurde nach dem Schwimmen getrocknet und pausierte, bis alle anderen Mäuse den gleichen Durchlauf geschwommen waren (Dauer: ca. eine Stunde). Eine kranke Maus 
wurde nicht getestet.

Die Schwimmversuche wurden wie folgt durchgeführt: (T: Training: 6 Läufe/Maus, W: Wiederholung: 3 Läufe/Maus, VP: Versetzte Plattform: 6 Läufe/Maus

\begin{tabular}{|l|l|l|l|l|l|l|l|}
\hline Tag & Mo & Di & Mi & Do & Fr & Sa & So \\
\hline Woche 1 & & & & T1 & T2 & T3 & \\
\hline Woche 2 & & & & & W1 & & $\begin{array}{l}\text { Infektion } \\
\text { Test 4 Tiere }\end{array}$ \\
\hline Woche 3 & $\begin{array}{l}\text { Infektion } \\
\text { Restl. Tiere }\end{array}$ & & & & & & \\
\hline Woche 4-15 & $\begin{array}{l}\text { W2-13 } \\
\text { Infektion }\end{array}$ & & & & & & \\
\hline Woche 16 & W14 & & & VP1 & VP2 & VP3 & \\
\hline
\end{tabular}

Tabelle 2-3. Zeitlicher Ablauf der Testung im Morris-Water-Maze

Die Wiederholungsläufe fanden wöchentlich und stets vor der Infektion statt.

Abgesehen von der Anzahl der Läufe/Maus unterschieden sich Training, Wiederholung und Versetzte Plattform wie folgt: Beim Training wurde eine Maus, die die Plattform nicht erreicht hatte, nach dem Schwimmen für mindestens 30 Sekunden auf die Plattform gesetzt, damit sie sich deren Lage einprägen konnte. Dies fand bei den Wiederholungsläufen, welche die Erinnerungsfähigkeit testen sollten, nicht statt. Die Versuche der Versetzten Plattform dienten dazu, herauszufinden, ob eine Maus noch genauso lernfähig war wie zu Beginn des gesamten Versuches. Daher wurde hier wie beim Training verfahren, nur dass die Plattform an einer anderen Stelle im Wasserbecken stand.

\subsubsection{Präparation des Gehirns}

Die Mäuse wurden durch Genickbruch getötet und die Schädelkalotten freipräpariert. Nach Eröffnung der Schädelkalotte konnte das Gehirn vorsichtig herausgenommen werden. Die linke Hirnhälfte wurde für die histologische Aufarbeitung über mindestens $24 \mathrm{~h}$ in $4 \%$ igem Formaldehyd fixiert. Anschließend erfolgte die Einbettung in Paraffin nach neuropathologischer Standardmethode.

Die andere Hirnhälfte wurde in Kleinhirn, vorderes und hinteres Großhirn geteilt und die in Eppendorfcups gefüllten Gewebsstücke in Stickstoff schockgefroren. Diese Proben dienten zur Aufarbeitung für Westernblots und ELISAs.

Die Kadaver wurden vorschriftsgemäß entsorgt.

\subsubsection{Präparation und Homogenisierung der Milz}

Die Milz wurde über eine Eröffnung der Bauchhöhle präpariert. Es erfolgte die Fixierung einer Hälfte in 4\% Formaldehyd über mindestens 24 Stunden und die Aufbewahrung zur 
histologischen Aufarbeitung. Die zweite Hälfte wurde in $450 \mu \mathrm{l} 0,9 \%$ igem $\mathrm{NaCl}$ gründlich homogenisiert.

Das Homogenat wurde zur Keimbestimmung verwendet wie unter 2.2.3 auf Seite 26 bei „Bestimmung der Keimanzahl im Inokulum und im Organgewebe“ beschrieben. Zur Zytokinbestimmung mittels ELISA konnte das Homogenat unverdünnt eingesetzt werden.

\subsubsection{Proteinextraktion}

Zur biochemischen Analyse des Detergenzien-löslichen sowie Detergenzien-unlöslichen Amyloid- $\beta$-Proteins $(A \beta)$ war eine Proteinextraktion aus dem Hirngewebe der Mäuse nötig.

Die gewonnenen Homogenate wurden jeweils in einem Probenaufnahmepuffer (PAP) gelöst, welcher aus folgenenden Substanzen, in $\mathrm{H}_{2} \mathrm{O}$ dd gelöst, hergestellt wurde (Rezept für $1 \mathrm{x}$ PAP):

0,36 M Bis-Tris

0,16 M Bicine

$15 \% \mathrm{w} / \mathrm{v}$ Sucrose $(=0,44 \mathrm{M})$

$1 \%$ SDS

0,0075\% Bromphenolblau.

\section{Proteinextraktion mit RIPA Puffer für Detergenzien-lösliches $A \beta$}

Der Radioimmunopräzipitations-Assay“ (RIPA) -Puffer zur Extraktion des Detergenzienlöslichen Aßs aus dem Hirngewebe der Tg2576-Tiere setzte sich wie folgt zusammen (Ansatz für $10 \mathrm{ml}$ Puffer):

Eine Tablette Protease-Inhibitor wurde in $6,6 \mathrm{ml}$ doppelt destilliertem Wasser gelöst. Hinzugefügt wurden $500 \mu \mathrm{l}$ einer 1 M HEPES Lösung (pH 7,4), $500 \mu \mathrm{l} 10 \%$ iges Na-DOC, $300 \mu \mathrm{l} 5 \mathrm{M}$ Kochsalzlösung, $100 \mu \mathrm{l} 10$ \%iges SDS $1 \mathrm{ml} 10$ \%iges Nonidet P40. Dabei war darauf zu achten, dass sich die Protease-Inhibitor-Tablette vor Zugabe der anderen Substanzen vollständig gelöst hatte. Der Lysis-Puffer sollte immer frisch hergestellt werden und während des gesamten Zeitraums auf Eis gekühlt werden.

Je $1 \mathrm{ml}$ des Lysis-Puffers wurden zu dem zuvor abgewogenen Hirngewebe (Optimum: 100 $\mathrm{mg}$ ) in ein 1,5 ml Eppendorfcup gegeben. Dann wurde das Gewebe mit Hilfe eines Branson Sonifiers mit einem pulsativen Output von 1,8 mit 15-20 sonifiziert. Um den Überstand (=Homogenat) zu gewinnen, erfolgte eine Zentrifugation bei $14000 \times \mathrm{g}$ und einer Temperatur von $4{ }^{\circ} \mathrm{C}$ für 10 Minuten. Das Sediment (=Pellet) sowie die aliquotierten Überstände wurden bei $-80 \stackrel{\circ}{\mathrm{C}}$ verwahrt.

Vor Einsatz im Westernblot wurden die Proben 1:1 mit doppelt konzentriertem Probeaufnahmepuffer (2x PAP) $+5 \%$-Mercaptoethanol bei $95 \stackrel{\circ}{\circ} 5$ Minuten aufgekocht 
und mit 1x PAP auf die gewünschte Proteinkonzentration verdünnt.

Proteinextraktion mit Ameisensäure für Detergenzien-unlösliches $A \beta$

Aus den Pellets der RIPA-Extraktion konnte das Detergenzien-unlösliche $A \beta$ gewonnen werden. Dazu wurden die Proben bei Raumtemperatur aufgetaut, erneut bei $14500 \times \mathrm{g}$ zentrifugiert und die Flüssigkeitsreste vollständig entfernt. Die Pellets wurden mit $300 \mu \mathrm{l} 70$ \%iger Ameisensäure versetzt, 20 Minuten bei Raumtemperatur geschüttelt und anschließend 10 Minuten bei $20000 \times \mathrm{g}$ zentrifugiert. Es erfolgte die Abnahme des Überstands und die Eintrocknung in einem Eppendorfcup im Speed Vac. Die Probe wurde in $300 \mu \mathrm{l} 1 \mathrm{x}$ PAP gelöst, 20 Minuten geschüttelt und 5 Minuten bei $95^{\circ} \mathrm{C}$ aufgekocht.

Die so aufgearbeiteten Proben konnten nun bei $-80 \stackrel{\circ}{\circ} \mathrm{C}$ tiefgefroren werden. Vor der Verwendung im Westernblot wurden sie mit 7,5 $\mu$ l $\beta$-Mercaptoethanol versetzt und nochmals 5 Minuten bei $95 \stackrel{\circ}{\mathrm{C}}$ unter dem Abzug aufgekocht. Je nach Proteinkonzentration wurden die Proben in einer 1:10 bis 1:100-Verdünnung mit 1x PAP im Westernblot eingesetzt.

\subsubsection{Bestimmung der Proteinkonzentration}

Die Methode der Proteinbestimmung mit Bicinchoninsäure erfolgte modifiziert nach Smith et al. (Smith et al. 1985): Aus der Albumin-Stammlösung wurde eine Standardreihe mit den Konzentrationen $5,10,15,25,50,75$ und $100 \mu \mathrm{g} / \mathrm{ml}$ hergestellt und doppelreihig je $100 \mu \mathrm{l}$ auf eine 96-Loch-Mikrotiterplatte pipettiert. Die Homogenate der RIPA-Extraktion wurden 1:200 in doppelt destilliertem Wasser verdünnt und zweimal je $100 \mu \mathrm{l}$ zur Doppelbestimmung neben die Standardreihe pipettiert.

Die Herstellung der frischen BCA-Färbelösung erfolgte aus 1 Teil $4 \% \mathrm{CuSO}_{4} 5 \mathrm{H}_{2} \mathrm{O}$ in $\mathrm{H}_{2} \mathrm{O}$ und 49 Teilen Bicinchoninsäure. Ohne Zeitverzögerung wurden je $100 \mu \mathrm{l}$ der Färbelösung zu Standards und Proben gegeben, die Mikrotiterplatte abgeklebt und 30 Minuten bei $60 \stackrel{\circ}{ }$ inkubiert. Die Auswertung erfolgte am Microplate-Reader bei einer Wellenlänge von $550 \mathrm{~nm}$.

\subsubsection{Urea-Aß-SDS-PAGE-Westernimmunoblot}

Der Urea-A $\beta$-SDS-PAGE-Westernimmunoblot beinhaltet die Auftrennung des Proteingemisches durch eine Urea-A $\beta$-SDS-Polyarcrylamidgelelektrophorese und konsekutive Antikörper-vermittelte Anfärbung der unterschiedlich langen $A \beta$-Fragmente. Die Banden der einzelnen $A \beta$-Peptide können durch eine Chemilumineszenzreaktion sichtbar gemacht werden. Die Konzentrationen wurden mittels einer für jedes Gel mitgeführten Standardeichreihe von synthetischen $A \beta$-Peptiden semiquantitativ bestimmt.

Der $A \beta$-Westernblot wurde in Zusammenarbeit mit der Arbeitsgruppe von Jens Wiltfang und Hermann Esselmann, letzterer war zum Zeitpunkt der Versuche Mitarbeiter der Abteilung Psychiatrie der Universität Göttingen, durchgeführt (Wiltfang et al. 2001). 


\section{Puffer und Gele}

Gelöst wurde jeweils in doppelt destilliertem Wasser.

Anodenpuffer $200 \mathrm{mM}$ Tris, $50 \mathrm{mM} \mathrm{H}_{2} \mathrm{SO}_{4}$

Kathodenpuffer $200 \mathrm{mM}$ Bicine, $100 \mathrm{mM} \mathrm{NaOH}, 0,25 \%$ SDS

Trenngelpuffer $\quad 1,6 \mathrm{M}$ Tris, $0,4 \mathrm{M} \mathrm{H}_{2} \mathrm{SO}_{4}, \mathrm{pH} 8,1$

Sammelgelpuffer $\quad 0,8 \mathrm{M}$ Bis-Tris, 0,2 $\mathrm{M} \mathrm{H}_{2} \mathrm{SO}_{4}, \mathrm{pH} 6,7$

Kammgelpuffer $\quad 0,72 \mathrm{M}$ Bis-Tris, 0,32 Bicine, $\mathrm{pH}$ 7,7

Schachtpuffer $\quad 0,36 \mathrm{M}$ Bis-Tris, 0,16 M Bicine, 0,1\% SDS, $\mathrm{pH} 7,7$

Trenngel für 12 Gele: 8,3 ml 60\%T5 \%C, $24 \mathrm{~g} 8$ M Harnstoff, 12,5 ml Trenngelpuffer, 1,25 ml $10 \% S D S, 9,25$ ml $\mathrm{H}_{2}$ Odd, $200 \mu \mathrm{l}$ APS, $25 \mu \mathrm{l}$ TEMED

Sammelgel für 12 Gele: $2 \mathrm{ml}$ Sammelgelpuffer, 0,4 ml 60\%T3 \%C, $1 \mathrm{ml} 1 \%$ SDS, 0,6 ml H $\mathrm{H}_{2} \mathrm{Odd}, 24 \mu \mathrm{l} 10 \%$ APS, $8 \mu \mathrm{l}$ TEMED; 30 min Polymerisation, langsam auf Trenngel pipettieren

Kammgel für 12 Gele: $6 \mathrm{ml}$ Kammgelpuffer, 1,2 $\mathrm{ml} 60 \%$ T3 \%C, $3 \mathrm{ml} 1 \%$ SDS, 1,8 $\mathrm{ml} \mathrm{H}$ Odd, $45 \mu$ l Bromphenolblau-Stocklösung, $72 \mu \mathrm{l} 10 \%$ APS, 24 $\mu \mathrm{l}$ TEMED, 30 min Polymerisation

Blotpuffer A $210 \mathrm{nM}$ Tris, $30 \% \mathrm{v} / \mathrm{v}$ Methanol, $\mathrm{pH} \approx 10,4$, ohne $\mathrm{pH}$-Einstellung

Blotpuffer B $25 \mathrm{mM}$ Tris, 30\% v/v Methanol, $\mathrm{pH}$ 10,4, ohne pH-Einstellung

Blotpuffer C $25 \mathrm{mM}$ Tris, 0,025 \% w/v SDS, pH 9,4, pH Einstellung auf 9,0 mit 0,5 M Borsäure

PBS 9,55 g PBS w/v 1 I $\mathrm{H}_{2} \mathrm{Odd}$

PBS-T $0,075 \%$ v/v Tween 20

ECL-Plus Lösung $\quad(1,25 \mathrm{ml}$ Reagenz A und 31,5 $\mu$ l Reagenz B pro Membran)

Erklärung zur Zusammensetzung des Polyacrylamids:

$\% \mathrm{~T}$ = total monomer concentration Acrylamid $(\mathrm{g})+$ Bisacrylamid $(\mathrm{g}) / 100 \mathrm{ml}$

$\% \mathrm{C}=$ Bisacrylamid $(\mathrm{g}) \times 100 / \% \mathrm{~T})$

\section{Die Urea-Aß-SDS-PAGE}

Die Urea-Aß-SDS-PAGE ist eine Form der Elektrophorese in einem Gel auf Polyacrylamidbasis unter von Zusatz von $8 \mathrm{M}$ Harnstoff (Urea) im Trenngelkompartiment. Sie wurde mit dem Bio-Rad-Mini-Protean-II-Elektrophorese-System durchgeführt. Das Polyacrylamid-Gel setzte sich aus einem $54 \mathrm{~mm}$ hohen Trenngel-Kompartiment, dem darüberliegenden $5 \mathrm{~mm}$ hohen Sammelgelkompartiment sowie dem 12-15 mm hohen Kammgelkompartiment zusammen. Die Geldicke betrug $0,5 \mathrm{~mm}$; die Gelbreite $85 \mathrm{~mm}$. In das noch flüssige Kammgel wurde ein 15-zähniger 0,5 mm starker Probenauftragskamm 
eingeführt. Die Polymerisationszeit für die im flüssigen Zustand in die Gießkammern eingefültten Gelkompartimente betrug je Kompartiment 30 min. Die Probenschächte wurden dreimal mit Schachtpuffer gespült und dann mit diesem aufgefüllt. Sowohl die Proben als auch die synthetischen A $\beta$-Peptid-Standards wurden in einem Volumen von $5 \mu \mathrm{l}$ aufgetragen. Die elektrophoretische Auftrennung der Proben erfolgte über 60 min bei $24 \mathrm{~mA}$ und Raumtemperatur.

\section{Westernimmunoblot}

Im Anschluss an die Urea-Aß-SDS-Page erfolgte der Transfer der aufgetrennten Peptide mittels eines Semidry-Westernblot auf PVDF-Nachweismembranen. Dafür benötigte wurden vier $3 \mathrm{~mm}$ starke Filterpapiere und eine PVDF-Nachweismembran. Die PVDF-Membran wurde entsprechend den Herstellerangaben vor Gebrauch mit Methanol benetzt, anschließend für 1 min in $\mathrm{H}_{2} \mathrm{O}$ dd gelegt und in den Puffer $B$ überführt. Eines der vier Filterpapiere wurde in Puffer A, eines in Puffer B und zwei in Puffer C inkubiert. Die Gele wurden unmittelbar im Anschluss an die Elektrophorese für 1 min in Puffer $C$ inkubiert.

Der Aufbau des Blots erfolgte von der Anode zur Kathode des Elektroblotters:

$1 x$ Filterpapier mit Puffer $A$

1x Filterpapier und 1x PVDF-Nachweismembran mit Puffer B

Gel aus Elektrophorese.

2x Filterpapier mit Puffer C

Der Transfer dauerte für den A $\beta$-SDS-Page/Immunoblot $30 \mathrm{~min}$ bei $47 \mathrm{~mA} / \mathrm{Gel}$ und Raumtemperatur.

Nach Beendigung des Westernblots wurden die PVDF-Membranen für ca. $30 \mathrm{~s}$ in $\mathrm{H}_{2} \mathrm{O}$ dd gewaschen und für $3 \mathrm{~min}$ in einer Mikrowelle in PBS gekocht. Der Kochschritt war essentiell, um die maximale Nachweisempfindlichkeit zu realisieren (Wiltfang et al. 1997). Es erfolgte nun die Immunfärbung:

Zunächst wurde die PVDF-Membran für $1 \mathrm{~h}$ in einem 1:10 in $\mathrm{H}_{2} \mathrm{O}$ dd verdünnten RotiblockBad unter ständigem Schütteln bei Raumtemperatur geblockt. Für die Inkubation der Membran mit dem primären monoklonalen Antikörper 1E8 wurde die Membran mit $3 \mathrm{ml}$ des 1:200 in Rotiblock verdünnten Antikörpers in eine Folie eingeschweißt. Die Inkubation auf einem Schüttler erfolgte über $20 \mathrm{~h}$ bei $4^{\circ} \mathrm{C}$. Danach wurde die Membran dreimal für $10 \mathrm{~min}$ mit PBS-T (4ml/cm² Membran) bei Raumtemperatur gewaschen und nachfolgend für $1 \mathrm{~h}$ bei Raumtemperatur mit dem sekundären, biotinyliertem Antikörper (Anti-Maus-lgG) inkubiert. Dieser war 1:300 in PBS-T verdünnt $\left(0,074 \mathrm{ml} / \mathrm{cm}^{2}\right.$ Membran). Nach erneutem dreimaligen Waschen für 10 Minuten mit PBS-T (4ml/ $\mathrm{cm}^{2}$ Membran) wurde die PVDF-Membran über $1 \mathrm{~h}$ bei Raumtemperatur mit dem Streptavidin-Peroxidase-Komplex inkubiert. Dieser war 1:3000 
in PBS-T verdünnt $\left(0,26 \mathrm{ml} / \mathrm{cm}^{2}\right.$ Membran). Es erfolgte ein abschließender Waschgang (3x 10 min mit PBS-T).

Im letzten Schritt wurde die Membran für 5 min bei Raumtemperatur mit der ECL-Plus Lösung inkubiert.

\section{Densitometrie}

Die Detektion des Chemilumineszenz-Lichtsignals wurde mit der "Charge-Coupled Device“ Kamera (Fluor-S Multi Imager) durchgeführt und Bilder nach 1, 5, 20, 60, 120, und $300 \mathrm{~s}$ gemacht. Die Auswertung fand nach einer Detektionszeit von $20 \mathrm{~s}$ statt.

Die Intensitäten der Banden wurden in Bezug zu denen der internen Verdünnungsreihe des Aß-Peptid-Standard Mix mittels der „Quantity One Software“ (Version 4.1) gesetzt und so die Konzentrationen ermittelt.

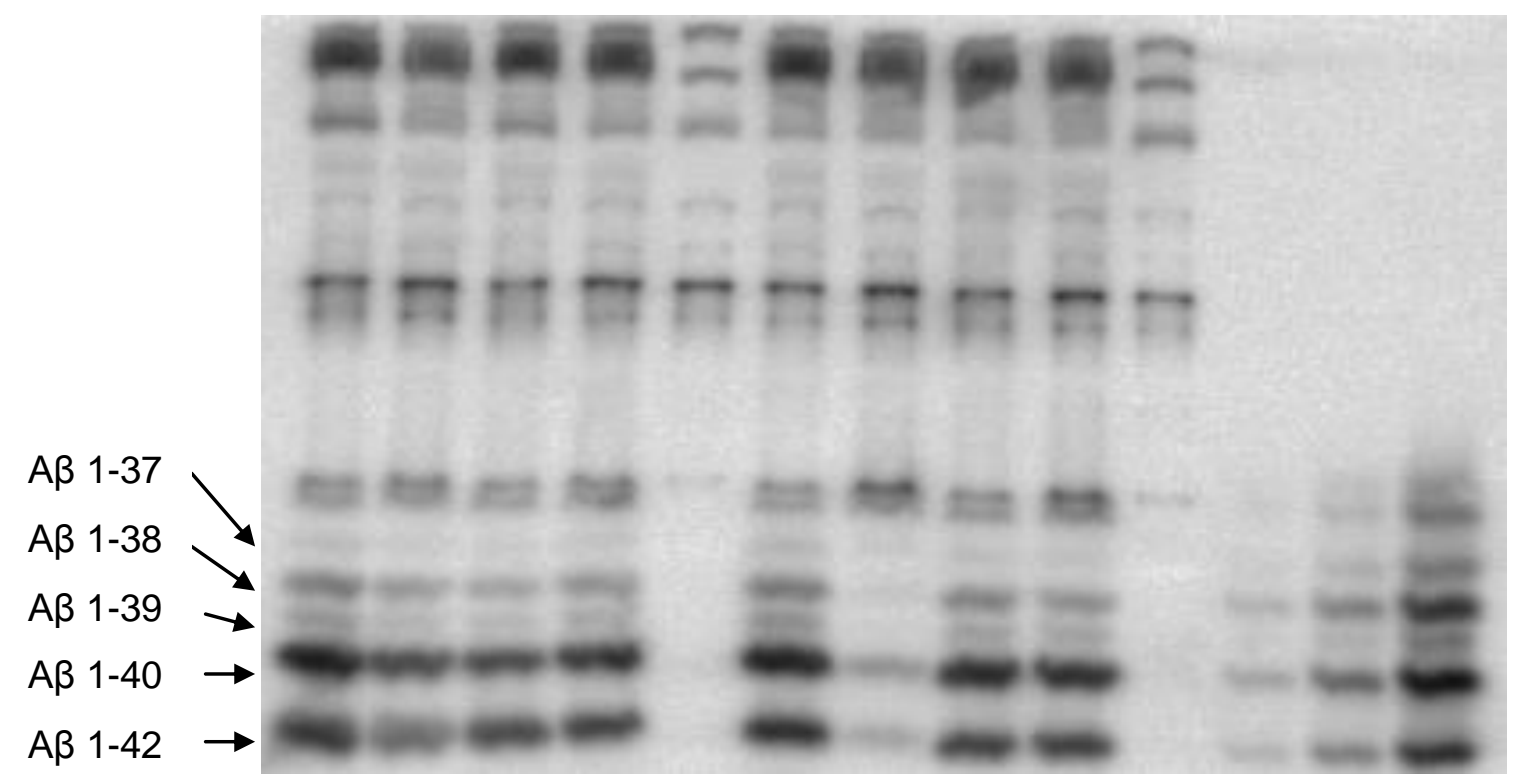

Abbildung 2-3. Beispiel einer Westernblot-Membran. Die rechten drei Reihen bilden die Standardreihen der $A \beta$-Peptid-Konzentrationen.

\subsubsection{Amyloid- $\beta$-ELISA}

Der hAmyloid $\beta 40 / \beta 42$ ELISA wurde gemäß den Herstellerangaben durchgeführt. Dieser ELISA ermöglichte die quantitative Bestimmung von humanem $A \beta$ 1-40 beziehungsweise 142 aus dem Überstand von homogenisiertem Hirngewebe. Abgewichen wurde lediglich von der Standardreihe: Hier wurden die Konzentrationen 1000; 500; 250; 125; 62,5; 31,25, $15,625 \mathrm{pg} / \mathrm{ml}$ und einen Blankowert eingesetzt.

\subsubsection{IL-6-ELISA}

Die Proteinextraktion und Konzentrationsbestimmung von IL-6 erfolgte nach Herstellerangaben. 


\subsubsection{Histologie}

Mit dem Schlittenmikrotom wurden vor der Färbung vom Paraffinblock 1-2 $\mu$ m dicke Schnitte gemacht.

Färbung mit Isolectin-B4 und Iba1

Nach der Entparaffinierung wurden die Schnitte $5 \times 3$ Minuten in der Mikrowelle in einem Puffer aus Zitronensäure (10 mmol/l gelöst in $\mathrm{H}_{2} \mathrm{O}$ dd, $\mathrm{pH} 6,0$ ) vorbehandelt. Anschließend wurden die Schnitte für 10 Minuten in $3 \%$ iges $\mathrm{H}_{2} \mathrm{O}_{2}$ getaucht und danach mit in PBS verdünntem 10\%igem FCS behandelt. Nun wurden die Schnitte entweder mit biotinyliertem Isolectin-B4 [(5 $\mu \mathrm{g} / \mathrm{ml}$, verdünnt in PBS mit $1 \%$ bovinen Serumalbumin (BSA)] für 90 Minuten inkubiert oder mit dem polyklonalen Kaninchen-anti-lba1-Antikörper (1:100-Verdünnung) über Nacht bei $4{ }^{\circ} \mathrm{C}$ inkubiert und nachfolgend mit einem biotinylierten anti-KaninchenAntikörper (1:200 Verdünnung) über 60 Minuten behandelt. Anschließend erfolgte die Inkubation die Schnitte mit dem Avidin-Biotin-Komplex für 30 Minuten und die Entwicklung der Somata und Ausläufer der Mikroglia durch DAB (5 Minuten). Abschließend konnten die Schnitte mit dem „Fluorescent Mounting Medium“ eingedeckelt werden. Es resultierte eine braune Färbung der Mikroglia bei der Färbung mit Isolectin-B4 und eine grüne Fluoreszenz bei der Färbung mit Iba1.

\section{Färbung mit Thioflavin S}

Thioflavin S ist ein Salz, welches sich an $\beta$-Faltblätter, wie sie in A $\beta$-Oligomeren vorkommen, bindet und dadurch eine charakteristische Veränderung des Emissionsspektrums bewirkt.

Zur Färbung mit Thioflavin S wurden die Paraffinschnitte entparaffiniert und anschließend in destilliertem Wasser gespült. Zwischen den folgenden Schritten erfolgte jeweils eine Spülung mit Wasser. Die Schnitte mussten erst 20 Minuten in 0,25\%iger $\mathrm{KMnO}_{4}$ (Kaliumpermanganat) Lösung inkubiert werden, anschließend zwei Minuten in einer Lösung von einem Teil 1\%iges $\mathrm{K}_{2} \mathrm{~S}_{2} \mathrm{O}_{2}$ (Kaliumdisulfid) und einem Teil 1 \%iger Oxalsäure. Danach wurde 20 Minuten in einer Lösung aus $1 \mathrm{~g} \mathrm{NaOH}, 3 \mathrm{ml} 30 \%$ iger $\mathrm{H}_{2} \mathrm{O}_{2}$ und $100 \mathrm{ml}$ Wasser inkubiert. Es erfolgte eine 5 sekündige Behandlung mit Essigsäure $(0,25 \%)$ und eine 5minütige Inkubation mit Thioflavin $S$, gelöst in 50\%igem Ethanol. Es schlossen sich zwei Spülschritte an, zuerst zweimalig mit in 50\%igem Ethanol und dann zweimalig in Wasser. Nun konnten die Schnitte mit dem „Fluorescent Mounting Medium“ eingedeckelt werden. Im Mikroskop zeigten sich grün fluoresziernde $A \beta$-Plaques.

\section{Beurteilung der Histologie}

Zur Quantifizierung der durch Thioflavin S angefärbten Plaques wurden die Schnitte zeitnah nach der Färbung unter dem Mikroskop BX 51 beurteilt. Dabei wurden mit dem Programm 
Analysis 3.2 die Flächen der einzelnen Plaques in je $1 \mathrm{~mm}$ ventral und dorsal der Großhirnmittellinie gelegenen Schnitte für jedes Tier addiert.

\subsection{Zellkulturen}

\subsubsection{Medien und Lösungen}

\section{Poly-L-Lysin-Lösung}

$100 \mathrm{~g}$ Poly-L-Lysin-Hydrobromid wurden in 1 I $\mathrm{H}_{2} \mathrm{O}$ dd gelöst, 6,183 g (1M) Borsäure hinzugegeben und die Lösung auf einen $\mathrm{pH}$ von 8,4 eingestellt. Die Lagerung erfolgte in Aliquots bei $-20 \stackrel{\circ}{ } \mathrm{C}$.

\section{Medium für die murine Mikroglia-Zellkultur}

Das nach Dulbecco modifizierte Eagle's Basalmedium D-MEM wurde mit $10 \%$ FCS und 1\% Penicillin/Streptomycin (10.000 IE/ml Penicillin; 10.000 $\mathrm{mg} / \mathrm{ml}$ Streptomycin) unter sterilen Bedingungen vermischt und auf $37^{\circ} \mathrm{C}$ im Wasserbad erwärmt. Die Lagerung des Mediums erfolgte bei $4 \stackrel{\circ}{\circ}$.

Medium für die murine Neuronen-Zellkultur

Zu $500 \mathrm{ml}$ Neurobasal Medium wurden 1,25 ml Glutamin und $10 \mathrm{ml}$ B-27 Supplement mit Antioxidanzien hinzugefügt.

Medium für die humane Makrophagen- sowie humane Neuroblastom-Zellkultur $500 \mathrm{ml}$ RPMI wurden mit $10 \%$ FCS und $1 \%$ Penicillin/Streptomycin (10.000 Units/ml Penicillin; $10.000 \mu \mathrm{g} / \mathrm{ml}$ Streptomycin) vermischt.

\section{Phosphat-Buffered-Saline-Lösung (PBS)}

In 1 I doppelt destilliertem Wasser wurden 9,55 g PBS Pulver auf dem Magnetrührer gelöst. Die Lösung musste anschließend autoklaviert werden.

\section{Lysis-Puffer}

Es wurde eine 9\%ige Triton-X-100-Lösung in doppelt destilliertem Wasser hergestellt.

\section{Trypsinlösung}

Trypsin/EDTA-Lösung $0,5 \% / 0,2 \% \mathrm{w} / \mathrm{v}$ in 10x PBS gelöst wurde weiter $1: 10$ mit $\mathrm{H}_{2} \mathrm{O}$ dd verdünnt. 


\subsubsection{Murine Zellkulturen}

Die murine Mikroglia-Zellkultur

Zum Gewinnen einer Mikroglia-Zellkultur wurden neugeborene Mäuse vom Typ C57/B6 benötigt, die zum Zeitpunkt der Präparation maximal drei Tage alt sein durften. Die Arbeit erfolgte unter sterilen Bedingungen. Das Präparierbesteck wurde in $70 \%$ igem Ethanol aufbewahrt, vor der Berührung mit dem Tier jedoch immer in PBS getaucht. Mit einer Schere wurde der Kopf der Tiere abgetrennt, dann kurz mit 70 \%igem Ethanol besprüht und in eine Petrischale überführt. Dort wurden Haut und Kalotte eröffnet und das Gehirn vorsichtig gelockert und in eine mit PBS gefüllte Petrischale auf Eis überführt. Darin wurden die Hirne mehrerer Tiere gesammelt. Anschließend mussten unter dem Mikroskop die Meningen entfernt werden. Dazu wurde das Hirn erneut in eine mit PBS gefüllte Petrischale gelegt, dort mit einer Pinzette fixiert und mit Hilfe einer sehr feinen Pinzette die Hirnhaut abgezogen. Ein fertig präpariertes Gehirn wirkt wie weißes, formloses Gewebe und hat keine rötlichen, fädigen Strukturen mehr aufzuweisen. Je zwei Hirne wurden in $2 \mathrm{ml}$ PBS auf Eis gelagert. Mit einer 1-ml-Pipette wurde das Gewebe trituiert und so zerkleinert. Es erfolgt dann die Zentrifugation bei $1000 \times \mathrm{g}$ über 10 Minuten bei einer Temperatur von $4 \stackrel{\circ}{\circ}$. Nach Abgießen des Überstandes wurde das Gewebe in $2 \mathrm{ml}$ Mikroglia-Medium vorsichtig resuspendiert und in der vorbereiteten Gewebekulturflasche mit 10,5 ml vorgewärmtem Medium vermischt. In jede Gewebekulturflasche wurden zwei Gehirne gegeben. Die Gewebekulturflasche wurde vorsichtig geschwenkt (dabei darf das Medium nicht in den Hals gelangen, da dieser als unsteril anzusehen ist) und im Brutschrank bei $37^{\circ} \mathrm{C}$ und $5 \% \mathrm{CO}_{2}$ gelagert. Alle 3-4 Tage erfolgte ein vollständiger Mediumwechsel. Nach jedem Präparationsvorgang erfolgte die Sterilisierung des Bestecks bei $200 \stackrel{\circ}{\mathrm{C}} \mathrm{im}$ Ofen über vier Stunden.

Die murine Neuronen-Zellkultur

Zum Gewinnen einer Neuronen-Zellkultur wurden am 16/17ten Tag schwangere C57/B6 Mäuseweibchen benötigt. Das Weibchen wurde mittels $\mathrm{CO}_{2}$-Narkose betäubt und per Genickbruch getötet. Außerhalb des sterilen Arbeitsplatzes wurde erst die Bauchdecke und dann das Peritoneum eröffnet. Die Feten wurden in eine nahe gelegene Petrischale transportiert, und der Kadaver der Mutter vorschriftsgemäß entsorgt.

Die folgenden Schritte fanden unter sterilen Bedingungen statt. Vorsichtig wurde das restliche mütterliche Gewebe entfernt und die abgetrennten Köpfe der Feten separat in einer mit PBS gefüllten Petrischale gesammelt. Dann wurde wie bei der Präparation der Neugeborenen für die Mikroglia-Zellkultur das Gehirn von allen umgebenden Strukturen befreit, zusätzlich wurden das Kleinhirn und der Hippokampus entfernt. Alle Hirne wurden in einem auf Eis gelagerten Röhrchen gesammelt, das mit $5 \mathrm{ml}$ der folgenden Lösung gefüllt ist: $1 \mathrm{M}$ sterilfiltrierte HEPES-Lösung 1\%ig mit D-MEM vermischt (z.B. $500 \mu \mathrm{l} 1 \mathrm{M}$ HEPES- 
Lösung + $50 \mathrm{ml}$ D-MEM). Waren alle Hirne gesammelt, wurde das D-MEM/HEPESGemisch gegen $10 \mathrm{ml}$ Trypsinlösung ausgetauscht und das Röhrchen zur Verdauung 10 Minuten ins $37^{\circ} \mathrm{C}$ Wasserbad gestellt. Das Trypsin wurde verwendet, um die Zellen zu vereinzeln. Dabei werden bei entsprechend kurzer Behandlungszeit nur die extrazellulären Proteine gespalten, während die Zellen nicht geschädigt werden. Mit der 1-ml-Pipette wurde das Trypsin möglichst gründlich abgesaugt. Die Verdauungsreaktion wurde mit ca. 5-10 ml FCS-haltigen Medium gestoppt und das Gewebe langsam trituiert. Anschließend erfolgte eine Zentrifugation mit $550 \times \mathrm{g}$ für 5 Minuten bei $22^{\circ} \mathrm{C}$, danach konnte der Überstand abpipettiert und das Pellet in etwa $5 \mathrm{ml}$ Neuronen-Medium aufgelöst werden. $10 \mu \mathrm{l}$ der zellhaltigen Flüssigkeit wurden mit $90 \mu \mathrm{l}$ Trypanblau vermischt und in der NeubauerZählkammer die Konzentration der Zellen ausgezählt. Die gewünschte Endkonzentration betrug in der Regel 450000 Zellen/ml, die Verdünnung erfolgte mit Neuronen-Medium

Schon am Vortag mussten die für die Neuronen-Zellkultur nötigen 24-Loch-Platten zur besseren Haftung der Zellen am Untergrund wie folgt vorbereitet wurden: In alle randständigen Vertiefungen wurde unter sterilen Bedingungen ein Coverslip mit $13 \mathrm{~mm}$ Durchmesser gelegt. Dieses ermöglichte ein Anfärben der Zellkultur auf dem Coverslip nach Beenden des Versuchs. Auf den Coverslip wurde pro Vertiefung 0,5 ml Poly-L-Lysin-Lösung pipettiert und die Platten über Nacht im Brutschrank inkubiert. Erst kurz vor Zugabe von 0,5 $\mathrm{ml}$ neuronenhaltigem Medium wurde die Poly-L-Lysin-Lösung mit einer MembranVakuumpumpe abgesaugt, da die Coverslips nicht austrocknen durften. Nach einer Stunde Inkubation im Brutschrank musste ein kompletter Mediumwechsel der zellhaltigen Vertiefungen erfolgen, um die Verunreinigung der Neuronen-Zellkultur mit glialen Zellen zu minimieren.

Herstellen und Stimulieren einer murinen Neuronen-Mikroglia-Kokultur

Sind nach 5 Tagen die Neuronen gewachsen und die Kultur keimfrei, so konnten die Mikroglia hinzugefügt und anschließend mit der Stimulation zu begonnen werden. Die Mikroglia-Zellkultur wurde nach ca. 14 Tagen Wachstum unter dem inversen Mikroskop beurteilt. Es sollte sich in diesem Zeitraum ein dichter Astrozytenrasen gebildet haben, dem die Mikroglia aufliegen. Bei ausreichender Dichte und Keimfreiheit wurden die Mikroglia geerntet. Die Ernte funktioniert wie folgt: Die Gewebekulturflaschen wurden für 200 x /min 20 Minuten auf dem Schüttler „rotomix“ geschwenkt, um die Mikroglia vom Astrozytenrasen zu lösen. Das Medium von vier Gewebekulturflaschen wurde ungeachtet des Präparationsdatums in ein 50-ml-Röhrchen pipettiert. Die Kulturen wurden mit neuem Medium versorgt und sofort in den Brutschank zurückgelegt. Währenddessen wurden die Röhrchen mit 250 x g über 10 Minuten bei $20 \stackrel{\circ}{C}$ zentrifugiert. Der Überstand musste in einer Bewegung abgegossen werden, das Pellet in dem verbliebenen Medium aufgemischt und 
alle Bodensätze gepoolt werden. $10 \mu \mathrm{l}$ der zellhaltigen Flüssigkeit wurden mit $90 \mu \mathrm{l}$ Trypanblau vermischt und in der Neubauer-Zählkammer die Konzentration der Zellen ausgezählt. Es erfolgte die Verdünnung der Zellen mit Neuronen-Medium auf die gewünschte Konzentration (in der Regel 20000 Zellen/ml). Im Anschluss wurde das alte Medium aus der Neuronen-Zellkultur entfernt und 0,5 ml der Mikroglialösung zu den Neuronen pipettiert. Nach 2 bis 24 Stunden konnte mit der Stimulation begonnen werden. Zur Stimulation der Kokultur wurde das Medium für die Neuronen-Kultur mit $100 \mathrm{U} / \mathrm{ml}$ murinem IFN-Y versetzt. Dies war nötig, um die Mikroglia ausreichend zu aktivieren. In dem angereicherten Neuronen-Medium wurden die Stimulanzien wie $\mathrm{A} \beta$ 1-40 oder $\mathrm{Pam}_{3} \mathrm{CysSK}_{4}$ verdünnt. Das Stoppen der Stimulation erfolgte nach $72 \mathrm{~h}$ wie folgt: Die Überstände wurden in Eppendorfcups bei -20 ${ }^{\circ} \mathrm{C}$ eingefroren, die Zellen vorsichtig mit PBS gewaschen und zur Fixierung eine halbe Stunde mit 4\%igem Formaldehyd bedeckt. Dieses wurde durch PBS ersetzt und die Platten zugeklebt im Kühlschrank aufbewahrt.

\subsubsection{Humane Zellkulturen}

Die humane Makrophagen-Zellkultur

Die Makrophagen wurden aus „Buffy-Coats“ gewonnen, welche bei der Gewinnung von Erythrozytenkonzentraten abfallen (Boyum 1984). Die „Buffy-Coats“ enthalten neben den peripher zirkulierenden Monozyten auch Granulozyten, Lymphozyten, Thrombozyten und Restmengen von Erythrozyten. Für die Versuche bekamen wir von der Transfusionsmedizin Göttingen die „Buffy-Coats“ der Blutspender vom Vortag zur Verfügung gestellt.

Während des gesamten Protokolls war darauf zu achten, dass sich Inhalte der unterschiedlichen "Buffy-Coats“ und somit eventuell unterschiedlicher Blutgruppen nicht vermischen, da es sonst zur Aggregation kommt. Je $30 \mathrm{ml}$ „Buffy-Coat“ wurden auf je $15 \mathrm{ml}$ $37^{\circ} \mathrm{C}$ warmes Ficoll Paque PLUS in ein 50-ml-Röhrchen pipettiert. Dies erfolgte mit einer 13ml-Pipette, wobei der „Bufffy-Coat“ vorsichtig auf das Ficoll geschichtet wurde. Eine Vermischung der beiden Flüssigkeiten musste vermieden werden. Mit dem anschließenden Zentrifugationsschritt (20 Minuten bei $770 \times$ g, $20 \stackrel{\circ}{\circ}$, ohne Bremse) konnte eine unterschiedlich tiefe Sedimentation der enthaltenen Blutbestandteile erreicht werden. Von unten nach oben befanden sich in dem Röhrchen: aggregierte Erythrozyten, Granulozyten, Plasma, Lymphozyten mit Monozyten und Thrombozyten, Ficoll-Paque. Vorsichtig konnte die Schicht der Lymphozyten mit einer 1-ml-Pipette abgesaugt werden und alle zu einem „Buffy-Coat“ gehörigen Konzentrate einem Röhrchen gesammelt werden. Um die Mischung der Lymphozyten und Monozyten von den Thrombozyten so gut wie möglich zu befreien, erfolgte ein weiterer Zentrifugationsschritt (770 x g, $20 \stackrel{\circ}{\mathrm{C}}, 10$ Minuten, mit Bremse). Der Überstand wurde abgesaugt, das Pellet in $10 \mathrm{ml}$ PBS aufgelöst und ein letztes Mal zentrifugiert (190 x g, $20^{\circ} \mathrm{C}, 10$ Minuten, mit Bremse). Nachdem auch dieser Überstand 
abgesaugt war, konnte das Pellet in 5-6 ml Medium gelöst und je $1 \mathrm{ml}$ in eine vorbereitete Petrischale gegeben werden. In den jeweiligen Petrischale befanden sich schon $6 \mathrm{ml}$ auf 37 ${ }^{\circ} \mathrm{C}$ vorgewärmtes Medium für die Makrophagen-Zellkultur. Nach Zugabe der Zellen wurden die Petrischalen vorsichtig geschwenkt und über Nacht im Brutschrank inkubiert. Der Mediumwechsel am Folgetag ermöglichte die Entfernung eines Großteils der Lymphozyten nach Absiedlung der Monozyten. Über 10-14 Tage wuchsen die Monozyten, das Medium wurde alle 3 bis 4 Tage gewechselt.

Die humane Neuroblastom-Zellkultur

Die humanen Neuroblastomzellen SH-SH5Y sind ein stabiler Subklon der NeuroblastomZelllinie SK-N-SK. Die Zelllinie wurde 1970 aus dem Tumor eines Kleinkindes gewonnen (Biedler et al. 1973). Die Lagerung der humanen Neuroblastomzellen SH-SY5Y erfolgte in FCS mit anteilig 10\% DMSO in flüssigem Stickstoff. Nach dem langsamen Auftauen wurden die SH-SY5Y-Zellen in Gewebekulturflaschen mit $12 \mathrm{ml}$ des Neuroblastom-ZellkulturMediums kultiviert. Das Medium musste alle 4 Tage gewechselt werden, bei sehr dichtem Zellrasen noch häufiger. Da sich die Zellen jedoch sehr schnell teilen, wurde eine Teilung der Kultur angestrebt, bevor sich die Zellen überlagerten. Das entsprach einem Zeitraum von ca. 7-10 Tagen. Eine Splittung der Zellkultur erfolgte mit Hilfe von Trypsinlösung. Diese wurde bei Raumtemperatur aufgetaut. Nach Entfernung des alten Mediums wurde pro Gewebekulturflasche $5 \mathrm{ml}$ Trypsinlösung verwendet, diese musste für wenige Minuten im Brutschrank einwirken. Durch Abklopfen konnte die vollständige Lösung der Zellen erreicht werden. Mit Zugabe von $10 \mathrm{ml}$ FCS-haltigem Medium wurde die Trypsin-Reaktion geblockt. Nach einem Zentrifugationsschritt bei $250 \mathrm{x}$ g über 10 Minuten bei $20^{\circ} \mathrm{C}$ und Verwerfen des Überstandes wurden die Zellen in $39 \mathrm{ml}$ Medium aufgelöst. Nach sorgfältigem Trituieren wurden 3 × $13 \mathrm{ml}$ in neue Gewebekulturflaschen überführt.

\section{Herstellen einer humanen Makrophagen-Neuroblastom-Kokultur}

Die für die Kokultur benötigten Neuroblastomzellen wurden wie im letzten Abschnitt erläutert mittels Trypsinlösung gewonnen. Das Protokoll unterschied sich jedoch darin, dass die Zellen nach dem Verwerfen des Überstandes nur in $10 \mathrm{ml}$ Medium sehr sorgfältig trituiert wurden. Es erfolgte die Zellzählung von $10 \mu$ Zellösung mit $90 \mu$ Trypanblau in der Neubauer-Zählkammer. Je nach Versuch wurde auf 20000-40000 Zellen/ml verdünnt, wobei je $400 \mu \mathrm{l}$ Lösung in die Vertiefungen pipettiert werden mussten. Dabei war eine 24Loch-Platte mit einem Coverslip pro Vertiefung nötig. Die Platte mit der Zellsuspension musste zur gleichmäßigen Verteilung in alle Richtungen bewegt werden. Vor Addition der Makrophagen sollte die Platte über Nacht im Brutschrank gelagert werden. Bevor die Makrophagen geerntet werden konnten, wurde die Kultur unter dem inversen Mikroskop auf 
ausreichende Dichte und Keimfreiheit begutachtet. Das Medium wurde mit einer MembranVacuumpumpe und aufgesetzter Glaspipette abgesaugt, $7 \mathrm{ml}$ PBS hinzugefügt, die Platte geschwenkt und die Flüssigkeit erneut abgesaugt. Dieser Waschvorgang wurde so oft wiederholt, bis nur noch bodenständige Zellen in der Petrischale vorhanden waren. Die ganze Zeit war darauf zu achten, dass die Platten nicht austrockneten. Anschließend wurden $2 \mathrm{ml}$ Medium pro Petrischale pipettiert und mit einem Zellschaber unter viel Druck die Zellen mechanisch vom Boden gelöst. Unter dem Mikroskop konnte kontrolliert werden, ob die Ablösung erfolgreich war. Nach Zugabe weiterer $4 \mathrm{ml}$ Medium wurden die Zellen einer Charge in einem 50-ml-Röhrchen gesammelt. Pro Charge war nur ein Zellschaber nötig. Es erfolgte eine Zentrifugation über 10 Minuten bei $770 \mathrm{x}$ g. Der Überstand wurde abgegossen und das Pellet wurde je nach Größe in $3-10 \mathrm{ml}$ Medium resuspendiert. $10 \mu \mathrm{l}$ der Zelllösung wurden mit $90 \mu \mathrm{l}$ Trypanblau vermischt, die Zellen in der Neubauer-Zählkammer ausgezählt und zu einer Konzentration von - je nach Versuch - 10000 - 20000 Zellen/ml verdünnt. Bevor die Makrophagen auf die mit Neuroblastomzellen gefüllte 24-Loch-Gewebekulturplatte gegeben werden konnten, wurde das alte Medium komplett entfernt und durch $400 \mu \mathrm{l}$ Makrophagen-haltiges Medium ersetzt.

\section{Stimulation der humanen Makrophagen-Neuroblastom-Kokultur}

Die Stimulanzien wurden entsprechend der gewünschten Konzentration in Makrophagen Medium verdünnt. Zwei Stunden, nachdem die Makrophagen-Neuroblastom-Kokultur zusammengefügt wurde, wurde das Stimulans hinzugefügt. Dazu wurde die Hälfte des Mediums mit dem Stimulans ausgetauscht. Über drei Tage wurde die Kokultur täglich mikroskopisch beurteilt und nach 72 Stunden die Stimulation gestoppt. Dies geschah wie in Kapitel 2.3.2 auf Seite 39 beschrieben.

\subsubsection{Zellkultur-Färbungen}

Anmerkung: Sofern nicht anders angegeben, bedeutet Waschen dreimaliges Waschen mit PBS. Die gesamte Arbeit erfolgte bei Raumtemperatur.

Isolectin-B4, $\beta$-Tubulin und Hämalaun

Die murine Kokultur aus Neuronen und Mikroglia wurde mit Isolectin-B4 und $\beta$-Tubulin gefärbt. Dabei handelt es sich bei dem biotinyliertem Isolectin-B4 um ein pflanzliches Zellmembranprotein der Schwarzbohne Griffonia simplicifolia, welches wie ein Antikörper eingesetzt werden kann und die Mikroglia braun färbt. Das $\beta$-Tubulin ist hingegen ein primärer monoklonaler Antikörper, welcher an Mikrotubuli bindet und zu einer rosafarbenen Zeichnung von Neuronenausläufern führt. Eine Färbung mit Hämalaun ermöglichte die violette Anfärbung der Zellkerne. 


\section{Tag 1:}

Die in PBS eingelegten Zellen wurden 30 Minuten in Triton $0,1 \%$ in PBS inkubiert und anschließend gewaschen. Nach 10-minütiger Inkubation mit $\mathrm{H}_{2} \mathrm{O}_{2}$ in PBS erfolgte erneutes Waschen. Nachdem die Zellen 30 Minuten mit FCS $10 \%$ in PBS bedeckt waren, konnten die Coverslips aus den Vertiefungen herausgenommen werden. Sie wurden mit ca. $50 \mu \mathrm{l}$ Isolectin, 1:40 in PBS verdünnt, bedeckt und nach 90 Minuten durch Eintunken in PBS gewaschen. Der nach Herstellerangaben 30 Minuten zuvor zusammengesetzte Avidin-BiotinKomplex konnte nun 30-45 Minuten auf die Coverslips einwirken. Nach einem weiteren Waschschritt blieben die Coverslips für 15 Minuten in PBS gefüllten Petrischalen liegen. Es erfolgte die einminütige Farbentwicklung mit DAB. Hiernach wurde mit destilliertem Wasser gewaschen und die Coverslips wurden über Nacht in PBS bei $4{ }^{\circ} \mathrm{C}$ aufbewahrt.

Tag 2:

Zu Beginn wurde über 30 Minuten mit FCS $10 \%$ in PBS inkubiert. Anschließend wurde der Antikörper $\beta$-Tubulin 1:200 in PBS verdünnt und die Coverslips für 90 Minuten darin inkubiert. Das Waschen erfolgte diesmal mit TBS. Die nächste Inkubation erfolgte mit Kaninchen-anti-Maus-Ig 1:50 in TBS verdünnt für 60 Minuten. Es folgte erneut ein Waschschritt mit TBS. Anschließend wurde eine 1:50 Verdünnung von APAAP in TBS hergestellt und die Coverslips wurden für 60 Minuten damit inkubiert. Nach einem weiteren Waschschritt mit TBS wurden die Coverslips für circa 15-30 Minuten in TBS gelagert. Währenddessen konnte die Neufuchsinlösung wie folgt hergestellt werden:

\begin{tabular}{|l|l|l|}
\hline Aktion & Menge & Substanz \\
\hline & $10 \mathrm{mg}$ & Levamisole \\
\hline Iösen in & $25 \mathrm{ml}$ & TBS \\
\hline pH-Einstellung auf 8,8 & & \\
\hline separat: & $5 \mathrm{mg}$ & Natriumnitrit \\
\hline lösen in & $125 \mu \mathrm{l}$ & destilliertem Wasser \\
\hline dazugeben & $50 \mathrm{ml}$ & Neufuchsin \\
\hline beide Lösungen vermischen & & \\
\hline separat: & $7 \mathrm{mg}$ & Naphthol \\
\hline unterm Abzug hinzufügen & $150 \mu \mathrm{l}$ & Dimethylformamid \\
\hline $\begin{array}{l}\text { Naphthollösung nach und nach zu den andren beiden Lösungen geben, den pH erneut } \\
\text { auf 8,8 einstellen und die Neufuchsinlösung filtrieren. }\end{array}$ \\
\hline
\end{tabular}

Tabelle 2-4. Zusammensetzung der Neufuchsinlösung

Die Farbentwicklung mit Neufuchsin erfolgte über 20-40 Minuten. Zum Schluss wurde mit destilliertem Wasser gewaschen. 
Die vorgefärbten Zellen wurden gegebenenfalls erneut in destilliertem Wasser gewaschen und für 3 Minuten mit Hämalaun (unverdünnte Herstellerlösung) bedeckt. Nach Abnahme der Hämalaunlösung wurden die Zellen fünfmal in Leitungswasser gewaschen. Anschließend wurde das Glasplättchen unter der Verwendung von DePeX mit der zellbedeckten Seite zum Objektträger hin eingedeckelt.

\section{Lichtgrün und CD-68}

Die humanen Kokulturen aus Neuroblastomzellen und Makrophagen wurden mit Lichtgrün und CD-68 angefärbt. Die Färbung mit Lichtgrün ist ein in der Histologie weit verbreitetes Verfahren und färbt die Neuroblastomzellen grün an. Die Doppelfärbung mit Hilfe der monoklonalen Maus-anti-Mensch-CD-68-Antikörper ermöglicht die Differenzierung der Makrophagen. Diese exprimieren zellspezifisch das Glykoprotein „Cluster of Differentiation 68“, kurz CD-68, welches immunhistochemisch mit unten stehender Methode schwarz angefärbt werden kann.

Zur Färbung mit CD-68 und Lichtgrün wurden die Coverslips zuerst 30 Minuten mit $0,1 \%$ igem Triton behandelt. Nach dem Waschen erfolgte eine 10-minütige Inkubation mit $\mathrm{H}_{2} \mathrm{O}_{2}$. Der Antikörper wurde 1:50 mit PBS verdünnt und die Zellen mit dieser Lösung 90 Minuten bedeckt. Erneut wurde gewaschen, dann mit 1:200 mit PBS verdünntem Anti-Mauslg-Antikörper vom Schaf über 45 Minuten inkubiert. Es schlossen sich ein weiterer Waschschritt und die Inkubation der Coverslips mit dem Vectastatin ABC (Avidin/BiotinKomplex) über 45 Minuten an. Nun wurde abschließend gewaschen und die Farbentwicklung mittels DAB durchgeführt.

Vor der Färbung mit Lichtgrün wurden die Coverslips in destilliertem Wasser gespült. Dann erfolgte die Inkubation der Coverslips in Lichtgrün über eine Minute, sowie im Anschluss die Spülung mit destilliertem Wasser und das Überführen in eine aufsteigende Alkoholreihe (Konzentrationen: $50 \%-70 \%-90 \%-100 \%$ Alkohol) zum Wasserentzug. Nach zweimaliger Behandlung mit Xylol konnten die Coverslips vorsichtig mit DePeX eingedeckelt werden.

\subsubsection{Quantifizierung des Zellschadens}

\section{NSE-Messung}

Die Neuronen-Spezifischen-Enolase ist ein Enzym des Glukosestoffwechsels und tritt bei Schädigung von Neuronen aus der Zelle aus. Die NSE-Konzentration wurde mittels eines zweiseitigen immunluminometrischen Assay (Sandwichtest) bestimmt. Die Messungen erfolgten in einem vollautomatischen "LIASON® Analyzer" unter Verwendung des NSE Liason-Kits. Die Überstände der Zellkulturen wurden hierzu unverdünnt eingesetzt. Die Messung der NSE wurde für die murine und die humane Kokultur verwendet. 


\section{Die Zellkultur-Schablone}

Die mikroskopische Auswertung von Kokulturen warf Probleme auf: Die Auswertung konnte nur in einer stärkeren Vergrößerung (1:20-1:40) stattfinden, da in einer geringeren Vergrößerung die Zellen nicht ausreichend gut beurteilbar sind. Da es praktisch unmöglich war, die Gesamtfläche eines Coverslips zu erfassen und auszuwerten, wurde nach objektiven Gesichtspunkten eine Stichprobe der Kokultur ausgewertet. Da die Kokulturen in der Regel mittig zu konzentriert und am Rand sehr dünn mit Zellen besiedelt sind, haben wir ein Hilfsmittel entworfen, welches eine Untersucher-unabhängige Auswertung ermöglicht und einen repräsentativen Bereich der Kokultur erfassen kann.

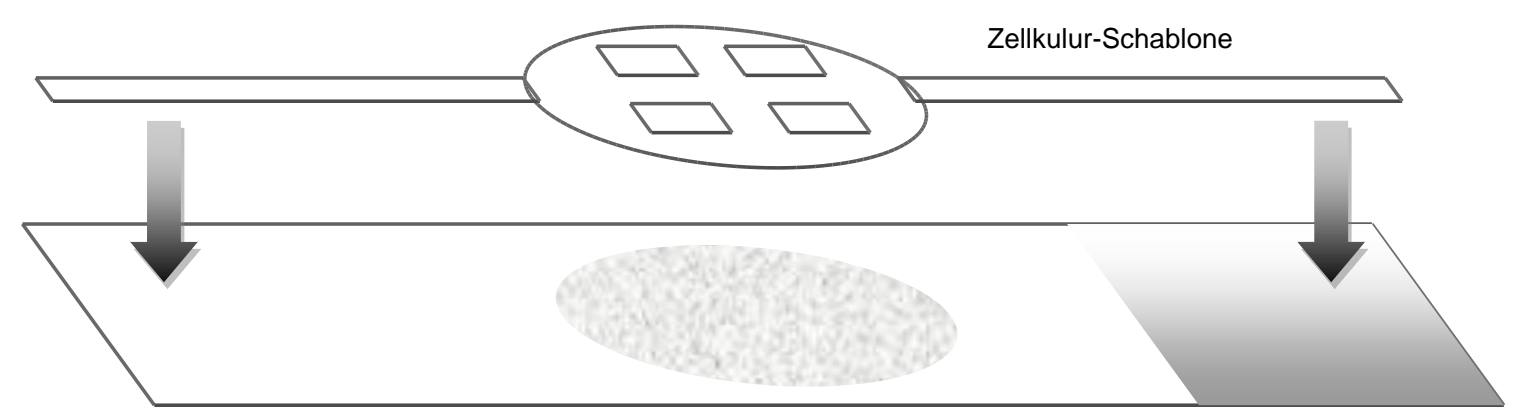

Objektträger mit Coverslip

\section{Abbildung 2-4. Schematische Darstellung der Zellkultur-Schablone}

Es wurden vier Stichproben einer Kokultur ausgewertet und die Ergebnisse später gemittelt. Eine Öffnung der Zellkultur-Schablone entspricht dem Mikroskop-Ausschnitt einer 1:10Vergrößerung. Sind höhere Vergrößerungen vonnöten, konnte die 1:10-Vergrößerung eingestellt und dann den Objektivkopf z.B. auf eine 1:20-Vergrößerung gedreht werden (ohne dabei den Objektträger in der Horizontalen zu verschieben).

\section{WCIF Image}

Die Fläche der Neuroblastomzellen wurde bei Schädigung geringer, so dass die Quantifizierung des Schadens über die mit Zellen bedeckte Fläche eines Bildausschnittes ermittelt werden konnte. Hierfür liefert das Programm WCIF Image $\mathrm{J}$ die notwendigen Möglichkeiten.

WCIF steht für „Wright Cell Imaging Facility“ und wird vom NIH = „National Institute of Mental Health“ online zum Herunterladen zur Verfügung gestellt.

Es ermöglicht, ein buntes Bild in ein schwarz-weißes Bild umzuwandeln und anschließend die Größe der schwarzen Fläche zu erfassen. So konnte die durch Neuroblastomzellen 
bedeckte Fläche bestimmt werden. Auch hier kam die Zellkultur-Schablone zur Auswahl der Bildausschnitte eines Coverslips zum Einsatz. Die Fotos wurden in einer 1:20 Vergrößerung gemacht und ausgewertet.

\subsection{Statistik}

Die statistischen Auswertungen und graphischen Darstellungen wurden mit Hilfe der „Graph Pad Prism Software" erstellt. Parametrische Daten werden als arithmetische Mittelwerte \pm Standardabweichung dargestellt, nicht-parametrische Daten als Mediane mit 25./75. Perzentile. Für den Vergleich von zwei Gruppen aus parametrischen Daten wurde der t-Test für unabhängige Stichproben angewandt. Die Gruppen aus nichtparametrischen Daten wurden mittels des U-Tests nach Mann-Whitney verglichen. Für den Vergleich der Kurven der neuropsychologischen und klinischen Testung sowie der Gewichte wurden die Flächen unter den Kurven (AUCs) errechnet und mit dem Mann-Whitney-U-Test verglichen. Bei Werten von $p<0,05$ wird von einem statistisch signifikanten Ergebnis gesprochen. 


\section{Ergebnisse}

\subsection{Auswirkung der systemischen Infektion durch Streptococcus pneumoniae im ZNS bei C57/B6-Mäusen}

Die akute Wirkung der systemischen Infektion, so wie sie in dieser Arbeit eingesetzt wurde, wurde anhand von C57/B6-Mäusen getestet. Dazu wurden die Tiere intraperitoneal mit $S$. pneumoniae infiziert und nach 12 Stunden $(n=3)$, nach 24 Stunden $(n=3)$ oder nach 36 Stunden $(n=3)$ getötet. Dabei erhielten die zuerst getöteten Tiere keine Antibiose, die später getöteten Tiere wurden einmal beziehungsweise zweimal durch Gabe von Ceftriaxon therapiert. In einer weiteren Tiergruppe, in welcher die Mäuse infiziert, aber nicht antibiotisch behandelt wurden, starben alle Tiere zwischen 24 und 36 Stunden nach Infektion $(n=4)$. Die Kontrolltiere, welchen intraperitoneal isotone Kochsalzlösung verabreicht wurde, wurden 36 Stunden nach Injektion getötet $(\mathrm{n}=3)$.

Mittels ELISA wurden die Konzentrationen des proinflammatorischen Zytokins IL-6 in den Homogenaten der Milz und des Gehirns während der Akutphase der Infektion gemessen. Die Konzentrationen von IL- 6 betrugen in den Homogenaten der Milz bei den Kontrolltieren $1,6 \pm 1,5 \mathrm{pg} / \mathrm{ml}$, bei den infizierten Tieren nach 12 Stunden 1084,0 $\pm 592,2 \mathrm{pg} / \mathrm{ml}$, nach 24 Stunden 139,3 $\pm 57,4 \mathrm{pg} / \mathrm{ml}$ und nach 36 Stunden 39,4 $\pm 36,6 \mathrm{pg} / \mathrm{ml}$. Tiere, welche infiziert wurden und keine Therapie mit Ceftriaxon erhielten, zeigten mit $1898 \pm 707,0 \mathrm{pg} / \mathrm{ml}$ die höchsten Werte für IL-6 im Milzhomogenat (nicht im Graphen dargestellt). In den Homogenaten des Gehirns ergaben sich folgende Konzentrationen von IL-6: Kontrolltiere 7,4 $\pm 3,7 \mathrm{pg} / \mathrm{ml}$, infizierte Tiere nach 12 Stunden 19,3 $\pm 2,8 \mathrm{pg} / \mathrm{ml}$, nach 24 Stunden 15,0 $\pm 2,4$ $\mathrm{pg} / \mathrm{ml}$ und nach 36 Stunden $12,7 \pm 9,6 \mathrm{pg} / \mathrm{ml}$. Auch in den Homogenaten des Gehirns zeigten die infizierten, nicht antibiotisch therapierten Mäuse mit 164,5 \pm 65,23 pg/ml die höchsten IL-6-Konzentrationen. 


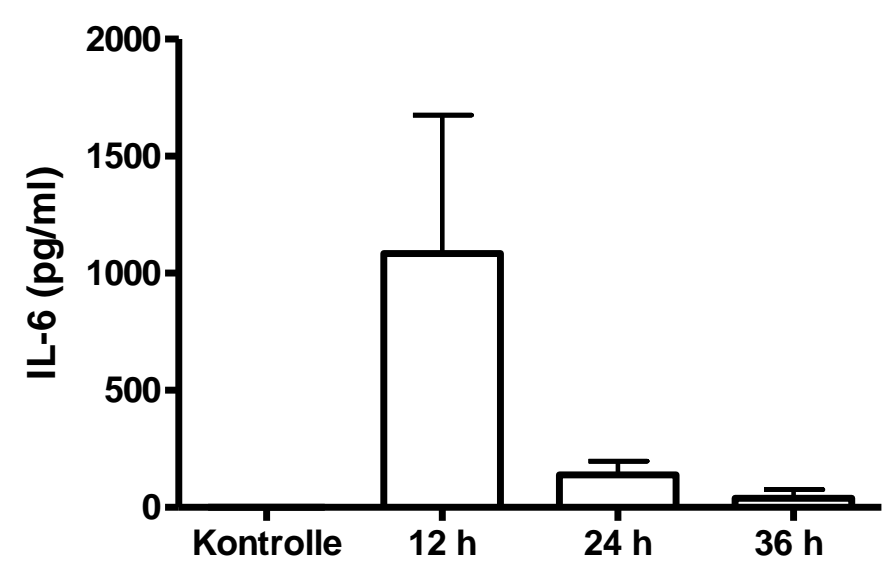

Abbildung 3-1. Konzentrationen von IL-6 in Milzhomogenaten von nicht-infizierten Kontrollmäusen $(n=3)$ und Mäusen, welche zu unterschiedlichen Zeitpunkten nach der intraperitonealen Infektion mit S. pneumoniae getötet wurden: 12 Stunden nach Infektion (vor der ersten antibiotischen Behandlung, $n=3$ ), 24 Stunden nach Infektion (12 Stunden nach der ersten antibiotischen Behandlung, $n=3$ ) und 36 Stunden nach Infektion (12 Stunden nach der zweiten antibiotischen Behandlung, $n=3$ ). Darstellung der Daten als Mittelwerte mit Standardabweichung.

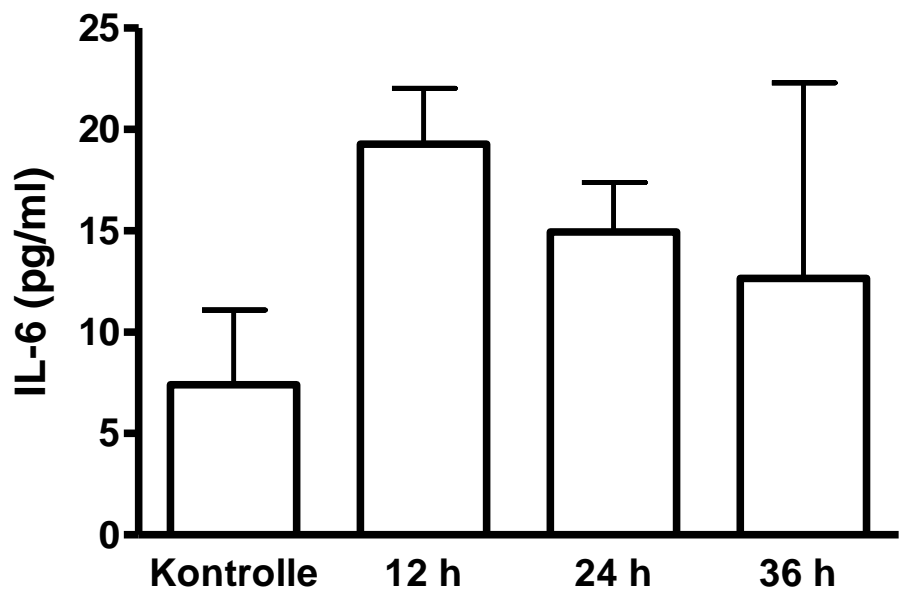

Abbildung 3-2. Konzentrationen von IL-6 in Homogenaten des Gehirns von nicht-infizierten Kontrollmäusen $(n=3)$ und Mäusen, welche $z u$ unterschiedlichen Zeitpunkten nach der intraperitonealen Infektion mit S. pneumoniae getötet wurden: 12 Stunden nach Infektion (vor der ersten antibiotischer Behandlung, $n=3$ ), 24 Stunden nach Infektion (12 Stunden nach der ersten antibiotischen Behandlung, $n=3$ ) und 36 Stunden nach Infektion (12 Stunden nach der zweiten antibiotischen Behandlung). Darstellung der Daten als Mittelwerte mit Standardabweichung.

Die ebenso mittels ELISA bestimmten TNF- $\alpha$-Konzentrationen in Gehirnhomogenaten unterschieden sich nicht signifikant zwischen infizierten und nicht-infizierten Tieren.

In der histologischen Färbung der Gehirnschnitte mit Isolectin-B4 oder Iba 1 konnten bezüglich Anzahl und Morphologie der Mikroglia keine Unterschiede zwischen infizierten und nicht-infizierten Tieren festgestellt werden. 


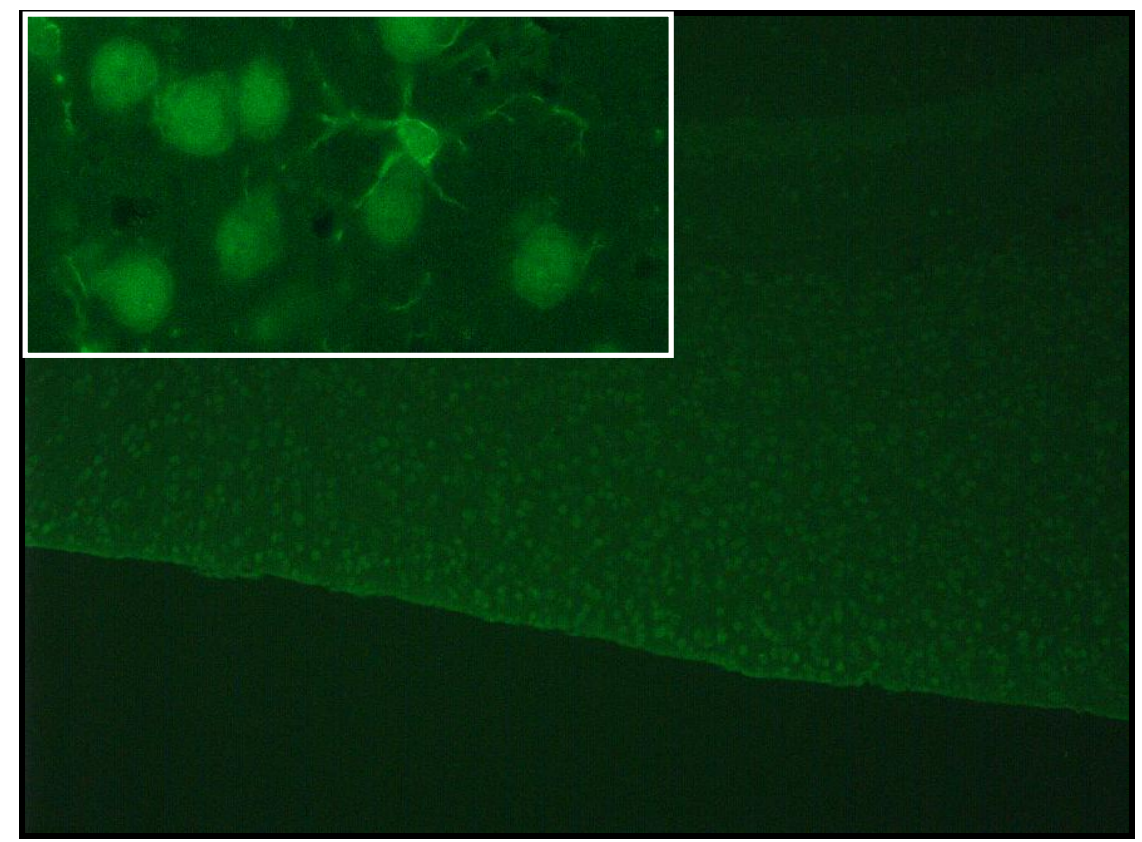

Abbildung 3-3. Fluoreszenzfärbung eines Gehirnschnittes nach Färbung mit Iba1. Im großen Bild Ausschnitt des Kortex, im kleinen Bild Vergrößerung einer Mikrogliazelle mit Ausläufern.

\subsection{Zucht und Genotypisierung von Tg2576-Mäusen}

Die Genotypisierung der APP-überexprimierenden Mäuse ergab bei insgesamt 242 genotypisierten Tieren 51\% transgene Mäuse und 49\% nicht transgene Mäuse.

\subsection{Auswirkung wiederholter systemischer Infektionen mit Streptococcus pneumoniae auf den Krankheitsverlauf bei Tg2576- Mäusen}

Dieser Versuch sollte zeigen, ob mehrfache systemische Infektionen bei APPüberexprimierenden Mäusen (=Tg2576-Mäuse) das Auftreten und den Fortschritt der Alzheimer-Demenz beschleunigt oder nicht. Dazu wurden Tg2576-Mäuse ab dem Alter von ca. 8 Monaten in Intervallen von 30 Tagen viermalig intraperitoneal mit S. pneumoniae infiziert, die nicht-infizierte Kontrollgruppe erhielt statt des Erregers Kochsalzlösung injiziert.

\subsubsection{Gruppenaufteilung}

Insgesamt standen 22 Tg2576-Tiere für den Versuch zur Verfügung. Beide Gruppen bestanden aus vier männlichen und sieben weiblichen Tieren. Das mittlere Alter der Tiere beider Gruppen bei Versuchsbeginn differierte um 13,8 Tage (Infektionsgruppe $224 \pm$ 34,2 Tage versus Kontrollgruppe 237,8 $\pm 21,7$ Tage). Die Gruppenaufteilung nach den Ergebnissen des Trainings und der ersten Wiederholung im MWM orientierte sich an der 
Schwimmzeit vor der ersten Infektion, so dass in den nachfolgenden Darstellungen diesbezüglich keine signifikanten Unterschiede zu erwarten sind. Der Median aller Läufe vor der ersten Infektion betrug für die geschwommene Zeit 41,85 s bei den zu infizierenden Tieren versus $30,05 \mathrm{~s}$ bei den Kontroltieren $(p=0,98)$, für die geschwommene Strecke $657,12 \mathrm{~cm}$ bei den zu infizierenden Tieren versus $609,26 \mathrm{~cm}$ bei den Kontrolltieren $(p=0,83)$ und für die Schwimmgeschwindigkeit $19.53 \mathrm{~cm} / \mathrm{s}$ bei den zu infizierenden Tieren versus 20 $\mathrm{cm} / \mathrm{s}$ bei den Kontrolltieren $(\mathrm{p}=0,66)$. 

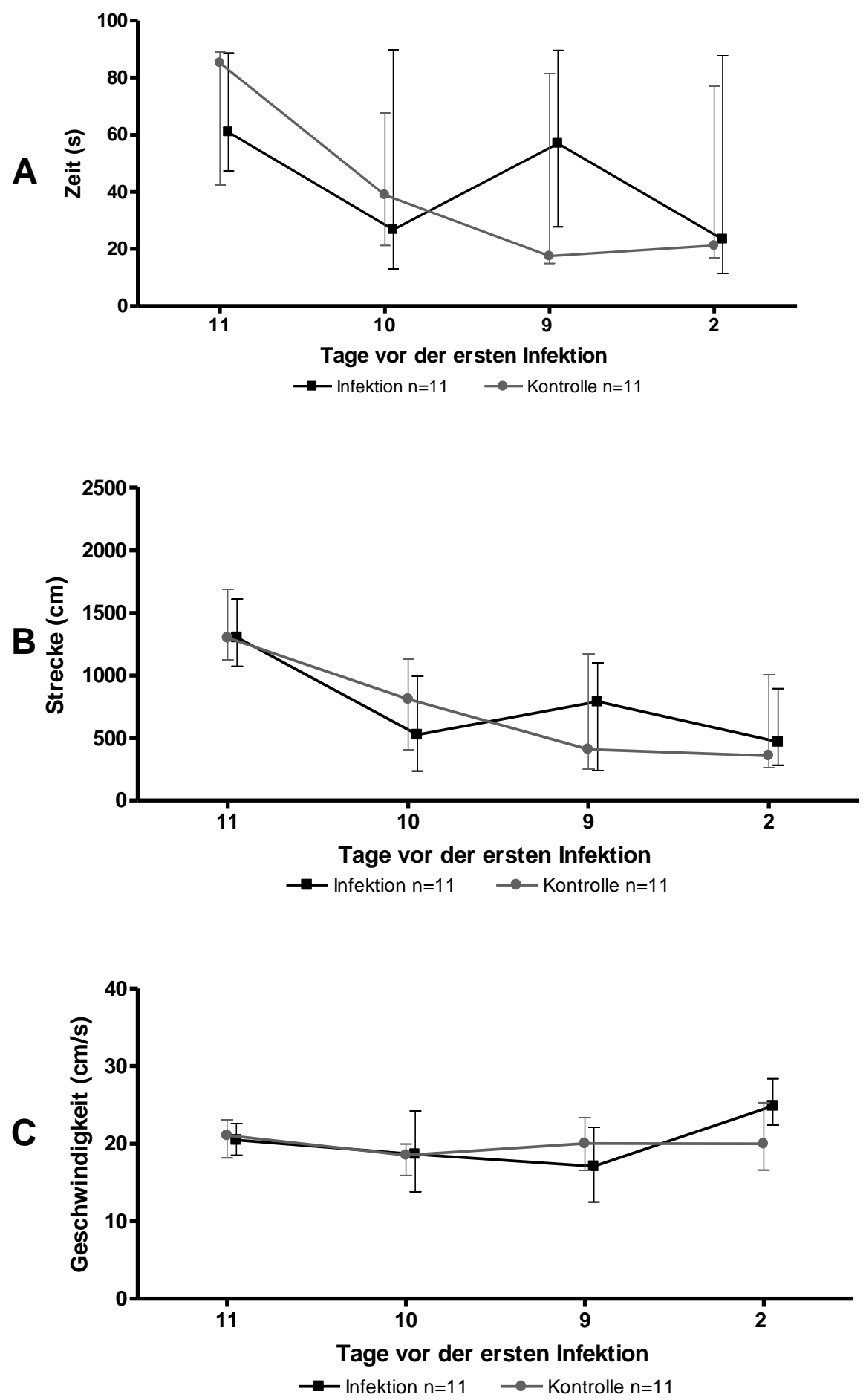

Abbildung 3-4. Darstellung der Trainingsläufe 1-3 mit je 6 Läufen pro Tier, welche 11 bis 9 Tage vor der ersten Infektion statt fanden; sowie des ersten Wiederholungslaufs mit je drei Läufen pro Tier, welcher zwei Tage vor der ersten Infektion stattfand. Aus den Ergebnissen der Läufe einer Maus pro Tag wurde jeweils der Median ermittelt. Dargestellt sind die Mediane der Gruppen mit den 25./75. Interquartilen. Es zeigt sich sowohl bei der geschwommenen Zeit (Graph A) und bei der geschwommenen Strecke (Graph B) der Lerneffekt vom Training 1 bis zur Wiederholung 1. Im Gegensatz zu Zeit und Strecke blieb die Schwimmgeschwindigkeit (Graph C) an allen Tagen vergleichsweise konstant und unterscheidet sich zwischen den Gruppen kaum. Dies ist ein Anzeichen dafür, dass sich die Kraft und Beweglichkeit von Gruppe zu Gruppe nicht unterscheidet. 


\subsubsection{Infektion}

Im Abstand von vier Wochen wurden die Tiere intraperitoneal mit einer Lösung des Streptococcus pneumoniae Typ 3 beimpft. Da unterschiedliche Tierstämme auf diese Infektion unterschiedlich stark reagieren, bildeten wir bei der Erstinfektion eine „Testgruppe“ aus je zwei Tieren pro Gruppe. Hier die Konzentrationen der Inokula aller durchgeführten Infektionen:

Infektion 1: Testgruppe: $\quad 2 \times 10^{5} \mathrm{KBE} /$ Maus

Restliche Tiere: $\quad 5 \times 10^{5} \mathrm{KBE} / \mathrm{Maus}$

Infektion 2: $1,5 \times 10^{6} \mathrm{KBE} /$ Maus

Infektion 3: $4 \times 10^{6} \mathrm{KBE} / \mathrm{Maus}$

Infektion 4: $4 \times 10^{6} \mathrm{KBE} /$ Maus

\subsubsection{Beurteilung der Gesundheit der Tiere}

Die Gesundheit der Tiere wurde anhand des Gewichts und des im Methodenteil erwähnten klinisch-neurologischen Scores beurteilt. Während des Versuchs blieben alle Tiere bei Score 0 , das heißt sie blieben gesundheitlich unbeeinträchtigt. Die Gewichte zeigten tagesabhängige Schwankungen, blieben jedoch insgesamt konstant und wiesen keine signifikanten Unterschiede zwischen den Gruppen auf: AUC (Gewicht x Tage) infizierte Tiere $2766 \pm 403,9$ versus nicht-infizierte Tiere $2622 \pm 430,7 ; p=0,34$. In den Akutphasen der Infektion konnte man regelmäßig eine Abnahme der Mittelwerte der Gewichte bei den mit $S$. pneumoniae infizierten Mäusen sehen, was als Anzeichen für eine ausreichend schwere Infektion gewertet werden kann. 


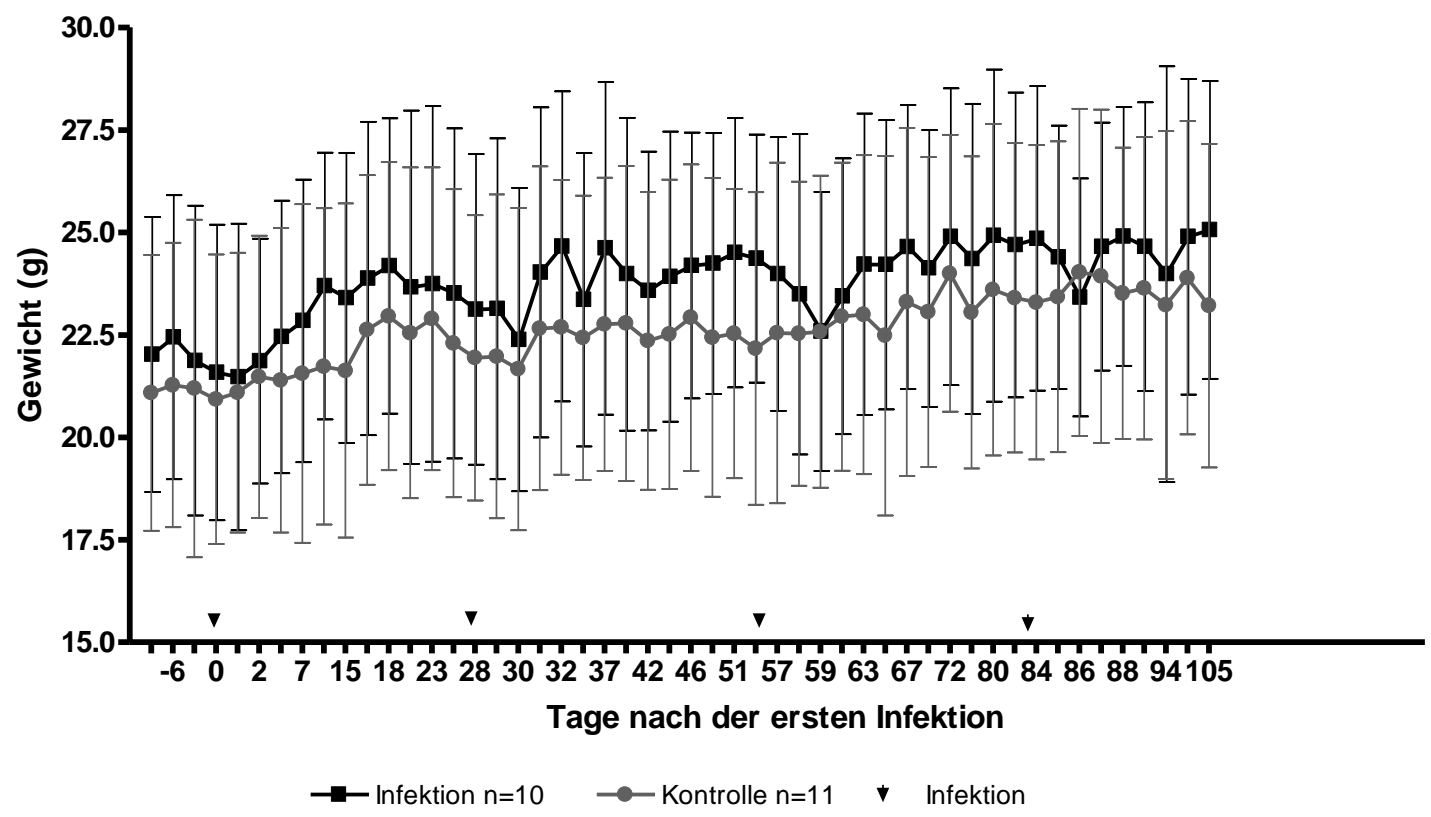

Abbildung 3-5. Dieser Graph zeigt die Gewichte der Mäuse beider Gruppen im Verlauf des Versuchs. Die Gewichte wurden dreimal wöchentlich bestimmt, in den Akutphasen der Infektion täglich. Zwischen den Gruppen gibt es keinen signifikanten Unterschied. Die kleinen schwarzen Pfeile markieren den Zeitpunkt einer Infektion. Danach sieht man regelmäßig einen Gewichtsabfall bei den mit $S$. pneumoniae infizierten Tieren. Dargestellt sind die Mittelwerte und Standardabweichungen.

\subsubsection{Sterblichkeit}

Von je 11 Tieren pro Gruppe starb bei der ersten Infektion ein Tier aus der Infektionsgruppe (danach $n=10$ ), während aus der Kontrollgruppe alle Tiere bis zum Ende des Versuchs überlebten. Trotz der geringen Sterblichkeit zeigte etwa die Hälfte aller infizierten Tiere in der jeweiligen Akutphase der Infektion Krankheitssymptome auf (Gewichtsverlust, Schwäche, geminderte Aktivität, struppiges Fell).

Die überlebenden Tiere der Infektionsgruppe waren zum Tötungszeitpunkt im Mittel 349,4 Tage alt, die Tiere der Kontrollgruppe 354,8 Tage, die Differenz beträgt 9,4 Tage $(p=0,84)$. Je einer Wildtypmaus (C57/B6) wurde zu Beginn des Versuchs S. pneumoniae Inokulum beziehungsweise Kochsalzlösung injiziert. Die mit dem Bakterium infizierte Maus zeigte innerhalb von 48 Stunden solch starke Krankheitssymptome auf, dass sie aus Tierschutzgründen getötet werden musste. Das mit Kochsalzlösung behandelte Tier zeigte keinerlei Symptome.

\subsubsection{Motorische Testung}

Die motorischen Fähigkeiten sowie die Ausdauer der Tiere blieb während es gesamten Versuchs unbeeinträchtigt, was sich in den gleichbleibenden Ergebnissen im Seiltest und Rotarod-Test zeigte. 


\section{Seiltest}

Der Seiltest wurde eingesetzt, um die Kraft und motorischen Fähigkeiten der Versuchstiere zu untersuchen, welche bei Tg2576-Mäusen nicht beeinträchtigt sein sollten. Der Seiltest wurde vor der Infektion viermal durchgeführt, nach der Infektion zweimal wöchentlich, jedoch nie in der Akutphase der Infektion. Wie erwartet zeigten sich keine motorischen Defizite und auch keine Unterschiede zwischen den Gruppen: AUC (Punktzahl x Tage) infizierte Tiere $434,4(390,5 / 465,5)$ versus Kontrollmäuse $519(406,0 / 621,5) ; p=0,13)$

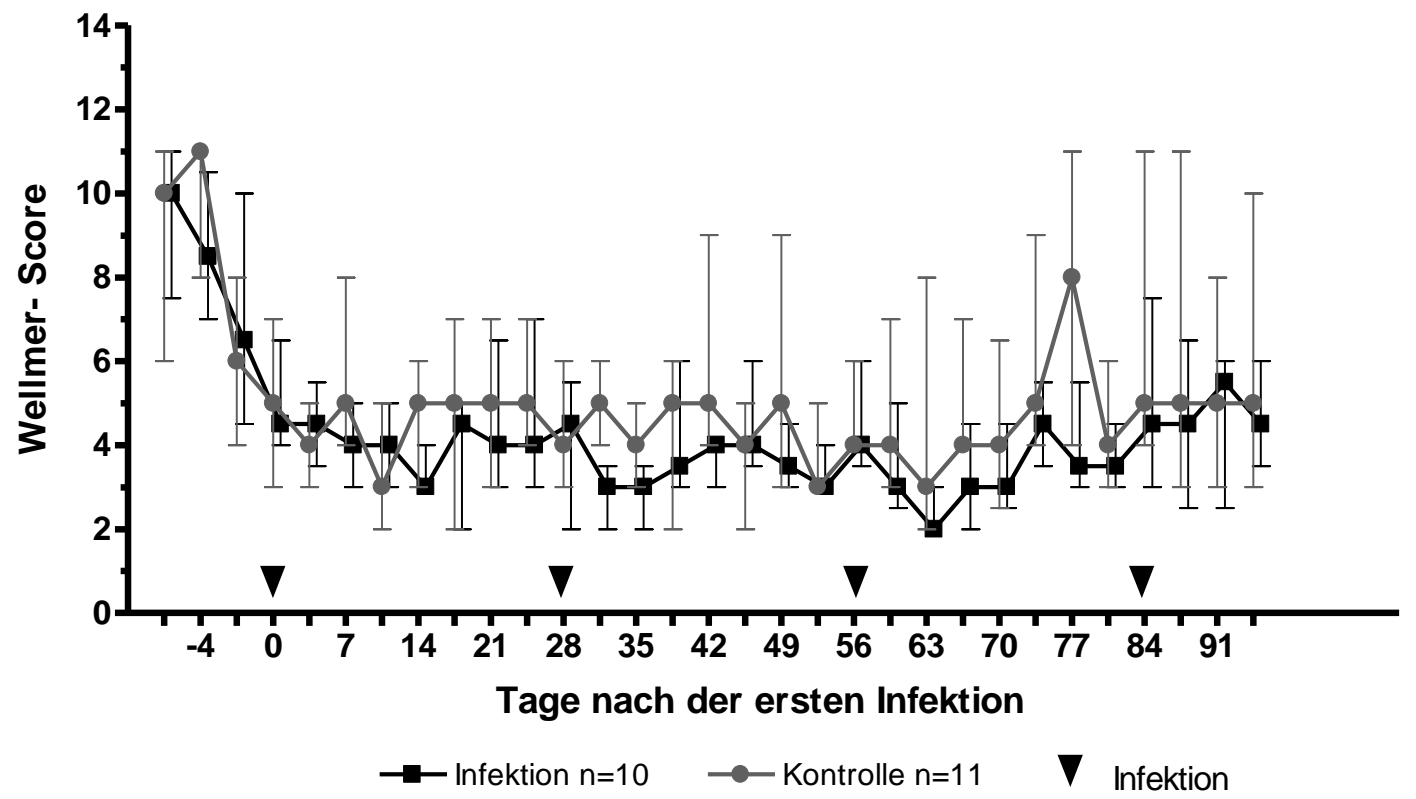

Abbildung 3-6. Während der Trainingsphase vor der ersten Infektion sieht man eine Verbesserung im Wellmer-Score, welche auf den Lerneffekt zurückzuführen ist. Zu Beginn der Infektion haben beide Gruppen eine ähnlich gute Kletterfähigkeit, die im Versuchsverlauf tagesabhängig schwankt und keine signifikanten Differenzen aufzeigt. Dargestellt sind Mediane und 25./75. Interquartilen.

\section{Rotarod}

Auch der Rotarod-Test diente der Untersuchung der motorischen Fähigkeiten und Kraftausdauer der Tiere, welche bei Tg2576-Tieren nicht beeinträchtigt sein sollten. Der Rotarod-Test wurde zweimalig vor der Infektion zum Training durchgeführt. Danach wurde jede Maus einmal wöchentlich getestet. Auch in diesem Test ließen sich wie erwartet weder motorische Defizite noch signifikante Unterschiede zwischen den Gruppen feststellen: AUC (Sekunden x Tage) infizierte Mäuse versus Kontrollmäuse: 29001,0 (27840,0/29483,0) versus $28385,0(24809,0 / 29002,0), p=0,19$ 


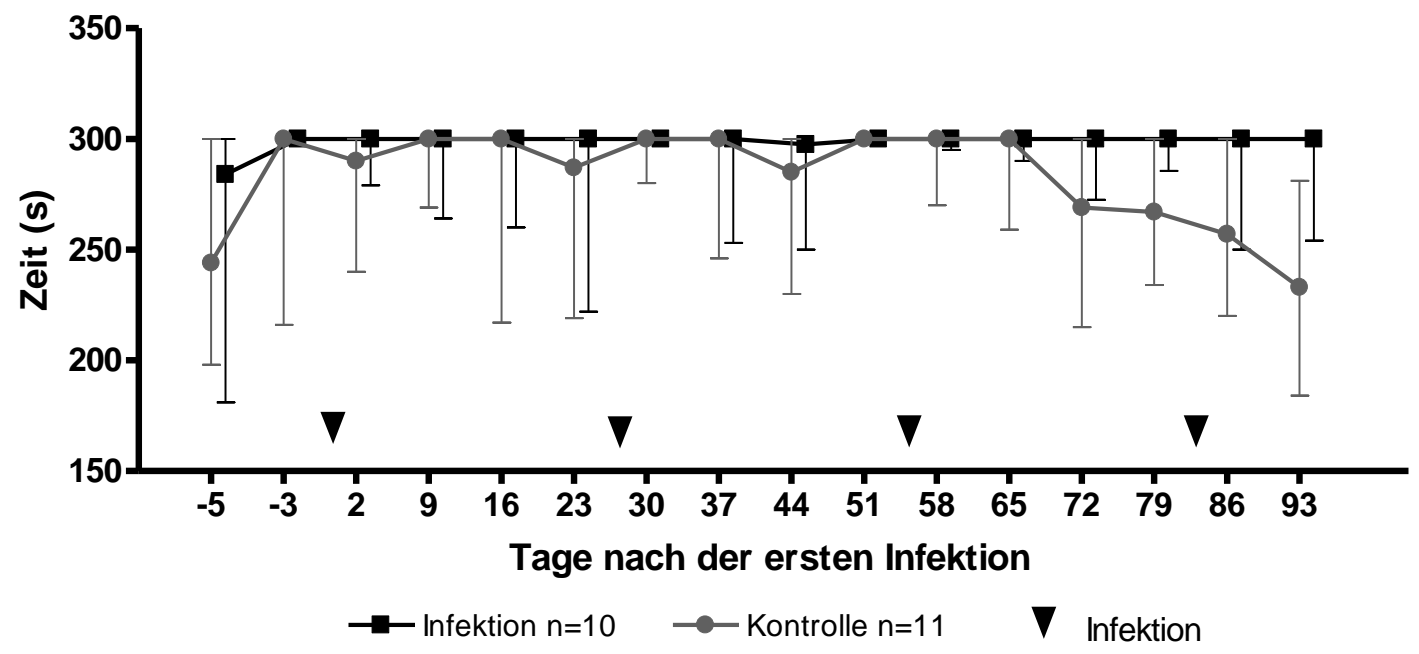

Abbildung 3-7. Im Rotarod zeigen sich keine signifikanten Unterschiede zwischen den Gruppen. Zu Beginn des Versuches sieht man einen Lerneffekt, der noch vor der ersten Infektion sein Maximum erreicht hat. Die Darstellung zeigt Mediane und die 25./75. Interquartilen.

\subsubsection{Neuropsychologische Testung}

Die neuropsychologische Testung erfolgte durch das Morris-Water-Maze. Dabei wurde durch die Wiederholungsläufe die Erinnerungsfähigkeit der Tiere getestet, während der Versuch der „Versetzten Plattform“ ermöglichte, die Lernfähigkeit am Ende des gesamten Experimentes einzuschätzen.

\section{Wiederholungsläufe im Morris-Water-Maze}

Die Testung im Morris-Water-Maze fand nach der ersten Infektion wöchentlich und immer vor der anstehenden Infektion statt. Dabei absolvierte eine Maus je drei Läufe. Die Infektion führte in Hinblick auf geschwommene Zeit, Strecke und Geschwindigkeit zu keinem Zeitpunkt zur einer signifikanten Differenz zwischen den beiden Gruppen. Auch zeigten beide Gruppen keine Verschlechterung der Gesamtleistung über die Zeit. So betrug die AUC der Wiederholungsläufe der infizierten Mäuse versus Kontrollgruppe für die Zeit (Sekunden $\mathrm{x}$ Tage) 2008,0 (1207,0/2972,0) versus 2324,0 (1273,0/3531,0), $p=0,55$, für die Strecke (cm x Tage) $37649,0(23933,0 / 60070,0)$ versus $39628,0(20570,0 / 61121,0), p=0,97$ und für die Geschwindigkeit (cm/Sekunden $x$ Tage) 1956,0 $\quad(1712,0 / 2156,0)$ versus 1628,0 $(1395,0 / 1904,0), p=0,053$. 

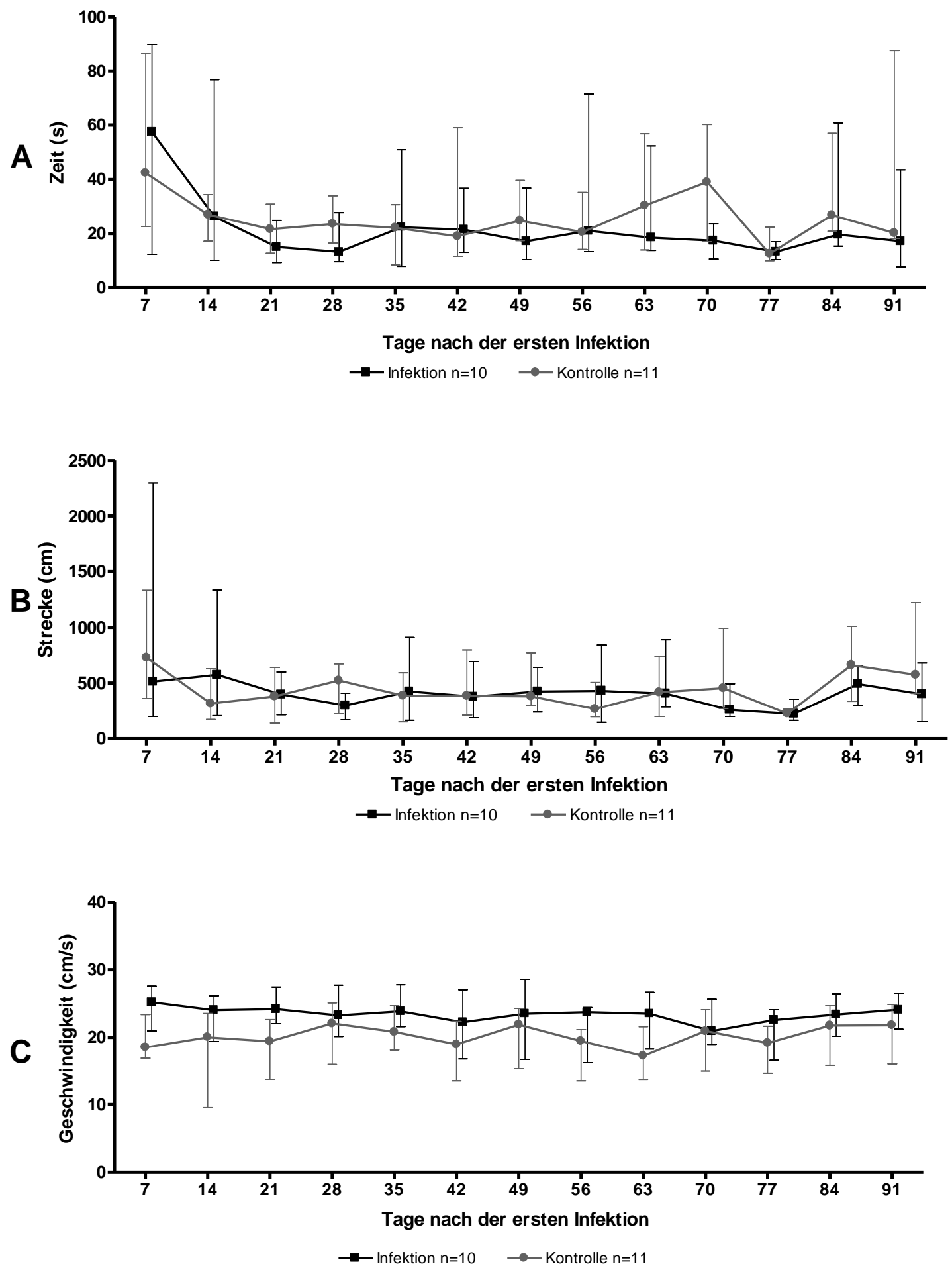

Abbildung 3-8. Die Wiederholungsläufe im MWM mit je 3 Läufen pro Tier fanden an den Tagen 7-91 nach der ersten Infektion statt. Aus den Ergebnissen der Läufe einer Maus pro Tag wurde jeweils der Median ermittelt. Dargestellt sind die Mediane der Gruppen mit den 25./75. Interquartilen. Graph A zeigt die geschwommenen Zeiten vom Einlassen der Mäuse ins Becken bis zum Auffinden der Plattform, der Graph B zeigt die Stecken, die die Mäuse bis zur Plattform zurücklegten und der Graph C zeigt die Schwimmgeschwindigkeit der Tiere. 


\section{Versetzte Plattform im Morris-Water-Maze}

Das mit „Versetzte Plattform“ bezeichnete MWM hat zum Ziel, die erhaltene Lernfähigkeit der Mäuse zum Ende des Versuchs zu dokumentieren. Vom Versuchsaufbau entspricht die „Versetzte Plattform“ dem Training, nur dass die Plattform in einen anderen Quadranten des Beckens gestellt wurde und die Mäuse diesen Ort neu kennen lernen mussten. Man konnte sehen, dass die Lernfähigkeit erhalten blieb und die Tiere im Vergleich zu den Trainingsläufen vor Infektion schneller lernten.

Die in den Graphen dargestellten Messwerte wiesen keine signifikanten Unterschiede auf. Die Zeit bis zum Erreichen der Plattform (AUCs Sekunden x Tage) von infizierten Mäusen versus Kontrolltiere betrug $53,5(22,1 / 142,3)$ versus $37,6(33,2 / 167,0), p=0,75$, die geschwommene Strecke (AUCs cm x Tage) betrug 707,1 (422,3/2016,0) versus 860,2 $(556,1 / 929,1), p=0,70$ und die Schwimmgeschwindigkeit (AUCs cm/Sekunde $x$ Tage) betrug $33,8(27,3 / 41,3)$ versus $32,1(25,2 / 44,4), p=0,89)$

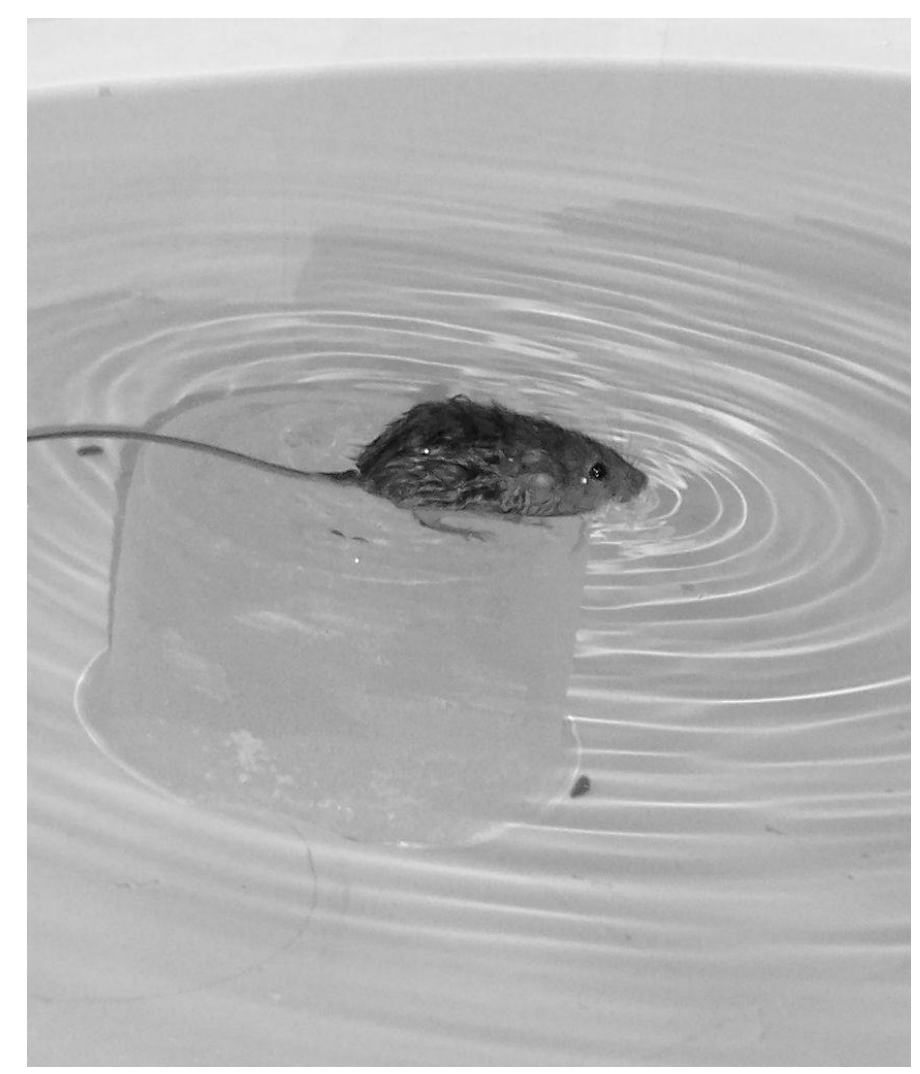

Abbildung 3-9. Maus auf der Plattform im Becken des Morris-Water-Maze. 

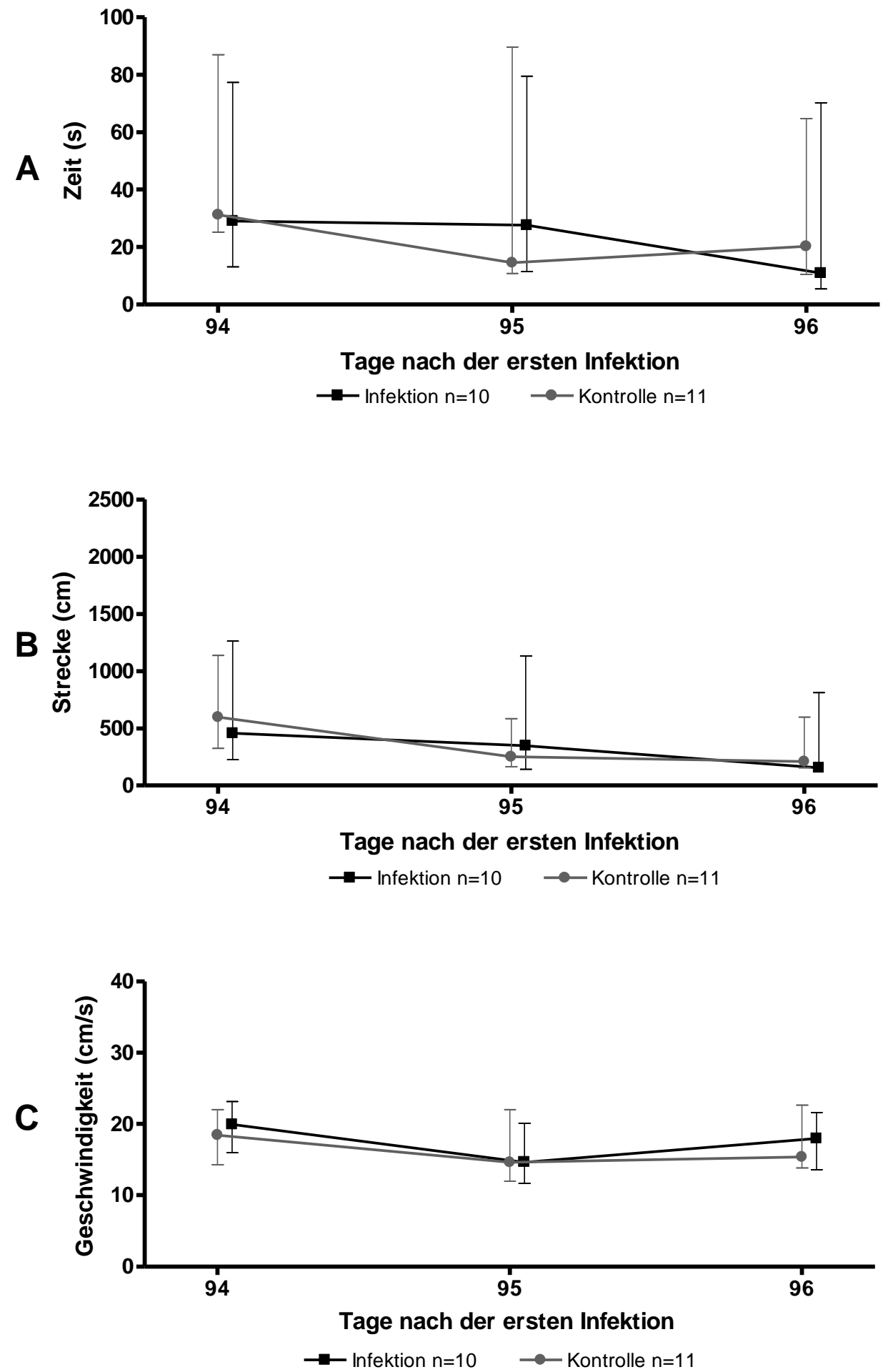

Abbildung 3-10. Die Testung mit der versetzten Plattform im MWM fand am $94-96$. Tag nach der ersten Infektion statt, dabei schwamm jede Maus 6 Läufe pro Tag. Aus den Ergebnissen der Läufe einer Maus pro Tag wurde jeweils der Median ermittelt. Dargestellt sind die Mediane der Gruppen mit den 25./75. Interquartilen. Der Graph A zeigt die Zeit, die die Mäuse benötigten, um zu der versetzten Plattform im Morris-Water-Maze zu schwimmen, der Graph B zeigt die geschwommenen Strecke. Es zeigt sich bei beiden Gruppen ein Lerneffekt bezüglich geschwommener Zeit und Strecke. Die Schwimmgeschwindigkeit (Graph C) zeigt sich zwischen Mäusen und Gruppen auch in diesem Versuch weitestgehend konstant. 
Gesamtverlauf im Morris-Water-Maze

Zur besseren Übersicht erfolgt hier nochmal die Darstellung aller Versuche im Morris-WaterMaze mit je einem Graphen für die Zeit, die geschwommene Strecke und die Schwimmgeschwindigkeit.
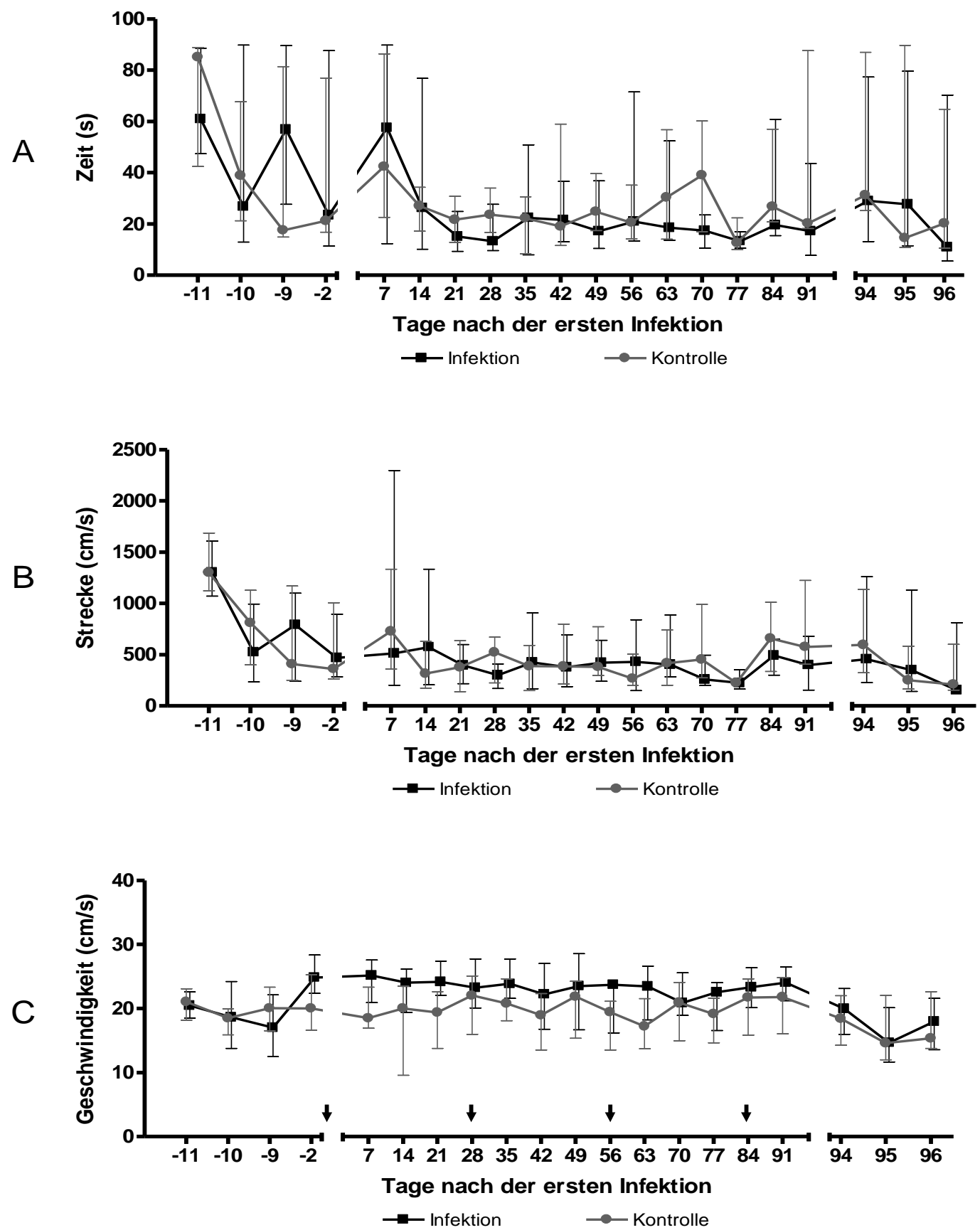

Abbildung 3-11. Darstellung des Gesamtverlaufs im MWM, die Abschnitte Training und Wiederholung 1, Wiederholungsläufe 2 - 14 und Versetzte Plattform sind dabei jeweils durch Unterbrechungen der $\mathrm{x}$-Achse zu erkennen. Aus den Ergebnissen der Läufe einer Maus pro Tag wurde jeweils der Median ermittelt. Dargestellt sind die Mediane der Gruppen mit den 25./75. Interquartilen. Graph A zeigt die geschwommene Zeit, Graph B die Strecke und Graph C die Schwimmgeschwindigkeit. Es kann in keiner der Qualitäten eine signifikante Differenz zwischen den wiederholt intraperitoneal mit S. pneumoniae infizierten Tg2576-Mäusen und den nicht-infizierten Kontrollmäusen festgestellt werden. 


\subsubsection{Westernblot}

Die Konzentrationen der Detergenzien-löslichen sowie der Detergenzien-unlöslichen Formen der $A \beta$-Peptide 1-37, 1-38, 1-39, 1-40 und 1-42 wurden per Westernblot bestimmt. Sie zeigen eine Tendenz zu niedrigeren Konzentrationen in den Hirnhomogenaten der infizierten Tiere verglichen mit der nicht-infizierten Kontrollgruppe. Dabei finden sich die höchsten Mengen $A \beta$ für das $A \beta$ 1-40 und 1-42, die niedrigsten Mengen für das $A \beta$ 1-37. Der $A \beta$ 142/1-40-Quotient ist tendenziell bei den infizierten Tieren höher als in der Kontrollgruppe. Diese Unterschiede sind jedoch nicht statistisch signifikant.

\begin{tabular}{|c|c|c|c|c|c|c|}
\hline \multirow[b]{2}{*}{$A \beta$} & \multicolumn{3}{|c|}{ Detergenzien-unlösliches $\mathbf{A} \beta$ (pg/mg brain) } & \multicolumn{3}{|c|}{ Detergenzien-lösliches A $\beta$ (pg/mg brain) } \\
\hline & Kontrolle & Infektion & $\mathbf{p}$ & Kontrolle & Infektion & $\mathbf{p}$ \\
\hline $1-37$ & $817.7 \pm 690.0$ & $355.6 \pm 466.4$ & 0.09 & $45.11 \pm 29.12$ & $27.40 \pm 14.58$ & 0.10 \\
\hline $1-38$ & $2463.0 \pm 2029.0$ & $1056.0 \pm 1111.0$ & 0.07 & $213.10 \pm 146.30$ & $121.70 \pm 94.63$ & 0.11 \\
\hline $1-39$ & $1466.0 \pm 1287.0$ & $595.6 \pm 735.7$ & 0.08 & $130.20 \pm 87.38$ & $78.14 \pm 64.33$ & 0.14 \\
\hline $1-40$ & $9533.0 \pm 7871.0$ & $4852.0 \pm 4182.0$ & 0.11 & $1075.00 \pm 626.40$ & $711.40 \pm 380.80$ & 0.13 \\
\hline $1-42$ & $5594.0 \pm 4389.0$ & $2977.0 \pm 2251.0$ & 0.11 & $683.90 \pm 428.80$ & $509.70 \pm 287.70$ & 0.29 \\
\hline \multicolumn{7}{|l|}{ Quotient } \\
\hline $1-42 / 1-40$ & $0.64 \pm 0.11$ & $0.76 \pm 0.33$ & 0.24 & $0.63 \pm 0.11$ & $0.70 \pm 0.17$ & 0.28 \\
\hline
\end{tabular}

Tabelle 3-1. Diese Tabelle zeigt die Konzentrationen der im Westernblot bestimmten

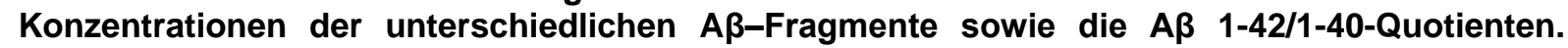
Linksseitig sind die Detergenzien-unlöslichen Anteile dargestellt, rechts die Detergenzienlöslichen $A \beta$-Anteile. Zwischen Infektions- und Kontrollgruppe lassen sich für keine der bestimmten Konzentrationen signifikante Unterschiede messen. Dargestellt sind Mittelwerte und Standardabweichung. 


\subsubsection{ELISA}

In der Bestimmung der Detergenzien-löslichen A $\beta$-Fragmente 1-40 und 1-42 mittels ELISA zeigt sich kein signifikanter Unterschied der Konzentrationen zwischen infizierten und nichtinfizierten Tieren ( $p=0,61$ und 0,38$)$.
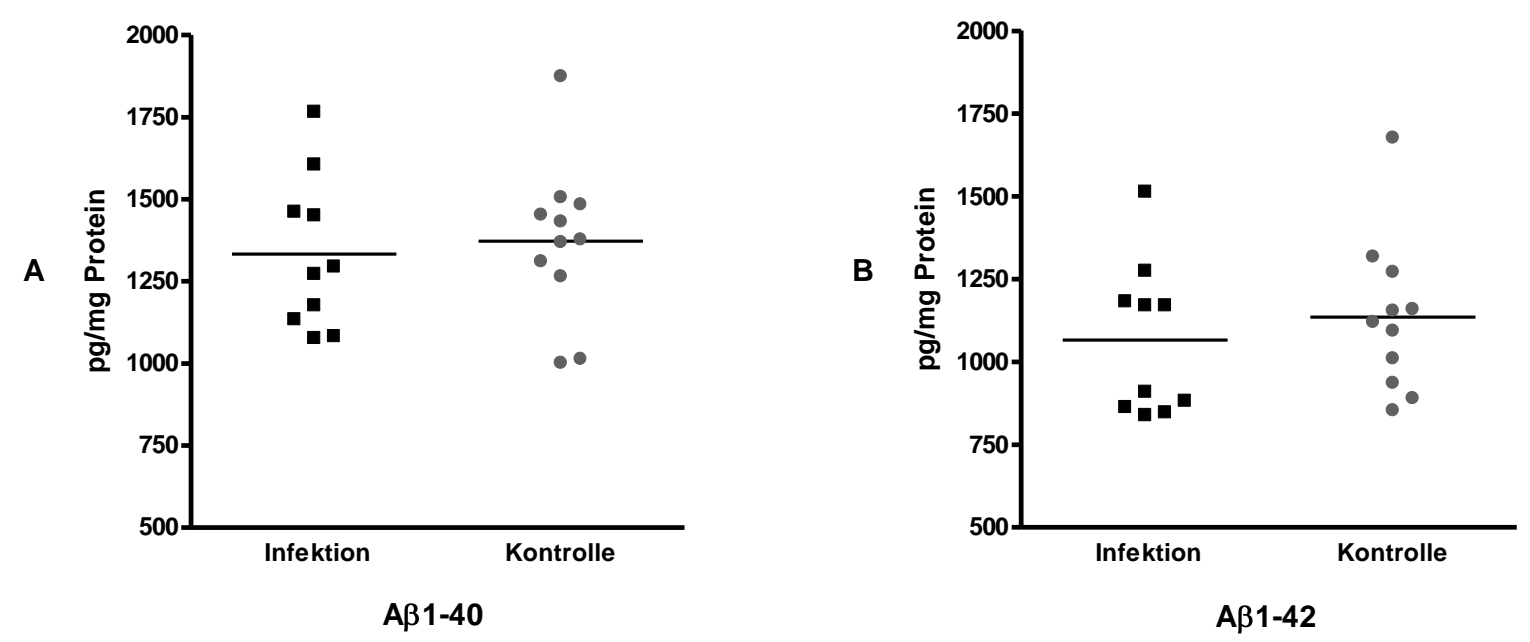

Abbildung 3-12. Der Graph A zeigt die Einzelwerte und Mittelwerte (Balken) der Konzentrationen des mittels ELISA bestimmten Detergenzien-löslichen $A \beta \quad 1-40$ in $\mathrm{pg} / \mathrm{mg}$ Gesamtprotein, $p=0,61$. Im Graph $B$ sind Einzelwerte und Mittelwerte (Balken) der Konzentration des Detergenzien-löslichen $A \beta$ 1-42 dargestellt, angegeben in $\mathrm{pg} / \mathrm{mg}$ Gesamtprotein, $p=0,38$

\subsubsection{Histologie}

Je zwei Gehirnschnitte der Tg2576-Mäuse wurden mit Thioflavin S gefärbt. Zur Quantifizierung wurde die Fläche der angefärbten $A \beta$-Plaques auf beiden Schnitten gemessen. Die Fläche unterscheidet sich nicht signifikant bei den infizierten Tieren (5280 \pm $\left.4686 \mu \mathrm{m}^{2}\right)$ und der Kontrollgruppe $\left(3992 \pm 2706 \mu \mathrm{m}^{2} ; \mathrm{p}=0,44\right)$ 


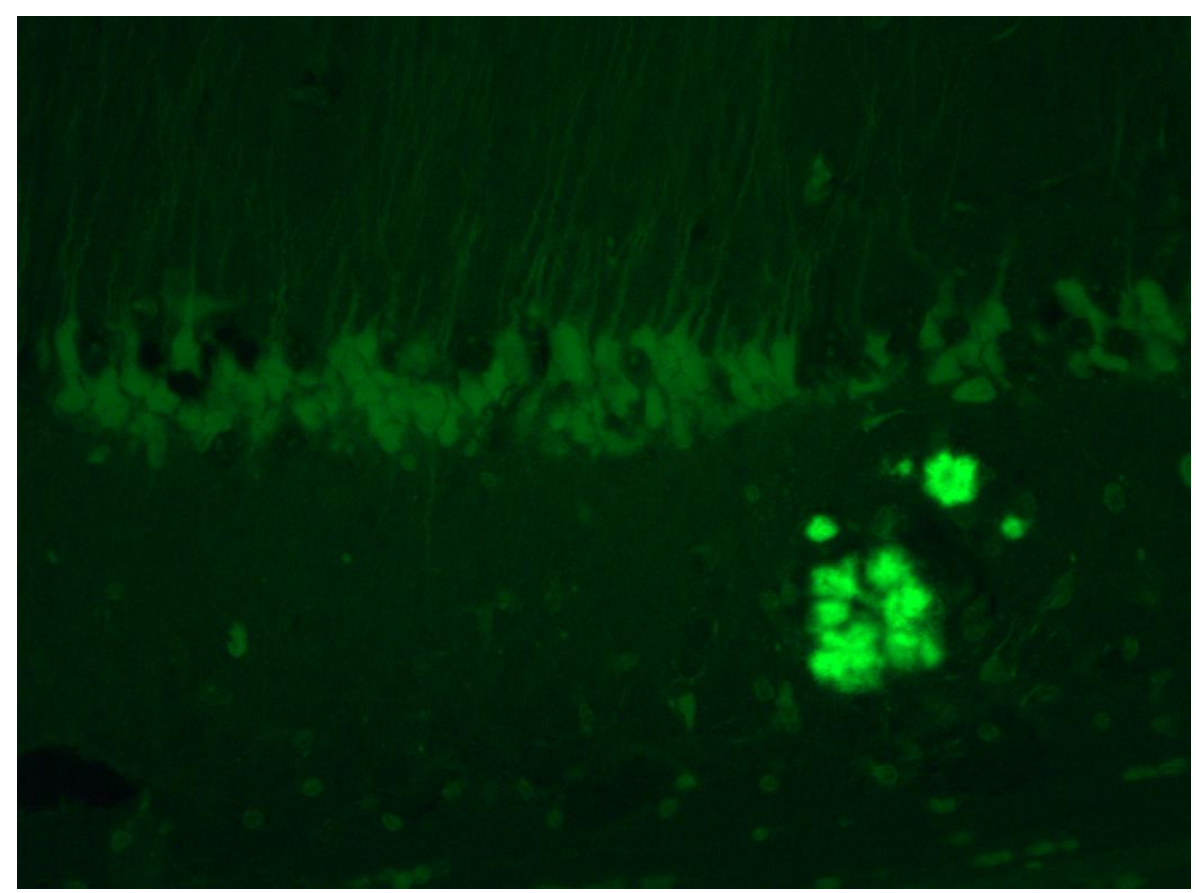

Abbildung 3-13. Mit Thioflavin $S$ angefärbte $A \beta$-Plaques.

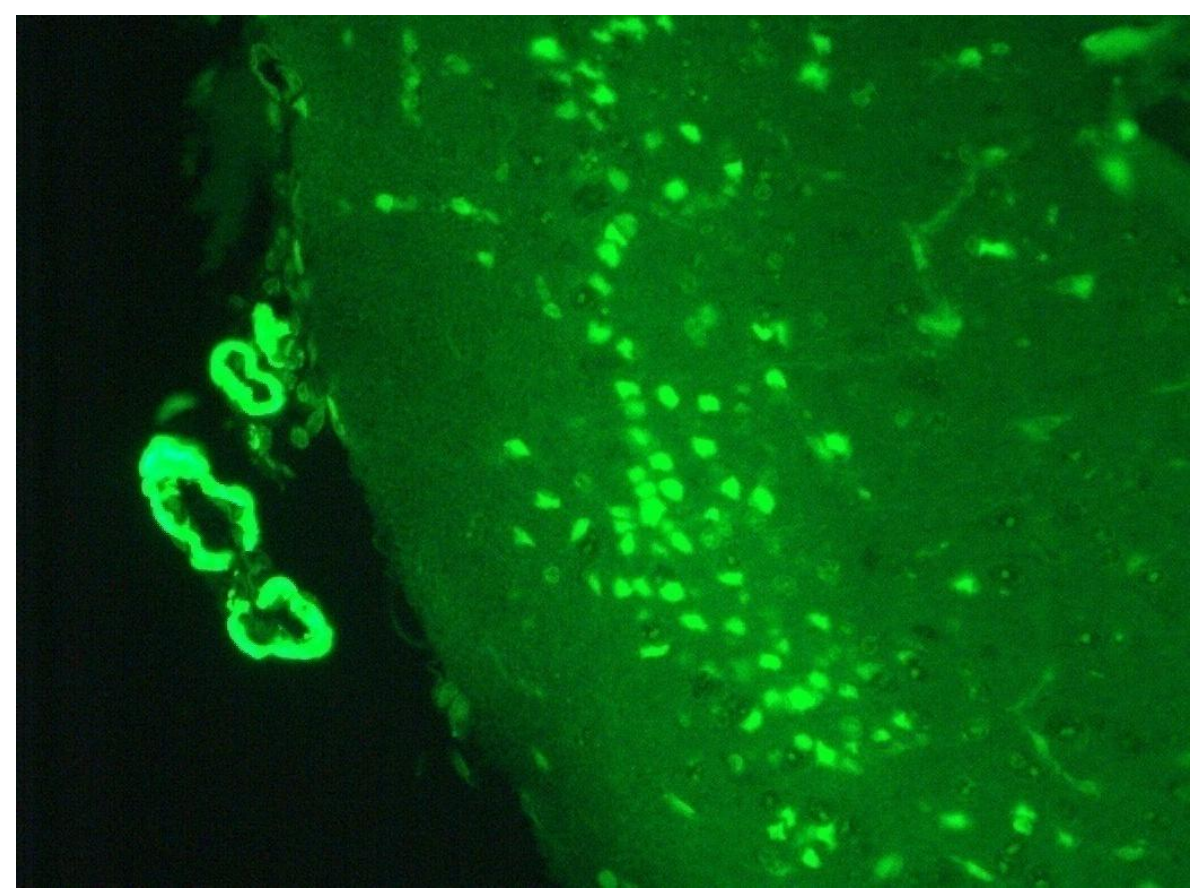

Abbildung 3-14. Am linken Bildrand erkennbar mit Thioflavin $S$ angefärbte amyloide Angiopathien. Diese Flächen wurden bei der Berechnung der Plaquegröße nicht miteinbezogen. 


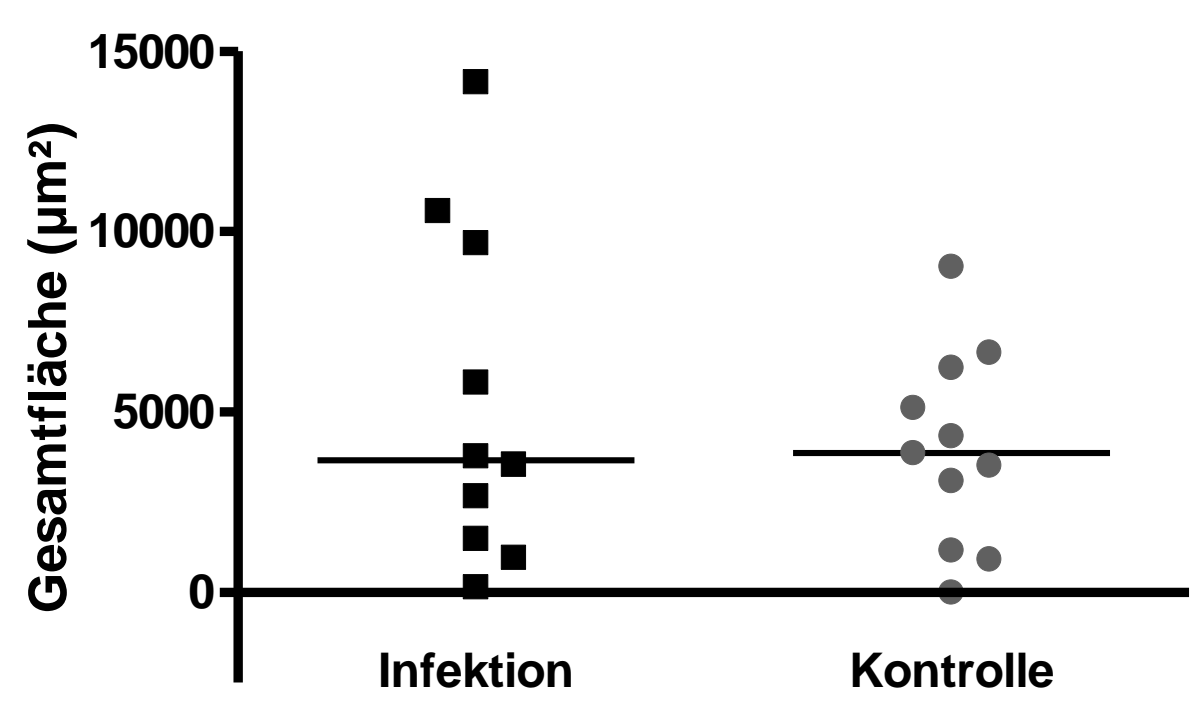

Abbildung 3-15. Nach der Färbung mit Thioflavin $S$ wurde die Fläche aller Plaques in zwei Schnitten des Großhirns bemessen. Es ergibt sich kein signifikanter Unterschied zwischen Infektions- und Kontrollgruppe. Dargestellt sind die Einzelwerte, die horizontalen Balken repräsentieren die Mittelwerte.

\subsection{Zellkulturen}

\subsubsection{Murines Zellkultur-Modell}

In der Kokultur aus murinen Mikroglia und Neuronen bildete sich ein dichtes neuronales Netzwerk aus. Bei Stimulation mit A 1-40 oder $\mathrm{Pam}_{3} \mathrm{CysSK}_{4}$ zeigte sich nach 72 Stunden in der Färbung mit $\beta$-Tubulin, Isolectin-B4 und Hämalaun ein deutlicher Schaden der Neuronen im Vergleich zu den nicht-stimulierten Kontrollkulturen. In Kokulturen, denen mit A 1 1-40 und $\mathrm{Pam}_{3} \mathrm{CysSK}_{4}$ beide Stimulanzien hinzugefügt wurden, war der neuronale Schaden rein optisch am größten. Dabei zeigte sich ein leichterer Schaden durch das Rarifizieren und Zusammenlagern der Neuronenausläufer, bei stärker geschädigten Kokulturen zeigten sich neben schwammartig wirkenden Mikroglia zusammengelagerte Neuronenzellkerne und das fast vollständige Fehlen von neuronalen Ausläufern.

\subsubsection{Humanes Zellkultur-Modell}

In der Kokultur aus Makrophagen und Neuroblastomzellen zeigten sich bei Zugabe von $A \beta$ 1-40 oder $\mathrm{Pam}_{3} \mathrm{CysSK}_{4}$ nach einer Stimulationdauer von 72 Stunden ein Schaden der Neuroblastomzellen und eine Aktivierung der Makrophagen. Diese Veränderungen waren in mit $A \beta$ 1-40 und $\mathrm{Pam}_{3} \mathrm{CysSK}_{4}$ kombiniert stimulierten Kokulturen am ausgeprägtesten sichtbar. In den humanen Kokulturen zeigte sich ein leichter Schaden durch ein Zusammenlagern der Neuroblastomzellen mit Reduktion ihrer Ausläufer, in stark 
geschädigten Kulturen zeigt sich neben der noch stärkeren Zusammenlagerung der Neuroblastomzellen vor allem die Veränderung der Makrophagen mit Bildung von Ausläufern und schwammartigem Aufblähen.

\subsubsection{Quantifizierung}

Der neuronale Schaden nach Stimulation der Mikroglia beziehungsweise Makrophagen durch $A \beta$ 1-40 und/oder Pam $_{3} \mathrm{CysSK}_{4}$ war sowohl im murinen als auch im humanen Zellkulturmodell reproduzierbar. Es wurden verschiedene Versuche unternommen, den sichtbaren Neuronenschaden zu quantifizieren. Keine der Auswertungsmethoden (Bestimmung der NSE, Auszählung der Neuronenausläufer wie bei lliev et al. 2004 beschrieben, Auswertung mit Hilfe des Programms WCIF Image J) spiegelte den optischen Eindruck ausreichend wider. Eine weitere Entwicklung zur Quantifizierung des Schadens ist gegebenenfalls mit Hilfe spezialisierter Software möglich und ist Thema anknüpfender Studien der Arbeitsgruppe. 


\subsubsection{Beispielbilder}
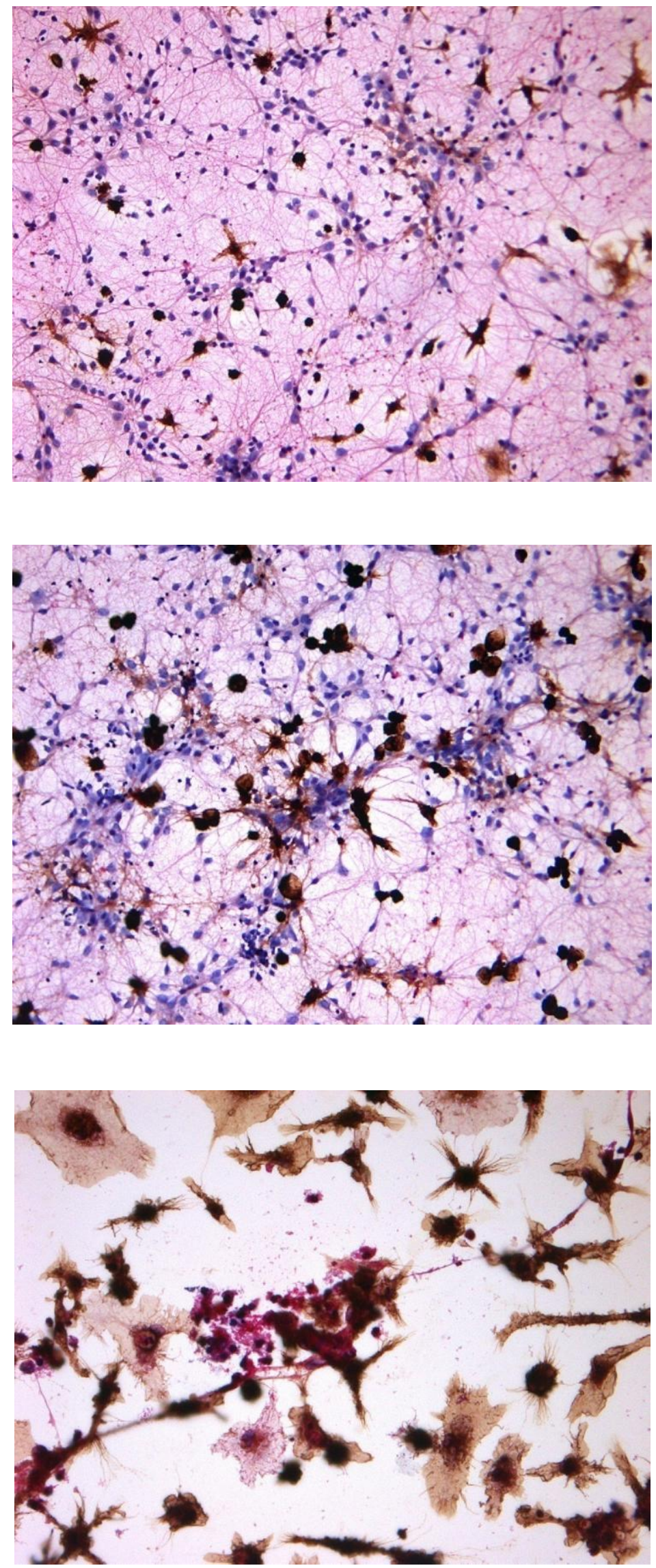

Abbildung 3-16. Murines Zellkultur-Modell: Bild einer intakten Neuronen-MikrogliaKokultur in 1:20 Vergrößerung. Färbung mit B-Tubulin (rosa, Neuronen), Isolectin-B4 (braun, Mikroglia) und Hämalaun (violett, Zellkerne).

Abbildung 3-17. Murines Zellkultur-Modell: Beginnende Schädigung des neuronalen Netzwerks durch die Mikroglia, insbesondere in der Bildmitte zu sehen. 1:20 Vergrößerung, Färbung mit B-Tubulin, IsolectinB4 und Hämalaun.

Abbildung 3-18. Murines

Zellkultur-Modell: Stark aktivierte Mikroglia (braun, unterschiedliche Morphologie) in 1:40 Vergrößerung mit geschädigten Neuronen (rosa, mittig). Färbung mit B-Tubulin, Isolectin-B4 und Hämalaun. 

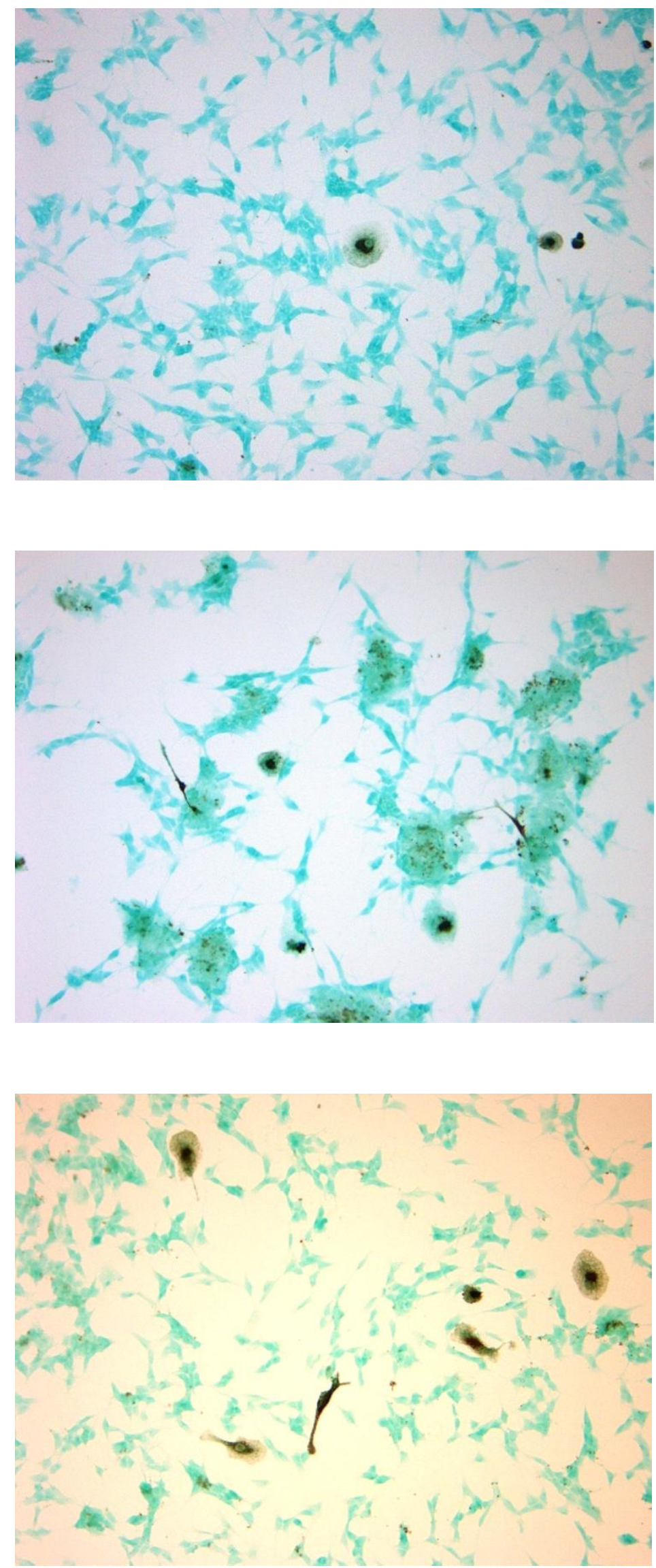

Abbildung 3-19. Humanes

Zellkultur-Modell: Bild einer intakten Makrophagen-

Neuroblastom-Kokultur. 1:20

Vergrößerung, Färbung mit CD-68

(schwarzbraun, Makrophagen)

und Lichtgrün (grün,

Neuroblastomzellen).

Abbildung 3-20. Humanes

Zellkultur-Modell: Bild einer Kokultur mit aktivierten Makrophagen und geschädigten Neuroblastomzellen. Bei

Schädigung lagern sich die Neuroblastomzellen zu Klumpen zusammen. 1:20 Vergrößerung, Färbung mit CD-68 und Lichtgrün.

Abbildung 3-21. Humanes Zellkultur-Modell: Aktivierte Makrophagen bilden Ausläufer, wie hier auf einem Bild einer Makrophagen-NeuroblastomzellKokultur zu sehen ist. 1:20 Vergrößerung, Färbung mit CD-68 und Lichtgrün. 


\section{Diskussion}

Systemische Infektionen können die Symptome der Alzheimer-Demenz und anderer neurodegenerativer Erkrankungen oft drastisch verschlechtern und den Krankheitsverlauf beschleunigen (Holmes et al. 2003; Perry et al. 2007; Holmes et al. 2009). Die Mechanismen dieses in der Klinik häufig beobachteten Phänomens sollten, nicht zuletzt wegen des häufigen Auftretens von Infektionen bei Patienten mit neurodegenerativen Erkrankungen, genauer erforscht werden. Erst dann wird es möglich sein, eine rationale Therapie bakterieller Infektionen bei der immer größer werdenden Anzahl an Demenzkranken zu etablieren.

\subsection{Systemische Infektionen mit Streptococcus pneumoniae führen zu erhöhten inflammatorischen Zytokinen im ZNS}

Ob und in welcher Stärke die im Hauptversuch durchgeführte systemische Infektion zu einer zentralen Entzündungsreaktion führt, sich also bei einer systemischen Infektion mit $S$. pneumoniae und einer anschließenden antibiotischen Therapie mit Ceftriaxon inflammatorische Zeichen im Gehirn nachweisen lassen, soll in diesem Teil der Arbeit überprüft werden. Für diese Versuche wurden C57/B6-Mäuse verwendet, da von den transgenen Tg2576-Mäusen nicht genügend Tiere vorhanden waren. Die C57/B6-Mäuse wurden entsprechend vorbehandelt und in Hirnhomogenaten die proinflammatorischen Zytokine IL-6 und TNF- $\alpha$ gemessen. Außerdem wurden in histologischen Schnitten Mikroglia angefärbt und deren Dichte und Morphologie untersucht. In Hinblick auf die TNF- $\alpha-$ Konzentrationen und die Dichte und Morphologie der Mikroglia ließen sich keine Unterschiede zwischen den infizierten Mäusen und den nicht-infizierten Kontrolltieren finden. In Hinblick auf das zerebral gemessene Zytokin IL-6 ließ sich jedoch eine KonzentrationsZeit-Kurve entsprechend dem Verlauf im peripheren Blut feststellen. Die höchste Konzentration von IL-6 zeigte sich auch im ZNS 12 Stunden nach der Infektion und vor der ersten Antibiotikagabe. IL-6 fiel im Laufe der Zeit unter weiterer Antibiotikagabe ab, wobei die intrazerebral gemessenen Konzentrationen insgesamt niedriger waren als die im peripheren Blut gemessenen Konzentrationen.

Verschiedene Arbeitsgruppen konnten zeigen, dass durch das Bakterienwandbestanteil LPS aktivierte Endothelzellen des Gehirns die Zytokine IL-1 $\beta$, TNF- $\alpha$ und IL-6 produzieren (Fabry et al. 1993; Breder et al. 1994; Reyes et al. 1999). Derartige Reaktionen auf LPS spielen sich nicht nur an der Blut-Hirn-Schranke ab, sondern werden an die daraufhin aktivierten Mikroglia weitergeleitet (Rivest 2003). Nach subkutaner Gabe von LPS ließen sich 
morphologische Veränderungen der aktivierten Mikroglia darstellen (Kloss et al. 2001). In einem Maus-Modell der Multiplen Sklerose zeigte sich nach Infektion mit S. pneumoniae im Vergleich zu nicht-infizierten Tieren neben einer Erhöhung der Konzentrationen von IL-6 im Gehirn auch eine leicht erhöhte Gewebszerstörung und eine Zunahme von monozytären Zellen (Herrmann et al. 2006). Unsere Ergebnisse zeigen sich im Einklang mit den Daten aus der Literatur. Es konnte demonstriert werden, dass auch bei der im Hauptversuch angewandten Form der peripheren Infektion eine inflammatorische Veränderung im ZNS stattfindet.

Über die Mechanismen, wie diese inflammatorischen Veränderungen im ZNS zustande kommen, gibt es unterschiedliche - vermutlich zusammenspielende - Erklärungsansätze. Das Gehirn ist durch die Blut-Hirn-Schranke weitestgehend vor dem Übergreifen schädlicher Organismen aus dem Körper geschützt, eine Interaktion zwischen dem peripheren Kreislauf und dem zentralen Nervensystem ist jedoch von hoher Relevanz. Die Kommunikation erfolgt dabei in erster Linie über Mediatoren, welche aktiv oder passiv die Blut-Hirnschranke überqueren können oder über den Nervus vagus Signale an das Gehirn senden können. In zweiter Linie können aber auch bakterielle Bestandteile selbst eine Signalkaskade im Gehirn auslösen (Sharshar et al. 2005). Diese unterschiedlichen Möglichkeiten, die das Immunsystem hat, um dem Gehirn die Anwesenheit von Mikroorganismen mitzuteilen, sind im Kapitel 1.2.2 auf Seite 11 genauer erläutert. Diese Mechanismen sind von Bedeutung, da sie bei der Entzündung im Gehirn, welche als Reaktion auf die Information aus der Peripherie als Sekundärantwort auf ein primäres Pathogen entsteht, dort den größeren und pathophysiologisch relevanteren Schaden verursachen können (Akiyama et al. 2000; Semmler et al. 2008). Nur bei einer funktionierenden Kommunikation kann das Gehirn die physiologischen Funktionen und Reaktionen des Körpers gerade in kritischen Situationen wie einer Sepsis steuern und aufrechterhalten (Rivest et al. 2000).

\subsection{Rezidivierende Infektionen mit Streptococcus pneumoniae bewirken keine Verschlechterung des Morbus Alzheimer im Maus-Modell}

Der Hauptteil dieser Arbeit kommt der Frage nach, ob sich das klinisch beobachtete Phänomen der Verschlechterung der Alzheimer-Demenz unter bakteriellen systemischen Infektionen im Tiermodell bestätigen lässt. Trotz des großen Interesses an den Zusammenhängen zwischen Entzündungen und Demenzen im Allgemeinen wurden bisher noch keine Experimente gemacht, die den Einfluss von systemischen bakteriellen Infektionen auf den Verlauf der Alzheimer-Erkrankung in vivo untersucht haben. Falls die durch eine bakterielle Infektion zentral hervorgerufenen inflammatorischen Veränderungen auf ein zuvor entzündlich geprägtes Gewebe eine verstärkt schädigende Auswirkung haben, 
so könnte die rasche Behandlung mit einem Antibiotikum, welches auf die Verringerung der Menge an freigesetzten proinflammatorischen beziehungsweise toxischen Bakterienbestandteilen abzielt, für das zukünftige therapeutische Procedere von Bedeutung sein (Stuertz et al. 1998; Spreer et al. 2003).

Daher wurde hier der Einfluss wiederholter systemischer Infektionen mit S. pneumoniae dem verbreitetsten Pathogen für Infektionen des oberen Respirationstraktes und für Pneumonien beim Erwachsenen - auf den Verlauf der Alzheimer-Demenz im Maus-Modell untersucht. Als Alzheimer-Modell wurden die Tg2576-Mäuse verwendet, welche das A $\beta$ Vorläuferprotein APP überexprimieren und deren neuropsychologischen und morphologischen Veränderungen gut untersucht sind.

Das im Morris-Water-Maze evaluierte räumliche Gedächtnis und die Lernfähigkeit der Tg2576-Tiere ergaben keine signifikanten Unterschiede zwischen den infizierten Mäusen und der nicht-infizierten Kontrollgruppe. Bezüglich der motorischen Fähigkeiten zeigten sich im Seiltest und Rotarod-Test während des gesamten Experiments keine Defizite bei den Mäusen. Das im Hauptversuch durchgeführte Morris-Water-Maze zeigt bei transgenen versus nicht-transgenen Mäusen ab einem Alter von 9-10 Monaten unterschiedliche Lernund Orientierungsfähigkeiten (Hsiao et al. 1996). Dies entspricht dem Alter, das die Versuchstiere etwa in der Mitte des Experimentes erreicht hatten, so dass sich sowohl eine zeitliche Vorverlagerung des Erkrankungsbeginns als auch eine rapide Verschlechterung danach bemerkbar gemacht hätte. Eine Beeinträchtigung von Motorik, Koordination oder Ausdauer ist bei den Tg2576-Mäusen nicht zu erwarten gewesen (Hsiao et al. 1996) und konnte als mögliche Ursache eines schlechteren Abschneidens im Morris-Water-Maze ausgeschlossen werden.

Im nicht-transgenen Tiermodell konnte nachgewiesen werden, dass die intrazerebrale oder intraperitoneale Injektion von LPS zu Erinnerungsdefiziten, einer erhöhten Expression von APP mit Akkumulation von A $\beta$ 1-42 und zu neuronalem Sterben führt (Hauss-Wegrzyniak et al. 1998; Lee et al. 2008). Auch über das Zusammenwirken eines peripheren bakteriellen Geschehens mit den inflammatorischen Veränderungen bei neurodegenerativen Erkrankungen gibt es Studien. Die systemische Gabe des Endotoxins LPS bei Mäusen mit einer noch nicht klinisch manifesten Prionenerkrankung führte zu einem rascheren Verlust der motorischen Fähigkeiten und einer stärkeren IL-1 $\beta$-Synthese im Gehirn als bei KontrollMäusen, die nicht mit LPS behandelt wurden (Combrinck et al. 2002). Des Weiteren konnte im Maus-Modell der Amyotrophen Lateralsklerose eine deutliche klinische Verschlechterung durch eine chronische systemische LPS-Gabe gezeigt werden (Nguyen et al. 2004). Eine Behandlung mit $\mathrm{CpG}$ bei mit Prion-Protein infizierten Mäusen resultierte hingegen in einer deutlichen Verlängerung der Überlebenszeit (Sethi et al. 2002). Diese differierenden 
Resultate bei der Gabe unterschiedlicher bakterielle Zerfallsbestandteile könnten sich durch die Interaktion mit verschiedenen TLR erklären (LPS bindet an TLR-4, CpG bindet an TLR9). Zusammengefasst konnte in vivo eine periphere Applikation eines bakteriellen Bestandteils, möglicherweise über eine weitere Aktivierung bereits stimulierter Mikroglia, zum Fortschreiten eines neurodegenerativen Prozesses führen (Combrinck et al. 2002; Perry et al. 2003; Nguyen et al. 2004; Cunningham et al. 2005; Morgan et al. 2005).

Ähnlich wie bei den neurodegenerativen Erkrankungen zeigt sich bei einer akuten Gehirnschädigung, z.B bei einem Schlaganfall, ein lokaler entzündlicher Prozess im ZNS. Auch hier wird der Einfluss eines zusätzlichen entzündlichen Stimulus kontrovers diskutiert. Eine intraperitoneale Gabe von LPS vor einem experimentellen Schlaganfall im Maus-Modell führte zu einer Exazerbation von Gehirnschaden und neurologischem Defizit (McColl et al. 2007). In anderen Studien konnte gezeigt werden, dass eine systemische Präkonditionierung mit LPS (Rosenzweig et al. 2004; Rosenzweig et al. 2007) oder anderen Stimuli der angeborenen Immunantwort, wie dem TLR-2 Agonisten $\mathrm{Pam}_{3} \mathrm{CysSK}_{4}$ (Hua et al. 2008) und dem TLR-9 Agonisten CpG (Stevens et al. 2008), zu einer Reduktion der Infarktgröße führte und eine Neuroprotektion im Maus-Modell des experimentellen Schlaganfalls bewirkte.

In den vorliegenden Experimenten zeigte sich bei den infizierten Tieren weder eine erhöhte noch eine verminderte $A \beta$-Konzentration. Es ergab sich kein signifikanter Unterschied der Plaquegröße und der Konzentrationen des Detergenzien-löslichen oder Detergenzienunlöslichen $A \beta s$ zwischen infizierten Tieren und nicht-infizierter Kontrollgruppe.

Wie im Gehirn von Alzheimer-Patienten akkumuliert im Gehirn von Tg2576-Mäusen das A $\beta$ in Plaques sowie in Form der zerebralen amyloiden Angiopathie (Kuo et al. 2000). Erhöhte Konzentrationen von $A \beta$ 1-40 und 1-42 sind bei Tg2576-Mäusen ab einem Alter von 6-7 Monaten nachweisbar, die Formation der Plaques beginnt um den 12. Lebensmonat herum (Kawarabayashi et al. 2001). Unter Einfluss eines rezidivierenden peripheren Entzündungsgeschehens, wie der systemischen Applikation von LPS, konnte ein Anstieg von $A \beta$ 1-40 und 1-42 bei transgenen, APP-überexprimierenden Mäusen beobachtet werden (Sheng et al. 2003). Die chronische intrazerebrale Injektion von LPS über ein Pumpensystem initiierte die Deposition von $A \beta$ in einem anderen Maus-Modell der Alzheimer-Demenz (Qiao et al. 2001). Im Gegensatz dazu konnte durch eine einmalige intrazerebrale Injektion von LPS die Konzentration des diffusen zerebralen A $\beta$ s über die Mikroglia-Aktivierung in einem ähnlichen Tiermodell gesenkt werden, während sich in Bezug auf das aggregierte $A \beta$ keine Veränderung zeigte (Dicarlo et al. 2001; Herber et al. 2007). Eine weitere Arbeitsgruppe hat Tg2576-Tiere einmalig intraperitoneal mit LPS behandelt und fand auch bei dieser Applikationsweise eine Reduktion der Aß-Plaques (Quinn et al. 2003). Interessanterweise schien die Induktion der Neuroinflammation durch Gabe von LPS eine Reduktion der A $\beta$ - 
Konzentration zu bewirken. Bei Immunisierung von transgenen Mäusen mit A $\beta$ 1-42 konnte, vermutlich auch über eine Aktivierung der Mikrogliazellen, der Abbau von amyloiden Plaques bewirkt werden (Wisniewski und Konietzko 2008).

Zusammengefasst zeigt sich in manchen Versuchen der LPS-Gabe an Tiere eines Alzheimer-Modells eine Reduktion, in anderen eine Zunahme der Aß-Plaques. Mögliche Erklärungsansätze zielen auf unterschiedliche Wirkung der Entzündung ab (Plaquezunahme durch Induktion der Ablagerung und außerdem Plaqueabnahme durch vermehrten Abbau) oder versuchen die Erklärung darin zu finden, dass die Aktivierung der Mikroglia bei chronischen Reizen andere Folgen (Plaquezunahme) nach sich zieht als eine akute Stimulation (Plaqueabnahme) (Morgan et al. 2005). Bezugnehmend auf letztere Hypothese von Morgan et al. (2005) könnte es sein, dass unser Infektionsschema von vier Infektionen im Abstand von vier Wochen sowohl die vermehrte Produktion von $A \beta$ als auch den vermehrten Abbau durch Mikroglia hervorgerufen hat, so dass die Endkonzentration unbeeinflusst blieb.

Sämtliche Tierversuche, in denen bakterielle Bestandteile wie LPS appliziert wurden, können nicht die spontane physiologische oder antibiotisch induzierte Freisetzung von bakteriellen Komponenten, wie sie bei einer bakteriellen Infektion mit anschließender antibiotischer Therapie entstehen, widerspiegeln. Die in dieser Arbeit durchgeführte systemische Applikation von $S$. pneumoniae mit anschließender Antibiotikatherapie wurde bislang an murinen Modellen der multiplen Sklerose, des Morbus Parkinson und der Amyotrophen Lateralsklerose verwendet (Herrmann et al. 2006; Ebert et al. 2009). Dabei zeigte sich in den Modellen des Morbus Parkinson und der Amyotrophen Lateralsklerose keine Beeinflussung des Krankheitsverlaufes durch mehrfache intraperitoneale Infektion mit S. pneumoniae. Im Modell der Multiplen Sklerose, der sogenannten Experimentellen Autoimmunen Enzephalitis $(E A E)$, wurde die Schwere der Erkrankung durch eine einzige Infektion mit einem vergleichbar konzentrierten Inokulum verstärkt (Herrmann et al. 2006). Bei der Multiplen Sklerose finden sich - wie auch bei der Alzheimer Demenz - entzündliche ZNS-Prozesse mit aktivierten Mikrogliazellen, welche unter anderem die Bestandteile des angeborenen Immunsystems TLR-2 und TLR-4 exprimieren. Das verwendete Bakterium S. pneumoniae enthält in seiner Zellwand z.B. Teichon - und Lipoteichonsäuren, welche Liganden von TLR2 darstellen sowie das Protein Pneumolysin, welches an TLR-4 bindet (Malley et al. 2003; Schröder et al. 2003; Koedel 2009). Über eine Aktivierung der TLR durch bakterielle Bestandteile können Mikroglia Neuronen töten, auch wenn dies möglichweise nur in bestimmten, z.B. entzündlich veränderten Umgebungen stattfinden kann (Bamberger und Landreth 2002; Perry et al. 2003; lliev et al. 2004; Salminen et al. 2009). Dabei spielen proinflammatorische Zytokine wie TNF- $\alpha$ eine Rolle. Diese zeigten bei TLR-2-defizienten 
Mäusen in der Studie von Herrmann et al. 2006 keine Konzentrationserhöhung - und es zeigte sich auch keine Verschlechterung der Erkrankung. So liegt die Vermutung nahe, dass die Infektion mit $S$. pneumoniae unter anderem über den TLR-2 krankheitsverschlechternde Wirkung zeigte (Herrmann et al. 2006).

In Anbetracht der vorliegenden klinischen Studien bezüglich Infektionen und Demenzen (Nee und Lippa 1999; Holmes et al. 2003; Dunn et al. 2005; Holmes et al. 2009) als auch unter Einbezug der verschiedenen tierexperimentellen Daten mit systemischer Applikation von LPS in Maus-Modellen von ALS (Nguyen et al. 2004), Prionerkrankungen (Cunningham et al. 2005) und Morbus Alzheimer (Qiao et al. 2001; Sly et al. 2001; Sheng et al. 2003) sind unsere Ergebnisse überraschend. Anknüpfend an diese Forschungsergebnisse wurde erwartet, dass auch in unserem Versuch die Freisetzung und Wirkung der bakteriellen Bestandteile von S. pneumoniae, wie z.B. Teichon - und Lipoteichonsäuren, zu einer Progredienz der neurodegenerativen Erkrankung führen würde.

Im Vergleich zu den Endotoxin-Konzentrationen im Bereich von pg/ml im Plasma, welche bei Patienten mit Sepsis gemessen wurden (Kojika et al. 2006), sind die in den genannten Versuchen applizierten LPS-Dosen allerdings zum Teil sehr hoch. In-vitro-Daten lassen vermuten, dass die Effekte bedingt durch die stimulierten Mikroglia - entweder Neuroprotektion oder Neurotoxizität - von der Dosis des inflammatorischen Stimulus abhängen (Li et al. 2007).

Die systemische Infektion in dieser Studie wäre ohne antibiotische Behandlung tödlich und somit nicht durchführbar gewesen. Auch spiegelt die relative kurze und starke systemische Infektion mit nachfolgender antibiotischer Therapie gut die Situation eines adäquat behandelten akut Kranken wider. Zudem resultiert die Behandlung einer $S$. pneumoniae Infektion mit dem bakteriolytischen Antibiotikum Ceftriaxon in einer schnellen Freisetzung von großen Mengen bakterieller Produkte, welche die angeborene Immunität stark stimulieren (Stuertz et al. 1998; Nau und Eiffert 2002).

Es ist möglich, dass die Stimulation des angeborenen Immunsystems im ZNS durch die Infektion weniger stark war, als die oben beschriebene durch hohe Dosen von LPS ausgelöste Reaktion (Sheng et al. 2003; Nguyen et al. 2004; Cunningham et al. 2005). Eine anhaltende systemische Infektion könnte die neurodegenerative Krankheit möglicherweise stärker beeinflussen. Hätte man die mit $S$. pneumoniae infizierten Tiere jedoch länger als 12 Stunden ohne antibiotische Therapie belassen, so wäre die Gesamtsterblichkeit stark angestiegen. In einer Studie, bei der LPS intraperitoneal appliziert und die zentrale Reaktion evaluiert wurde, war nach einer einmaligen Injektion noch 10 Monate später eine erhöhte

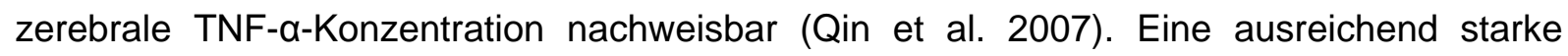
Aktivierung scheint sich daher auch zerebral auf lange Frist bemerkbar zu machen. 
Warum in dem Maus-Modell der EAE, nicht aber in den Tiermodellen für neurodegenerative Erkrankungen gezeigt werden konnte, dass systemische Infektionen mit $S$. pneumoniae den Krankheitsbeginn oder die Krankheitsprogression beschleunigen, bleibt unklar (Herrmann et al. 2006; Ebert et al. 2009). Bei der Multiplen Sklerose ist im Vergleich zu den anderen neurodegenerativen Erkrankungen die entzündliche Komponente ausgeprägter. In dem Modell der Multiplen Sklerose waren bei den infizierten Tieren erhöhte zerebrale Konzentrationen von TNF- $\alpha$ nachweisbar. Sobald das TNF- $\alpha$ in geringeren Mengen, nämlich bei den TLR-2 defizienten Tieren, nachweisbar war, fand sich auch kein krankheitsverschlimmernder Effekt. In den vorliegenden Versuchen konnten erhöhte zerebrale Werte für IL-6, nicht aber für TNF- $\alpha$ nachgewiesen werden. Auch in den klinischen Studien von Holmes (2009) ließ sich zeigen, dass die Konzentration von TNF- $\alpha$ in einem positiven Zusammenhang mit der Verschlechterung der Demenz steht. Bezüglich der Expression von TNF- $\alpha$ und neuronalen TNF- $\alpha$ Rezeptoren wurde festgestellt, dass diese im Gehirn von Alzheimer-Patienten erhöht ist (Fillit et al. 1991; Tarkowski et al. 1999; Zhao et al. 2003). Eine erhöhte Expression der neuronalen TNF- $\alpha$ Rezeptoren könnte wiederum zu einem erhöhten Schaden im Gehirn des Alzheimerkranken führen. Möglichweise fällt dem Zytokin TNF- $\alpha$ eine Schlüsselrolle bei der Wechselwirkung von Infektion, Inflammation und Alzheimer-Demenz zu.

Es existiert kein Schema für eine Infektion durch $S$. pneumoniae bei Mäusen, welches eine moderate, anhaltende systemische Infektion verursachen kann. Alternative Vorgehensweisen wären Infektionsmodelle einer septischen Arthritis, einer Endokarditis oder einer Weichteilinfektion durch z.B. Staphylococcus aureus. Interessant wäre auch die Untersuchung des Einflusses einer systemischen Infektion durch Escherischia coli, ein Keim, der für viele urologische Infektionen verantwortlich ist. Dies würde durch die dann entstehende LPS-Freisetzung den bisher damit künstlich induzierten Infektionen versuchstechnisch näher kommen. Außerdem wäre es spannend, den Verlauf des Morbus Alzheimer unter einer chronischen Infektion von Chlamydia pneumoniae zu untersuchen. Die chronische Entzündungsreaktion, die sich bei der sporadischen Alzheimer-Demenz findet, könnte durch die Infektion durch das obligat intrazellulär lebende Bakterium Chlamydia pneumoniae mitbedingt sein (Balin und Appelt 2001; Holmes und Cotterell 2009). Die Zellwand von C. pneumoniae enthält LPS. Laut einer Studie wurde C. pneumoniae sehr häufig in den glialen Zellen betroffener Gebiete im Gehirn von Alzheimer-Patienten gefunden. Ob dieser Organismus Mitschuld an der Entwicklung der Erkrankung trägt oder als Opportunist einen leichteren Weg in vorgeschädigtes Gewebe hatte, ist unklar. Ein Zusammenhang zwischen einem Mikroorganismus und einer chronischen neurologischen Erkrankung wäre denkbar, zumal sich ähnliche Zusammenhänge z.B. bei der LymeKrankheit durch Borrelien oder bei dem Post-Polio-Syndrom zeigen (Balin und Appelt 2001). 
Auch ist z.B. eine Herpes-Simplex-1-Infektion bei Menschen, welche das apoE-£4-Allel tragen, ein möglicher Risikofaktor für die Entwicklung des Morbus Alzheimer (Itzhaki 2004; Holmes und Cotterell 2009).

Weitere mögliche Ursachen für das unerwartete Ergebnis unseres Versuchs könnte man im Versuchsaufbau und im Tiermodell suchen. Bezüglich des Versuchsaufbaus war möglicherweise der Zeitpunkt der Tötung der Tiere zu früh gewählt, da sich neurodegenerative Unterschiede unter Umständen erst im Verlauf mehrerer Monate manifestieren können. In einer Studie im Tiermodell wurde z.B. vier Monate nach LPSInjektion kein Rückgang der Neuronendichte in der Substantia nigra festgestellt, sieben bis zehn Monate später zeigte sich jedoch eine Differenz (Qin et al. 2007). Außerdem führte die Infektion, obwohl allen Tieren stets die gleiche Keimmenge verabreicht wurde, von Tier zu Tier zu unterschiedlich schweren Krankheitszeichen. Dieses sowie die Tatsache, dass die Tiere ein sehr individuell schwankendes und stark tagesabhängiges Leistungsmuster zeigten, machen sich in kleinen Versuchsgruppen mit $n=10$ beziehungsweise 11 stärker bemerkbar als in größeren Gruppen. Auch ließen sich die Nachweismethoden für die Lernund Erinnerungsdefizite unter einem allerdings erheblichen Aufwand sensibler gestalten (Gallagher et al. 1993; Crawley und Paylor 1997; Van Meer und Raber 2005)

Zusammenfassend konnte nicht gezeigt werden, dass wiederholte systemische Infektionen mit S. pneumoniae den Beginn und Verlauf der Alzheimer-Demenz im Maus-Modell beeinflussen. Dies könnte bedeuten, dass der Effekt von mäßig schweren akuten Infektionen auf den Verlauf neurodegenerativer Erkrankungen weniger ausgeprägt ist als angenommen. Weitere Untersuchungen sollten den Einfluss Gram-negativer LPS-haltiger Bakterien und/oder den Einfluss chronischer Infektionen auf neurodegenerative Erkrankungen im Tiermodell beleuchten. Sollte sich dort eine Verschlimmerung der Erkrankung finden, so sollten anschließend Versuche mit unterschiedlichen Antibiotika zur Therapie der Infektion durchgeführt werden. Hier sollten im Gegensatz zu dem Bakterienwand-zerstörenden Antibiotikum Ceftriaxon solche Antibiotika zum Einsatz kommen, welche die Freisetzung der bakteriellen Bestandteile möglichst gering halten (Stuertz et al. 1998; Nau und Eiffert 2002). Dies könnte in einer geringeren Aktivierung der innaten Immunabwehr und somit in einer verminderten neurotoxischen Wirkung resultieren.

\subsection{Die Stimulation neuronal-monozytärer Kokulturen durch $A \beta$ 1-40 und bakterielle Zerfallsbestandteile führt zur Schädigung der Neuronen}

Der letzte Teil der Arbeit soll die Zusammenhänge zwischen Alzheimer-Demenz und bakteriellen Infektionen in vitro näher analysieren. Dazu wurden neuronal-monozytäre 
Kokulturen dem Alzheimer Protein $A \beta$ 1-40 und bakteriellen Bestandteilen wie dem Lipopeptid $\mathrm{Pam}_{3} \mathrm{CysSK}_{4}$ ausgesetzt. Es zeigte sich sowohl in den murinen NeuronenMikroglia-Kokulturen als auch in den humanen Neuroblastomzellen-MakrophagenKokulturen eine Aktivierung der Immunzellen sowie ein deutlicher Schaden der Nervenzellen durch $A \beta$ 1-40 als auch durch das synthetische Bakterienbestandteil Pam ${ }_{3} \mathrm{CysSK}_{4}$. Bei Kombination der beiden Stimulanzien schien sich der Neuronenschaden zu potenzieren. Leider warf die Quantifizierung des Schadens Probleme auf, so dass sich das durch Inspektion der Schnitte gewonnene Ergebnis letztendlich nicht objektivieren lies.

Auf Zellkultur-Ebene konnte bereits gezeigt werden, dass primäre Mikrogliakulturen durch zytolytische bakterielle Produkte in Dosis-abhängiger Weise stimuliert werden. Außerdem führt das von S. pneumoniae produzierte Pneumolysin zu einer starken Aktivierung der Mikrogliazellen und reduziert in hohen Dosen deren Vitalität (Ebert et al. 2005). Dabei wirken die bakteriellen Produkte als Agonisten unterschiedlicher TLR, welche von Mikroglia, Astrozyten und Oligodendrozyten exprimiert werden (Olson und Miller 2004) und als Teil des angeborenen Immunsystems verschiedene funktionale Bestandteile von Viren, Bakterien und Pilzen erkennen (Kaisho und Akira 2006). Eine Aktivierung der Mikroglia über TLR führt über eine vermehrte Expression von Zytokinen, wie z.B. IL-6 und TNF- $\alpha$, zur weiteren Stimulation der Immunabwehr. Auch die endogenen $\beta$-Amyloid-Peptide, wie sie bei Morbus Alzheimer im Gehirn gefunden werden, können Immunzellen über TLR (insbesondere TLR2/4) oder andere Rezeptoren stimulieren (Lotz et al. 2005; Tahara et al. 2006; Salminen et al. 2009).

Dies könnte dazu führen, dass Mikroglia von Alzheimer-Patienten, welche ohnehin dem dauerhaften Reiz durch $A \beta$ ausgesetzt sind, bei einer zusätzlichen bakteriellen Begleitinfektion überschießend reagieren. Bei einer kombinierten Behandlung von MikrogliaZellkulturen mit $A \beta$ und bakteriellen TLR-2/4-Agonisten wie LPS oder dem Lipopeptid $\mathrm{Pam}_{3} \mathrm{CysSK}_{4}$ resultierte eine stärkere Aktivierung von Mikroglia als bei der Behandlung mit einem einzigen Stimulans. Im Gegensatz dazu führte die gleichzeitige Gabe von A 1 1-40 und CpG (TLR-9 Agonist) zu einer geringeren Produktion proinflammatorischer Zytokine verglichen mit der Stimulation durch CpG alleine. Auch ließ sich dabei im Gegensatz zu den anderen Stimulanzien nicht nur eine geringere Produktion proinflammatorischer Zytokine, sondern auch die Produktion des antiinflammatorischen IL-10 nachweisen. Offensichtlich verstärken nicht alle TLR Agonisten den stimulatorischen Effekt von $A \beta$ auf die angeborene Immunität, es kann aber eine additive Wirkung bei der Stimulation mit endogenen und exogenen Faktoren resultieren (Lotz et al. 2005). Dabei ist die Anregung der angeborenen Immunabwehr mittels der Stimulation von Mikroglia für die neuronalen Zellen nicht unbedingt protektiv. Während z.B. Pneumokokken-DNA (Schmidt et al. 2001) und unmethylierte CpGDNA (lliev et al. 2004) in isolierten Neuronen-Kulturen keinen neurotoxischen Effekt haben, 
kommt es in organotypischen hippokampalen Kulturen jedoch zu einer Schädigung der Neuronen. Diese Neurotoxizität von CpG-DNA war auch in Kokulturen von Mikroglia und Neuronen nachweisbar (lliev et al. 2004). Dabei antworteten Mikrogliazellen auf die Stimulation durch CpG-DNA mit einer Produktion von bakteriotoxischem Stickoxid und proinflammatorischem TNF- $\alpha$. Auch wenn die proinflammatorischen Zytokine wie IL-1, IL-6 oder TNF- $\alpha$ neuroprotektive Effekte haben können, können sie eine neurotoxische Wirkung entfalten (Allan und Rothwell 2001). TNF-a kann einen direkten Zelltod durch Anbindung an Zelltodrezeptoren vermitteln (Downen et al. 1999) oder in niedrigeren Dosen das Wachsen und Teilen der Neuriten verhindern (Neumann et al. 2002). Passend dazu führten die Hemmung der Stickoxid-Synthase und neutralisierende Antikörper gegen TNF- $\alpha$ zu einer verringerten Neurotoxizität von CPG-DNA (lliev et al. 2004).

Sollte sich der optische Eindruck, den die in dieser Arbeit durchgeführten Zellkulturversuche erwecken, in Zukunft objektivieren lassen, so wäre auch die Untersuchung des Zusammenspiels von A 1-40 mit bakteriellen Bestandteilen wie LPS und CpG-DNA von großem Interesse. So könnte man den komplexen in vivo stattfindenden Vorgängen detaillierter auf die Spur kommen.

Zusammengefasst lässt sich eine Bestätigung der Hypothese einer synergistischen Aktivierung der Mikrogliazellen mit resultierender verstärkter Neuronentoxizität bei Stimulation neuronal-monozytären Kokulturen durch $A \beta$ 1-40 und den bakteriellen Bestandtteil Pam ${ }_{3} \mathrm{CysSK}_{4}$ aufgrund des optischen Gesamteindrucks vermuten, zuvor muss jedoch eine adäquate Quantifizierungsmethode des Neuronenschadens etabliert werden. 


\section{Zusammenfassung}

Die Alzheimer-Demenz ist eine Erkrankung des Seniums, deren Bedeutung aufgrund der demographischen Veränderungen mit einer steigenden Lebenserwartung weiter zunehmen wird. Es gibt zahlreiche Hinweise dafür, dass entzündliche Vorgänge bei dem Pathomechanismus eine Rolle spielen und dass die dementiellen Symptome im Rahmen einer bakteriellen Infektion zunehmen können.

Wir haben die Beeinflussung der Alzheimer-Demenz durch rezidivierende systemische Infektionen mit dem häufigsten respiratorischen Pathogen des Erwachsenen - $S$. pneumoniae - in einem Maus-Modell untersucht. Die transgenen, das $A \beta$-Vorläuferprotein APP überexprimierenden Tg2576-Mäuse wurden wiederholt intraperitoneal mit dem lebenden Bakterium S. pneumoniae Typ 3 infiziert und danach über drei Tage alle 12 Stunden mit dem bakteriziden Antibiotikum Ceftriaxon therapiert.

Die Infektion führte zu einer inflammatorischen Antwort im ZNS mit erhöhten Konzentrationen von Interleukin-6 in Hirnhomogenaten. Die motorische Leistungsfähigkeit der Tiere wurde durch den Seiltest und den Rotarod-Test überprüft und ergab keine Defizite. Das räumliche Lernen, Lerndefizite und Erinnerungsdefizite wurden durch das Morris-WaterMaze evaluiert. Weder ein früherer Beginn noch ein schneller Verlauf der AlzheimerErkrankung konnte durch diese Tests bei den infizierten Tieren beobachtet werden. Die durch Thioflavin S angefärbten Plaques zeigten keine Größenunterschiede zwischen den Gruppen. Mittels Westernblot wurden aus Hirnhomogenaten die Detergenzien-löslichen und Detergenzien-unlöslichen $A \beta-F r a g m e n t e ~ 1-37,1-38,1-39,1-49$ und 1-42 bestimmt. Die Konzentrationen der Detergenzien-löslichen Konzentrationen von $A \beta$ 1-40 und $A \beta$ 1-42 wurden auch mittels der sensitiveren ELISA-Methode gemessen. Weder im Westernblot noch bei den mittels ELISA bestimmten Konzentrationen der A $\beta$-Fragmente konnten signifikante Differenzen in den Gehirnen von infizierten versus nicht-infizierten Tieren nachgewiesen werden.

Die in dieser Arbeit außerdem durchgeführten Versuche zur kombinierten Wirkung von $A \beta 1$ 40 und bakteriellen Zerfallsbestandteilen auf murine oder humane neuronal-monozytäre Kokulturen zeigten optisch einen deutlichen Zellschaden, führten aber aufgrund der fehlenden Genauigkeit der Quantifizierung zu keinem statistisch verwertbaren Ergebnis.

Zusammenfassend konnten wiederholte systemische Infektionen mit $S$. pneumoniae den Beginn und Verlauf der Alzheimer-Demenz im Maus-Modell nicht beeinflussen. Dies könnte bedeuten, dass der Effekt von mäßig schweren akuten Infektionen auf den Verlauf der Alzheimer-Demenz weniger ausgeprägt ist als bislang angenommen. Weitere Untersuchungen sollten den Einfluss chronischer Entzündungen auf die neurodegenerative Alzheimer-Erkrankung im Tiermodell beleuchten. 


\section{Literaturverzeichnis}

Akiyama H, Barger S, Barnum S, Bradt B, Bauer J, Cole GM, Cooper NR, Eikelenboom P, Emmerling M, Fiebich BL, et al. (2000): Inflammation and Alzheimer's disease. Neurobiol Aging 21, 383-421

Allan SM, Rothwell NJ (2001): Cytokines and acute neurodegeneration. Nat Rev Neurosci $\underline{2}$, 734-44

Aloisi F (2001): Immune function of microglia. Glia $\underline{36}$, 165-79

APA: Diagnostic and Statistical Manual of Menal Disorders DMS-IV-TR, 4, Text Revision, American Psychiatric Publishing, Inc., Washington DC 2000.

Balin BJ, Appelt DM (2001): Role of infection in Alzheimer's disease. J Am Osteopath Assoc 101, S1-6

Bamberger ME, Landreth GE (2001): Microglial interaction with beta-amyloid: implications for the pathogenesis of Alzheimer's disease. Microsc Res Tech $\underline{54}$, 59-70

Bamberger ME, Landreth GE (2002): Inflammation, apoptosis, and Alzheimer's disease. Neuroscientist $\underline{8}, 276-83$

Beyreuther K, EinhäuptI KM, H. F, Kurz A. Demenzen - Grundlagen und Klinik, Georg Thieme Verlag, Stuttgart 2002.

Bickel H (2000): [Dementia syndrome and Alzheimer disease: an assessment of morbidity and annual incidence in Germany]. Gesundheitswesen 62, 211-8

Biedler JL, Helson L, Spengler BA (1973): Morphology and growth, tumorigenicity, and cytogenetics of human neuroblastoma cells in continuous culture. Cancer Res $\underline{33}$, 2643-52

Blalock EM, Chen KC, Stromberg AJ, Norris CM, Kadish I, Kraner SD, Porter NM, Landfield PW (2005): Harnessing the power of gene microarrays for the study of brain aging and Alzheimer's disease: statistical reliability and functional correlation. Ageing Res Rev $\underline{4}$, 481-512

Blennow K, de Leon MJ, Zetterberg H (2006): Alzheimer's disease. Lancet 368, 387-403

Boyum A (1984): Separation of lymphocytes, granulocytes, and monocytes from human blood using iodinated density gradient media. Methods Enzymol 108, 88-102

Breder CD, Hazuka C, Ghayur T, Klug C, Huginin M, Yasuda K, Teng M, Saper CB (1994): Regional induction of tumor necrosis factor alpha expression in the mouse brain after systemic lipopolysaccharide administration. Proc Natl Acad Sci U S A 91, 11393-7

Cagnin A, Brooks DJ, Kennedy AM, Gunn RN, Myers R, Turkheimer FE, Jones T, Banati RB (2001): In-vivo measurement of activated microglia in dementia. Lancet $\underline{358}, 461-7$

Combrinck MI, Perry VH, Cunningham C (2002): Peripheral infection evokes exaggerated sickness behaviour in pre-clinical murine prion disease. Neuroscience 112, 7-11

Combs CK, Karlo JC, Kao SC, Landreth GE (2001): beta-Amyloid stimulation of microglia and monocytes results in TNFalpha-dependent expression of inducible nitric oxide synthase and neuronal apoptosis. J Neurosci 21 , 1179-88 
Crawley JN, Paylor R (1997): A proposed test battery and constellations of specific behavioral paradigms to investigate the behavioral phenotypes of transgenic and knockout mice. Horm Behav 31, 197-211

Cunningham C, Wilcockson DC, Campion S, Lunnon K, Perry VH (2005): Central and systemic endotoxin challenges exacerbate the local inflammatory response and increase neuronal death during chronic neurodegeneration. J Neurosci $\underline{25}, 9275-84$

De Kimpe SJ, Kengatharan M, Thiemermann C, Vane JR (1995): The cell wall components peptidoglycan and lipoteichoic acid from Staphylococcus aureus act in synergy to cause shock and multiple organ failure. Proc Natl Acad Sci U S A 92, 10359-63

Deckert M, Reifenberger G, Riede UN, Schlote W, Thal DR, Wiestler OD: Nervensystem; in: Allgemeine und spezielle Pathologie; hrsg. v. Riede U N, Werner M,Schaefer H E; Georg Thieme Verlag, Stuttgart 2004, 1069-1071.

DiCarlo G, Wilcock D, Henderson D, Gordon M, Morgan D (2001): Intrahippocampal LPS injections reduce Abeta load in APP+PS1 transgenic mice. Neurobiol Aging 22, 1007-12

Dilger RN, Johnson RW (2008): Aging, microglial cell priming, and the discordant central inflammatory response to signals from the peripheral immune system. J Leukoc Biol $\underline{84}$, 932-9

Doody RS, Geldmacher DS, Gordon B, Perdomo CA, Pratt RD (2001): Open-label, multicenter, phase 3 extension study of the safety and efficacy of donepezil in patients with Alzheimer disease. Arch Neurol $\underline{58}$, 427-33

Downen M, Amaral TD, Hua LL, Zhao ML, Lee SC (1999): Neuronal death in cytokineactivated primary human brain cell culture: role of tumor necrosis factor-alpha. Glia $\underline{28}, 114-27$

Dunham NW, Miya TS (1957): A note on a simple apparatus for detecting neurological deficit in rats and mice. J Am Pharm Assoc Am Pharm Assoc (Baltim) 466, 208-9

Dunn N, Mullee M, Perry VH, Holmes C (2005): Association between dementia and infectious disease: evidence from a case-control study. Alzheimer Dis Assoc Disord 19, 91-4

Ebert S, Gerber J, Bader S, Mühlhauser F, Brechtel K, Mitchell TJ, Nau R (2005): Dosedependent activation of microglial cells by Toll-like receptor agonists alone and in combination. J Neuroimmunol $\underline{159}, 87-96$

Ebert S, Goos M, Rollwagen L, Baake D, Zech WD, Esselmann H, Wiltfang J, Mollenhauer B, Schliebs R, Gerber J, et al. (2009): Recurrent systemic infections with Streptococcus pneumoniae do not aggravate the course of experimental neurodegenerative diseases. J Neurosci Res $\underline{88}, 1124-36$

Elie M, Cole MG, Primeau FJ, Bellavance F (1998): Delirium risk factors in elderly hospitalized patients. J Gen Intern Med 13, 204-12

Engelhart MJ, Geerlings MI, Meijer J, Kiliaan A, Ruitenberg A, van Swieten JC, Stijnen T, Hofman A, Witteman JC, Breteler MM (2004): Inflammatory proteins in plasma and the risk of dementia: the rotterdam study. Arch Neurol 61, 668-72

Fabry Z, Fitzsimmons KM, Herlein JA, Moninger TO, Dobbs MB, Hart MN (1993): Production of the cytokines interleukin 1 and 6 by murine brain microvessel endothelium and smooth muscle pericytes. J Neuroimmunol $\underline{47}$, 23-34 
Farrer LA, Cupples LA, Haines JL, Hyman B, Kukull WA, Mayeux R, Myers RH, Pericak-Vance MA, Risch N, van Duijn CM (1997): Effects of age, sex, and ethnicity on the association between apolipoprotein $\mathrm{E}$ genotype and Alzheimer disease. A meta-analysis. APOE and Alzheimer Disease Meta Analysis Consortium. JAMA 278, 1349-56

Ferri CP, Prince M, Brayne C, Brodaty H, Fratiglioni L, Ganguli M, Hall K, Hasegawa K, Hendrie $H$, Huang Y, et al. (2005): Global prevalence of dementia: a Delphi consensus study. Lancet $\underline{366}, 2112-7$

Fick DM, Agostini JV, Inouye SK (2002): Delirium superimposed on dementia: a systematic review. J Am Geriatr Soc 므, 1723-32

Fillit H, Ding WH, Buee L, Kalman J, Altstiel L, Lawlor B, Wolf-Klein G (1991): Elevated circulating tumor necrosis factor levels in Alzheimer's disease. Neurosci Lett $\underline{129}, 318-20$

Frautschy SA, Yang F, Irrizarry M, Hyman B, Saido TC, Hsiao K, Cole GM (1998): Microglial response to amyloid plaques in APPsw transgenic mice. Am J Pathol 152, 307-17

Gallagher M, Burwell R, Burchinal M (1993): Severity of spatial learning impairment in aging: development of a learning index for performance in the Morris water maze. Behav Neurosci 107, 618-26

Gatz M, Reynolds CA, Fratiglioni L, Johansson B, Mortimer JA, Berg S, Fiske A, Pedersen NL (2006): Role of genes and environments for explaining Alzheimer disease. Arch Gen Psychiatry $\underline{63}, 168-74$

Hahn H, Schulz TF, Kaufmann SHE, Suerbaum S. Medizinische Mikrobiologie und Infektiologie, 6. Auflage, Springer Medizin Verlag, Heidelberg 2009.

Harvey RJ, Skelton-Robinson M, Rossor MN (2003): The prevalence and causes of dementia in people under the age of 65 years. J Neurol Neurosurg Psychiatry $\underline{74}, 1206-9$

Hauss-Wegrzyniak B, Dobrzanski P, Stoehr JD, Wenk GL (1998): Chronic neuroinflammation in rats reproduces components of the neurobiology of Alzheimer's disease. Brain Res 780, 294-303

Herber DL, Mercer M, Roth LM, Symmonds K, Maloney J, Wilson N, Freeman MJ, Morgan D, Gordon MN (2007): Microglial activation is required for Abeta clearance after intracranial injection of lipopolysaccharide in APP transgenic mice. J Neuroimmune Pharmacol $\underline{2}, 222-31$

Herrmann I, Kellert M, Schmidt H, Mildner A, Hanisch UK, Brück W, Prinz M, Nau R (2006): Streptococcus pneumoniae Infection aggravates experimental autoimmune encephalomyelitis via Toll-like receptor 2 . Infect Immun $\underline{74}$, 4841-8

Hildebrandt H. Klinisches Wörterbuch, 258. Auflage, Walter de Gruyter \& Co. , Berlin 1997.

Holmes C, Cotterell D (2009): Role of infection in the pathogenesis of Alzheimer's disease: implications for treatment. CNS Drugs 23 , 993-1002

Holmes C, El-Okl M, Williams AL, Cunningham C, Wilcockson D, Perry VH (2003): Systemic infection, interleukin 1beta, and cognitive decline in Alzheimer's disease. J Neurol Neurosurg Psychiatry $\underline{74}, 788-9$

Holmes C, Cunningham C, Zotova E, Woolford J, Dean C, Kerr S, Culliford D, Perry VH (2009): Systemic inflammation and disease progression in Alzheimer disease. Neurology $\underline{73}$, 768-74 
Hsiao K, Chapman P, Nilsen S, Eckman C, Harigaya Y, Younkin S, Yang F, Cole G (1996): Correlative memory deficits, Abeta elevation, and amyloid plaques in transgenic mice. Science $\underline{274}, 99-102$

Hua F, Ma J, Ha T, Kelley J, Williams DL, Kao RL, Kalbfleisch JH, Browder IW, Li C (2008): Preconditioning with a TLR2 specific ligand increases resistance to cerebral ischemia/reperfusion injury. J Neuroimmunol 199, 75-82

Iliev Al, Stringaris AK, Nau R, Neumann H (2004): Neuronal injury mediated via stimulation of microglial toll-like receptor-9 (TLR9). FASEB J $\underline{18}$, 412-4

Irizarry MC, McNamara M, Fedorchak K, Hsiao K, Hyman BT (1997): APPSw transgenic mice develop age-related $A$ beta deposits and neuropil abnormalities, but no neuronal loss in CA1. J Neuropathol Exp Neurol 56, 965-73

Itzhaki R (2004): Herpes simplex virus type 1, apolipoprotein E and Alzheimer' disease. Herpes 11 Suppl 2, 77A-82A

Jacobsen KT, Iverfeldt K (2009): Amyloid precursor protein and its homologues: a family of proteolysis-dependent receptors. Cell Mol Life Sci $\underline{66}$, 2299-318

Janus C, Westaway D (2001): Transgenic mouse models of Alzheimer's disease. Physiol Behav $\underline{73}, 873-86$

Jellinger KA (2004): Head injury and dementia. Curr Opin Neurol 17, 719-23

Kaisho T, Akira S (2006): Toll-like receptor function and signaling. J Allergy Clin Immunol 117 , 979-87; quiz 988

Karow T, Lang-Roth R. Allgemeine und spezielle Pharmakologie und Toxikologie - Vorlesungsorientierte Darstellung und klinischer Leitfaden, Eigenverlag, Pulheim 2005.

Kawarabayashi T, Younkin LH, Saido TC, Shoji M, Ashe KH, Younkin SG (2001): Agedependent changes in brain, CSF, and plasma amyloid (beta) protein in the Tg2576 transgenic mouse model of Alzheimer's disease. J Neurosci 21, 372-81

Kayser FH, Bienz KA, Eckert J, Zinkernagel RM. Medizinische Mikrobiologie Verstehen - Lernen - Nachschlagen, 10. Auflage, Georg Thieme Verlag, Stuttgart 2001.

Kloss CU, Bohatschek M, Kreutzberg GW, Raivich G (2001): Effect of lipopolysaccharide on the morphology and integrin immunoreactivity of ramified microglia in the mouse brain and in cell culture. Exp Neurol 168, 32-46

Klunk WE, Xu CJ, McClure RJ, Panchalingam K, Stanley JA, Pettegrew JW (1997): Aggregation of beta-amyloid peptide is promoted by membrane phospholipid metabolites elevated in Alzheimer's disease brain. J Neurochem $\underline{69}$, 266-72

Koedel U (2009): Toll-like receptors in bacterial meningitis. Curr Top Microbiol Immunol $\underline{336}$, $15-40$

Kojika M, Sato N, Yaegashi Y, Suzuki Y, Suzuki K, Nakae H, Endo S (2006): Endotoxin adsorption therapy for septic shock using polymyxin B-immobilized fibers (PMX): evaluation by high-sensitivity endotoxin assay and measurement of the cytokine production capacity. Ther Apher Dial 10, 12-8

Konat GW, Kielian T, Marriott I (2006): The role of Toll-like receptors in CNS response to microbial challenge. J Neurochem $\underline{99}, 1-12$ 
Kreutzberg GW (1996): Microglia: a sensor for pathological events in the CNS. Trends Neurosci $\underline{19}, 312-8$

Kuo YM, Crawford F, Mullan M, Kokjohn TA, Emmerling MR, Weller RO, Roher AE (2000): Elevated $A$ beta and apolipoprotein $E$ in $A$ betaPP transgenic mice and its relationship to amyloid accumulation in Alzheimer's disease. Mol Med $\underline{6}$, 430-9

Lanctot KL, Herrmann N, Yau KK, Khan LR, Liu BA, LouLou MM, Einarson TR (2003): Efficacy and safety of cholinesterase inhibitors in Alzheimer's disease: a meta-analysis. CMAJ $\underline{169}, 557-64$

Launer L, Andersen K, Dewey ME, Letenneur L, Ott A, Amaducci LA, Brayne C, Copeland JR, Dartigues JF, Kragh-Sorensen P, et al. (1999): Rates and risk factors for dementia and Alzheimer's disease: results from EURODEM pooled analyses. EURODEM Incidence Research Group and Work Groups. European Studies of Dementia. Neurology $\underline{52}$, 7884

Lee JW, Lee YK, Yuk DY, Choi DY, Ban SB, Oh KW, Hong JT (2008): Neuro-inflammation induced by lipopolysaccharide causes cognitive impairment through enhancement of beta-amyloid generation. J Neuroinflammation $\underline{5}, 37$

Lemstra AW, Groen in't Woud JC, Hoozemans JJ, van Haastert ES, Rozemuller AJ, Eikelenboom P, van Gool WA (2007): Microglia activation in sepsis: a case-control study. J Neuroinflammation $\underline{4}, 4$

Lerner AJ, Hedera P, Koss E, Stuckey J, Friedland RP (1997): Delirium in Alzheimer disease. Alzheimer Dis Assoc Disord 11, 16-20

Li L, Lu J, Tay SS, Moochhala SM, He BP (2007): The function of microglia, either neuroprotection or neurotoxicity, is determined by the equilibrium among factors released from activated microglia in vitro. Brain Res $\underline{1159}$, 8-17

Lotz M, Ebert S, Esselmann H, lliev Al, Prinz M, Wiazewicz N, Wiltfang J, Gerber J, Nau R (2005): Amyloid beta peptide 1-40 enhances the action of Toll-like receptor-2 and -4 agonists but antagonizes Toll-like receptor-9-induced inflammation in primary mouse microglial cell cultures. J Neurochem $\underline{94}$, 289-98

Lue LF, Brachova L, Civin WH, Rogers J (1996): Inflammation, A beta deposition, and neurofibrillary tangle formation as correlates of Alzheimer's disease neurodegeneration. J Neuropathol Exp Neurol 55, 1083-8

Maier SF, Goehler LE, Fleshner M, Watkins LR (1998): The role of the vagus nerve in cytokine-to-brain communication. Ann N Y Acad Sci $\underline{840}$, 289-300

Malley R, Henneke P, Morse SC, Cieslewicz MJ, Lipsitch M, Thompson CM, Kurt-Jones E, Paton JC, Wessels MR, Golenbock DT (2003): Recognition of pneumolysin by Toll-like receptor 4 confers resistance to pneumococcal infection. Proc Natl Acad Sci U S A $100,1966-71$

Masuhr KF, Neumann M: Neurologie; in: Duale Reihe; hrsg. v. Bob A,Bob K; Georg Thieme Verlag, Stuttgart 2007, 191-196.

Mattsson N, Zetterberg $\mathrm{H}$, Hansson $\mathrm{O}$, Andreasen N, Parnetti L, Jonsson M, Herukka SK, van der Flier WM, Blankenstein MA, Ewers M, et al. (2009): CSF biomarkers and incipient Alzheimer disease in patients with mild cognitive impairment. JAMA 302, 385-93

Mayeux R (2003): Epidemiology of neurodegeneration. Annu Rev Neurosci 26, 81-104 
McColl BW, Rothwell NJ, Allan SM (2007): Systemic inflammatory stimulus potentiates the acute phase and CXC chemokine responses to experimental stroke and exacerbates brain damage via interleukin-1- and neutrophil-dependent mechanisms. J Neurosci $\underline{27}, 4403-12$

McGeer PL, Itagaki S, Boyes BE, McGeer EG (1988): Reactive microglia are positive for HLADR in the substantia nigra of Parkinson's and Alzheimer's disease brains. Neurology 38, $1285-91$

Miller G (2005): Neuroscience. The dark side of glia. Science $\underline{308}, 778-81$

Miquel J, Blasco M (1978): A simple technique for evaluation of vitality loss in aging mice, by testing their muscular coordination and vigor. Exp Gerontol 13, 389-96

Morgan D, Gordon MN, Tan J, Wilcock D, Rojiani AM (2005): Dynamic complexity of the microglial activation response in transgenic models of amyloid deposition: implications for Alzheimer therapeutics. J Neuropathol Exp Neurol 64, 743-53

Morris R (1984): Developments of a water-maze procedure for studying spatial learning in the rat. J Neurosci Methods $\underline{11}, 47-60$

Mortimer JA, Snowdon DA, Markesbery WR (2003): Head circumference, education and risk of dementia: findings from the Nun Study. J Clin Exp Neuropsychol 25, 671-9

Münch G, Apelt J, Rosemarie Kientsch E, Stahl P, Lüth HJ, Schliebs R (2003): Advanced glycation endproducts and pro-inflammatory cytokines in transgenic Tg2576 mice with amyloid plaque pathology. J Neurochem $\underline{86}$, 283-9

Munoz-Fernandez MA, Fresno M (1998): The role of tumour necrosis factor, interleukin 6, interferon-gamma and inducible nitric oxide synthase in the development and pathology of the nervous system. Prog Neurobiol $\underline{56}, 307-40$

Murray AM, Levkoff SE, Wetle TT, Beckett L, Cleary PD, Schor JD, Lipsitz LA, Rowe JW, Evans DA (1993): Acute delirium and functional decline in the hospitalized elderly patient. J Gerontol 48, M181-6

Nau R, Eiffert H (2002): Modulation of release of proinflammatory bacterial compounds by antibacterials: potential impact on course of inflammation and outcome in sepsis and meningitis. Clin Microbiol Rev $\underline{15}$, 95-110

Nee LE, Lippa CF (1999): Alzheimer's disease in 22 twin pairs--13-year follow-up: hormonal, infectious and traumatic factors. Dement Geriatr Cogn Disord 10, 148-51

Neugroschl J, Sano M (2009): An update on treatment and prevention strategies for Alzheimer's disease. Curr Neurol Neurosci Rep $\underline{9}$, 368-76

Neumann H, Schweigreiter R, Yamashita T, Rosenkranz K, Wekerle H, Barde YA (2002): Tumor necrosis factor inhibits neurite outgrowth and branching of hippocampal neurons by a rho-dependent mechanism. J Neurosci 22, 854-62

Nguyen MD, D'Aigle T, Gowing G, Julien JP, Rivest S (2004): Exacerbation of motor neuron disease by chronic stimulation of innate immunity in a mouse model of amyotrophic lateral sclerosis. J Neurosci $\underline{24}, 1340-9$

Nordberg A (2008): Amyloid plaque imaging in vivo: current achievement and future prospects. Eur J Nucl Med Mol Imaging 35 Suppl 1, S46-50 
Olson JK, Miller SD (2004): Microglia initiate central nervous system innate and adaptive immune responses through multiple TLRs. J Immunol 173, 3916-24

Perry VH, Newman TA, Cunningham C (2003): The impact of systemic infection on the progression of neurodegenerative disease. Nat Rev Neurosci 4 , 103-12

Perry VH, Cunningham C, Holmes C (2007): Systemic infections and inflammation affect chronic neurodegeneration. Nat Rev Immunol 7, 161-7

Pickering M, O'Connor JJ (2007): Pro-inflammatory cytokines and their effects in the dentate gyrus. Prog Brain Res $\underline{163}$, 339-54

Qiao X, Cummins DJ, Paul SM (2001): Neuroinflammation-induced acceleration of amyloid deposition in the APPV717F transgenic mouse. Eur J Neurosci 14, 474-82

Qin L, Wu X, Block ML, Liu Y, Breese GR, Hong JS, Knapp DJ, Crews FT (2007): Systemic LPS causes chronic neuroinflammation and progressive neurodegeneration. Glia $\underline{55}$, 45362

Quinn J, Montine T, Morrow J, Woodward WR, Kulhanek D, Eckenstein F (2003): Inflammation and cerebral amyloidosis are disconnected in an animal model of Alzheimer's disease. J Neuroimmunol 137, 32-41

Raber J, Huang Y, Ashford JW (2004): ApoE genotype accounts for the vast majority of AD risk and AD pathology. Neurobiol Aging 25, 641-50

Reisberg B, Doody R, Stoffler A, Schmitt F, Ferris S, Mobius HJ (2003): Memantine in moderate-to-severe Alzheimer's disease. N Engl J Med 348, 1333-41

Reyes TM, Fabry Z, Coe CL (1999): Brain endothelial cell production of a neuroprotective cytokine, interleukin-6, in response to noxious stimuli. Brain Res $\underline{851}$, 215-20

Rittirsch D, Hoesel LM, Ward PA (2007): The disconnect between animal models of sepsis and human sepsis. J Leukoc Biol 1 1, 137-43

Rivest S (2003): Molecular insights on the cerebral innate immune system. Brain Behav Immun $\underline{17}, 13-9$

Rivest S, Lacroix S, Vallieres L, Nadeau S, Zhang J, Laflamme N (2000): How the blood talks to the brain parenchyma and the paraventricular nucleus of the hypothalamus during systemic inflammatory and infectious stimuli. Proc Soc Exp Biol Med 223, 22-38

Rosenberg PB (2005): Clinical aspects of inflammation in Alzheimer's disease. Int Rev Psychiatry $\underline{17}, 503-14$

Rosenzweig HL, Lessov NS, Henshall DC, Minami M, Simon RP, Stenzel-Poore MP (2004): Endotoxin preconditioning prevents cellular inflammatory response during ischemic neuroprotection in mice. Stroke $\underline{35}, 2576-81$

Rosenzweig HL, Minami M, Lessov NS, Coste SC, Stevens SL, Henshall DC, Meller R, Simon RP, Stenzel-Poore MP (2007): Endotoxin preconditioning protects against the cytotoxic effects of TNFalpha after stroke: a novel role for TNFalpha in LPS-ischemic tolerance. J Cereb Blood Flow Metab 27, 1663-74

Salminen A, Ojala J, Kauppinen A, Kaarniranta K, Suuronen T (2009): Inflammation in Alzheimer's disease: amyloid-beta oligomers trigger innate immunity defence via pattern recognition receptors. Prog Neurobiol $\underline{87}$, 181-94 
Schmidt H, Tlustochowska A, Stuertz K, Djukic M, Gerber J, Schütz E, Kuhnt U, Nau R (2001): Organotypic hippocampal cultures. A model of brain tissue damage in Streptococcus pneumoniae meningitis. J Neuroimmunol $\underline{113}, 30-9$

Schmidtke K, Riepe W: Degenerative Erkrankungen; in: Leitlinien für Diagnostik und Therapie in der Neurologie; hrsg. v. Diener H C, Putzki P,Berlit P; Georg Thieme Verlag, Stuttgart 2005, 130-152.

Schröder NW, Morath S, Alexander C, Hamann L, Hartung T, Zähringer U, Göbel UB, Weber JR, Schumann RR (2003): Lipoteichoic acid (LTA) of Streptococcus pneumoniae and Staphylococcus aureus activates immune cells via Toll-like receptor (TLR)-2, lipopolysaccharide-binding protein (LBP), and CD14, whereas TLR-4 and MD-2 are not involved. J Biol Chem 278, 15587-94

Semmler A, Hermann S, Mormann F, Weberpals M, Paxian SA, Okulla T, Schäfers M, Kummer MP, Klockgether T, Heneka MT (2008): Sepsis causes neuroinflammation and concomitant decrease of cerebral metabolism. J Neuroinflammation $\underline{5}, 38$

Sethi S, Lipford G, Wagner H, Kretzschmar H (2002): Postexposure prophylaxis against prion disease with a stimulator of innate immunity. Lancet $\underline{360}, 229-30$

Sharshar T, Annane D, de la Grandmaison GL, Brouland JP, Hopkinson NS, Francoise G (2004): The neuropathology of septic shock. Brain Pathol 14, 21-33

Sharshar T, Hopkinson NS, Orlikowski D, Annane D (2005): Science review: The brain in sepsis--culprit and victim. Crit Care $\underline{9}, 37-44$

Sheng JG, Bora SH, Xu G, Borchelt DR, Price DL, Koliatsos VE (2003): Lipopolysaccharideinduced-neuroinflammation increases intracellular accumulation of amyloid precursor protein and amyloid beta peptide in APPswe transgenic mice. Neurobiol Dis $\underline{14}$, 133-45

Shoji M, Matsubara E, Kanai M, Watanabe M, Nakamura T, Tomidokoro Y, Shizuka M, Wakabayashi K, Igeta $Y$, Ikeda $Y$, et al. (1998): Combination assay of CSF tau, A beta 1-40 and A beta 1-42(43) as a biochemical marker of Alzheimer's disease. J Neurol Sci $\underline{158}$, $134-40$

Sly LM, Krzesicki RF, Brashler JR, Buhl AE, McKinley DD, Carter DB, Chin JE (2001): Endogenous brain cytokine mRNA and inflammatory responses to lipopolysaccharide are elevated in the Tg2576 transgenic mouse model of Alzheimer's disease. Brain Res Bull 56, 581-8

Smith PK, Krohn RI, Hermanson GT, Mallia AK, Gartner FH, Provenzano MD, Fujimoto EK, Goeke NM, Olson BJ, Klenk DC (1985): Measurement of protein using bicinchoninic acid. Anal Biochem 150, 76-85

Spreer A, Kerstan H, Böttcher T, Gerber J, Siemer A, Zysk G, Mitchell TJ, Eiffert H, Nau R (2003): Reduced release of pneumolysin by Streptococcus pneumoniae in vitro and in vivo after treatment with nonbacteriolytic antibiotics in comparison to ceftriaxone. Antimicrob Agents Chemother 47, 2649-54

Stevens SL, Ciesielski TM, Marsh BJ, Yang T, Homen DS, Boule JL, Lessov NS, Simon RP, Stenzel-Poore MP (2008): Toll-like receptor 9: a new target of ischemic preconditioning in the brain. J Cereb Blood Flow Metab 28, 1040-7 
Stuertz K, Schmidt H, Eiffert H, Schwartz P, Mader M, Nau R (1998): Differential release of lipoteichoic and teichoic acids from Streptococcus pneumoniae as a result of exposure to beta-lactam antibiotics, rifamycins, trovafloxacin, and quinupristindalfopristin. Antimicrob Agents Chemother $\underline{42}$, 277-81

Tahara K, Kim HD, Jin JJ, Maxwell JA, Li L, Fukuchi K (2006): Role of toll-like receptor signalling in Abeta uptake and clearance. Brain 129, 3006-19

Tan ZS, Vasan RS (2009): Thyroid function and Alzheimer's disease. J Alzheimers Dis 16, 5037

Tarkowski E, Blennow K, Wallin A, Tarkowski A (1999): Intracerebral production of tumor necrosis factor-alpha, a local neuroprotective agent, in Alzheimer disease and vascular dementia. J Clin Immunol $\underline{19}$, 223-30

Terai K, Iwai A, Kawabata S, Tasaki Y, Watanabe T, Miyata K, Yamaguchi T (2001): betaamyloid deposits in transgenic mice expressing human beta-amyloid precursor protein have the same characteristics as those in Alzheimer's disease. Neuroscience $\underline{104}$, 299-310

Tomidokoro Y, Harigaya Y, Matsubara E, Ikeda M, Kawarabayashi T, Shirao T, Ishiguro K, Okamoto K, Younkin SG, Shoji M (2001): Brain Abeta amyloidosis in APPsw mice induces accumulation of presenilin-1 and tau. J Pathol 194, 500-6

Tsao N, Hsu HP, Wu CM, Liu CC, Lei HY (2001): Tumour necrosis factor-alpha causes an increase in blood-brain barrier permeability during sepsis. J Med Microbiol $\underline{50}$, 812-21

Van Den Heuvel C, Thornton E, Vink R (2007): Traumatic brain injury and Alzheimer's disease: a review. Prog Brain Res 161, 303-16

Van Meer P, Raber J (2005): Mouse behavioural analysis in systems biology. Biochem J $\underline{389}$, 593-610

Versijpt JJ, Dumont F, Van Laere KJ, Decoo D, Santens P, Audenaert K, Achten E, Slegers G, Dierckx RA, Korf J (2003): Assessment of neuroinflammation and microglial activation in Alzheimer's disease with radiolabelled PK11195 and single photon emission computed tomography. A pilot study. Eur Neurol $\underline{50}$, 39-47

Villareal DT, Morris JC (1999): The diagnosis of Alzheimer's disease. J Alzheimers Dis 1 , 24963

Webster S, Lue LF, Brachova L, Tenner AJ, McGeer PL, Terai K, Walker DG, Bradt B, Cooper NR, Rogers J (1997): Molecular and cellular characterization of the membrane attack complex, C5b-9, in Alzheimer's disease. Neurobiol Aging 18, 415-21

Wellmer A, von Mering M, Spreer A, Diem R, Eiffert H, Noeske C, Bunkowski S, Gold R, Nau R (2004): Experimental pneumococcal meningitis: impaired clearance of bacteria from the blood due to increased apoptosis in the spleen in Bcl-2-deficient mice. Infect Immun $\underline{72}$, 3113-9

WHO: Internationale statistische Klassifikation der Krankheiten und verwandter Gesundheitsprobleme ICD-10-GM, Version 2010, World Health Organization, Genf 2006.

Wiltfang J, Smirnov A, Schnierstein B, Kelemen G, Matthies U, Klafki HW, Staufenbiel M, Hüther G, Rüther E, Kornhuber J (1997): Improved electrophoretic separation and immunoblotting of beta-amyloid (A beta) peptides 1-40, 1-42, and 1-43. Electrophoresis $\underline{18}$, 527-32 
Wiltfang J, Esselmann H, Cupers P, Neumann M, Kretzschmar H, Beyermann M, Schleuder D, Jahn H, Rüther E, Kornhuber J, et al. (2001): Elevation of beta-amyloid peptide 2-42 in sporadic and familial Alzheimer's disease and its generation in PS1 knockout cells. J Biol Chem 276, 42645-57

Winblad B, Poritis N (1999): Memantine in severe dementia: results of the 9M-Best Study (Benefit and efficacy in severely demented patients during treatment with memantine). Int J Geriatr Psychiatry 14, 135-46

Wisniewski T, Konietzko U (2008): Amyloid-beta immunisation for Alzheimer's disease. Lancet Neurol $\underline{7}, 805-11$

Wyss-Coray T (2006): Inflammation in Alzheimer disease: driving force, bystander or beneficial response? Nat Med $\underline{12}, 1005-15$

Zhao M, Cribbs DH, Anderson AJ, Cummings BJ, Su JH, Wasserman AJ, Cotman CW (2003): The induction of the TNFalpha death domain signaling pathway in Alzheimer's disease brain. Neurochem Res 28, 307-18 


\section{Abbildungsverzeichnis}

Abbildung 1-1. Veränderungen im Gehirn bei der Alzheimer-Demenz ............................................ 3

Abbildung 1-2. Aktivierungszustände der Mikroglia ........................................................................ 15

Abbildung 2-1. Elektrophorese-Ergebnis einer Genotypisierung..................................................... 25

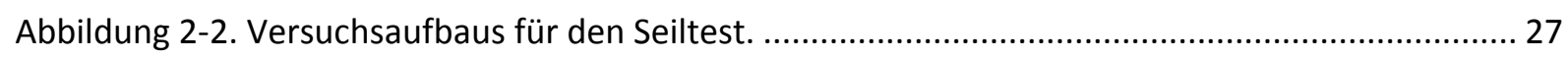

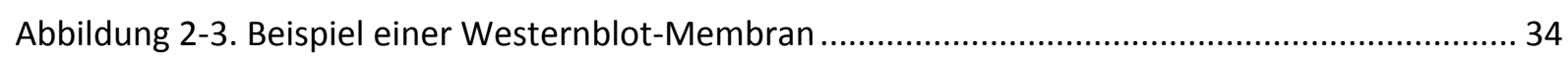

Abbildung 2-4. Schematische Darstellung der Zellkultur-Schablone ................................................... 44

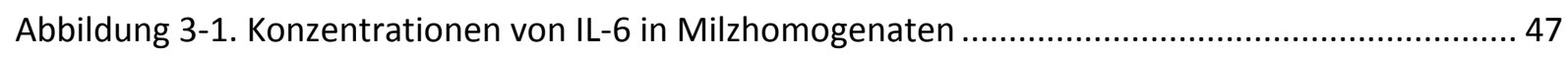

Abbildung 3-2. Konzentrationen von IL-6 in Homogenaten des Gehirns.......................................... 47

Abbildung 3-3. Fluoreszenzfärbung eines Gehirnschnittes nach Färbung mit Iba1 ............................ 48

Abbildung 3-4. Darstellung der Trainingsläufe im Morris-Water-Maze................................................. 50

Abbildung 3-5. Gewichte der Mäuse im Verlauf des Versuchs .......................................................... 52

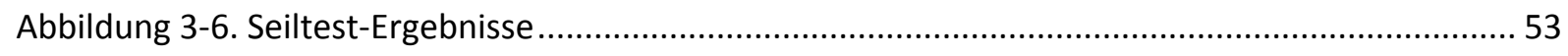

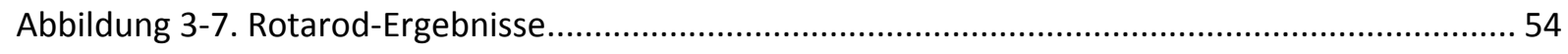

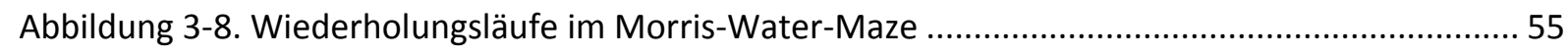

Abbildung 3-9. Maus auf der Plattform im Becken des Morris-Water-Maze. ....................................... 56

Abbildung 3-10. Versetzten Plattform im Morris-Water-Maze ....................................................... 57

Abbildung 3-11. Gesamtverlauf im Morris-Water-Maze. ....................................................................... 58

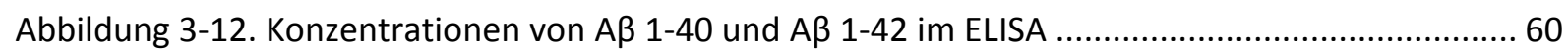

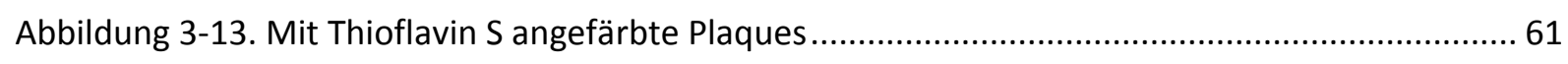

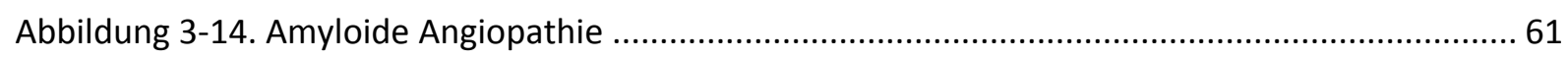

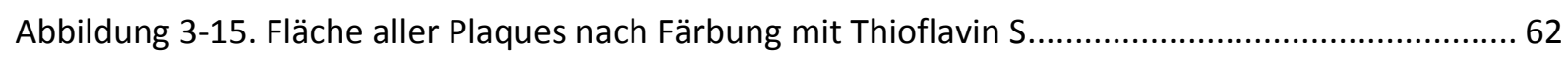

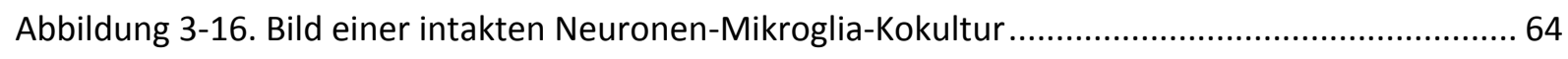

Abbildung 3-17. Murines Zellkultur-Modell: Beginnender Neuronenschaden..................................... 64

Abbildung 3-18. Murines Zellkultur-Modell: Starker Neuronenschaden ............................................. 64

Abbildung 3-19. Bild einer intakten Makrophagen-Neuroblastom-Kokultur ....................................... 65

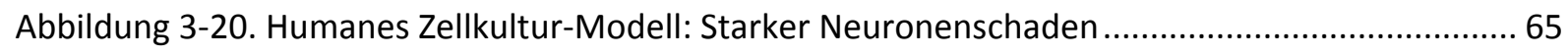

Abbildung 3-21. Humanes Zellkultur-Modell: Aktivierte Makrophagen ............................................. 65 


\section{Tabellenverzeichnis}

Tabelle 2-1. Programmierung des PCR-Thermocyclers

Tabelle 2-2. Klinisch-neurologischer Score zur Gesundheitsbeurteilung............................................. 27

Tabelle 2-3. Zeitlicher Ablauf der Testung im Morris-Water-Maze ..................................................... 29

Tabelle 2-4. Zusammensetzung der Neufuchsinlösung .................................................................. 42

Tabelle 3-1. Konzentrationen der im Westernblot bestimmten $A \beta-$ Fragmente .................................. 59

\section{Abkürzungsverzeichnis}

$A \beta$

$A B C$

ALS

APA

APAAP

APS

AUC

Bicine

Bistris

bp

CD-68

$\mathrm{CH}$

D

DAB

D-MEM

DNA

dNTP

EAE

EDTA

ELISA

FCS

g

$\mathrm{h}$

HEPES

$\mathrm{H}_{2} \mathrm{O}$ dd
Amyloid beta

Avidin-Biotin-Komplex

Amyotrophe Lateral Sklerose

American Psychological Assosciation

Alkalische-Phosphatase-Anti-Alkalische-Phosphatase-Komplex

Ammoniumpersulfat

Area under the Curve

2-(Bis(2-hydroxyethyl)amino)acetic acid

Bis-[2-Hydroxyethyl]amino-Tris-[Hydroxymethyl]-Methan

Basenpaar

Cluster of Differentiation 68

Schweiz

Deutschland

Diaminobenzidin

Dulbeccos modifiziertes Eagle`s Basalmedium

Desoxyribonukleinsäure

Desoxyribonukleosidtriphosphate

Experimentelle autoimmune Enzephalomyelitis

Ethylendiamintetraessigsäure

Enzyme Linked Immunosorbent Assay

fötales Kälberserum

Erdbeschleunigung

Stunde

2-(4-(2-Hydroxyethyl)-1-piperazinyl)-ethansulfonsäure

doppelt destilliertes Wasser

Italien 


\begin{tabular}{|c|c|}
\hline $\lg$ & Immunglobulin \\
\hline IL & Interleukin \\
\hline LPS & Lipopolysaccharid \\
\hline MHC & Major Histocompatibility Complex \\
\hline $\min$ & Minuten \\
\hline MWM & Morris-Water-Maze \\
\hline $\mathrm{NaCl}$ & Natriumchlorid \\
\hline $\mathrm{Na}-\mathrm{DOC}$ & Natriumdesoxycholat \\
\hline $\mathrm{NaOH}$ & Natriumhydroxid in Wasser/Natronlauge \\
\hline NL & Niederlande \\
\hline NSE & Neuronen-spezifische Enolase \\
\hline $\mathrm{Pam}_{3} \mathrm{CysSK}_{4}$ & $\begin{array}{l}\text { N-Palmitoyl-S-[2,3-bis(palmitoyloxy)-(2RS)-propyl]-[R]-cysteinyl-[S]- } \\
\text { seryl-[S]-lysyl-[S]-lysyl-[S]-lysyl-[S]--lysine }\end{array}$ \\
\hline PAP & Probenaufnahmepuffer \\
\hline PBS & Phosphat-Buffered Saline \\
\hline PCR & Polymerase-Kettenreaktion \\
\hline RIPA & Radioimmunoprecipitation assay \\
\hline $\mathrm{rpm}$ & revolutions per minute \\
\hline $\mathrm{s}$ & Sekunde \\
\hline SDS & Sodium-dodecyl-sulfate/Natriumdodecylsulfat \\
\hline SDS-PAGE & Sodium-dodecyl-sulfate - polyacrylamide-gel-electrophoresis \\
\hline TBE & Tris-Borsäure-EDTA \\
\hline TBS & Tris-Buffered Saline \\
\hline TLR & Toll-like Rezeptor \\
\hline UK & United Kingdom \\
\hline USA & Vereinigte Staaten von Amerika \\
\hline$v / v$ & Volume/Volume \\
\hline $\mathrm{v} / \mathrm{w}$ & Volume/Weight \\
\hline WHO & World Health Organization \\
\hline ZNS & Zentrales Nervensystem \\
\hline
\end{tabular}




\section{Verzeichnis der Publikationen in Zusammenhang mit der Dissertation}

\section{Originalarbeit}

Ebert S, Goos M, Rollwagen L, Baake D, Zech WD, Esselmann H, Wiltfang J, Mollenhauer B, Schliebs R, Gerber J, et al. (2009): Recurrent systemic infections with Streptococcus pneumoniae do not aggravate the course of experimental neurodegenerative diseases. J Neurosci Res 88, 1124-36

\section{$\underline{\text { Vortrag }}$}

Ebert S, Goos M, Rollwagen L, Baake D, Zech W-D, Esselmann H, Wiltfang J, Mollenhauer B, Schliebs R, Gerber G, Nau R. Einfluss systemischer Infektionen mit Streptococcus pneumoniae auf den Verlauf neurodegenerativer Erkrankungen im Mausmodell. 116. Kongress der Deutschen Gesellschaft für Innere Medizin (DGIM), Wiesbaden, 10.-14. April 2010. (Endrunde des Young Investigator Award, Bereich Geriatrie)

\section{Poster}

Ebert S, Goos M, Rollwagen L, Baake D, Zech W-D, Esselmann H, Wiltfang J, Mollenhauer B, Schliebs R, Gerber G, Nau R. Einfluss systemischer Infektionen mit Streptococcus pneumoniae auf den Verlauf neurodegenerativer Erkrankungen im Mausmodell. 116. Kongress der Deutschen Gesellschaft für Innere Medizin (DGIM), Wiesbaden, 10.-14. April 2010. (Endrunde des Young Investigator Award, Bereich Geriatrie)

Ebert S, Goos M, Rollwagen L, Baake D; Zech; W-D, Esselmann H, Wiltfang J, Mollenhauer B, Schliebs R, Gerber J, Nau R. Recurrent systemic infections with Streptococcus pneumoniae do not aggravate the course of experimental neurodegenerative diseases. 9th International Conference AD/PD 2009, Prag, 11.-15.März 2009. 


\section{Danksagung}

Am Ende dieser Arbeit möchte ich mich ganz herzlich bei Prof. Dr. med. Roland Nau für die Überlassung dieses spannenden und zukunftsrelevanten Themas bedanken. Er stand jederzeit mit vielen Ideen bei Problemen zur Seite und hat die Bezeichnung des „Doktorvaters“ wahrlich verdient.

Ein großes Dankeschön steht meinen Betreuerinnen Dr. med. Miriam Goos und Dr. med. Sandra Ebert zu. Beide haben mich an das wissenschaftliche Arbeiten herangeführt und mir immer hilfsbereit zur Seite gestanden. Ich möchte beiden für die Unterstützung während des experimentellen Teils und Dr. med. Sandra Ebert für die Korrektur des schriftlichen Teils der Arbeit meinen Dank aussprechen. Die Zusammenarbeit war mir eine große Freude!

Für die gute Teamarbeit und den schönen Zusammenhalt möchte ich meinen Mitdoktoranden Nicole Wiazewicz, Moritz Zeretzke, Wolf-Dieter Zech, Daniel Baake, Benjamin Winkler, Benedikt Kellert und Tobias Loleit danken.

Dem kompetenten Ruhepol unserer Arbeitsgruppe, Stefanie Bunkowski, gilt Dank für Ihre Mühe beim Beibringen der Zellkultur-Färbungen, dem Anfertigen zahlreicher weiterer Färbungen und die dauerhafte Hilfsbereitschaft.

Prof. Dr. Reinhard Schliebs möchte ich für die Überlassung der transgenen Tg2576-Mäuse danken, ohne die diese Arbeit nicht zustande gekommen wäre.

Dem Team des Neurochemischen Labors und hier insbesondere Peter Lange gilt Dank für die Mithilfe bei der Durchführung der Aß-ELISAs sowie der NSE-Messung.

Auch danken möchte ich Birgit Otte und Dr. Hermann Esselmann, ohne die die Durchführung der A $\beta$ Westernblots nicht möglich gewesen wäre.

Besonders danken möchte ich meiner Familie für ihre kontinuierliche Unterstützung, speziell meiner Mutter für die Korrektur dieser Arbeit und Daniel für seine unermüdliche moralische und technische Unterstützung. 


\section{Lebenslauf}

Am 26.10.1982 wurde ich, Lena Rollwagen, als Tochter von Dr. agr. Christian Rollwagen und Dipl.-agr. Barbara Rollwagen in Lauterbach/Hessen geboren.

Nach dem Besuch der Mittelpunktgrundschule Engelrod von 1988-1892 wechselte ich an das Alexander - von - Humboldt Gymnasium in Lauterbach, an welchem ich im Frühjahr 2001 den Abschluss der Allgemeinen Hochschulreife erlangte.

Von August 2001 bis zum Juni 2002 nahm ich das Angebot des „Work and Travel Visa“ für Australien wahr, besuchte dort einen Sprachkurs und bereiste große Teile Australiens.

Das Studium der Humanmedizin an der Georg-August-Universität Göttingen begann ich zum Wintersemester 02/03. Das Physikum bestand ich im Frühjahr 2004. Mit der Vorbereitung und Anfertigung meiner Promotion in der Arbeitsgruppe für Neuroinfektiologie unter der Leitung von Prof. Dr. med. Nau begann ich im Januar 2006. Um mich eine Zeitlang vollständig mit den Experimenten befassen zu können, pausierte ich den regulären Studienverlauf im Sommersemester 2006.

Das Staatsexamen legte ich im Frühjahr 2009 ab, seit November 2009 bin ich als Assistenzärztin in der Kinderheilkunde tätig. 